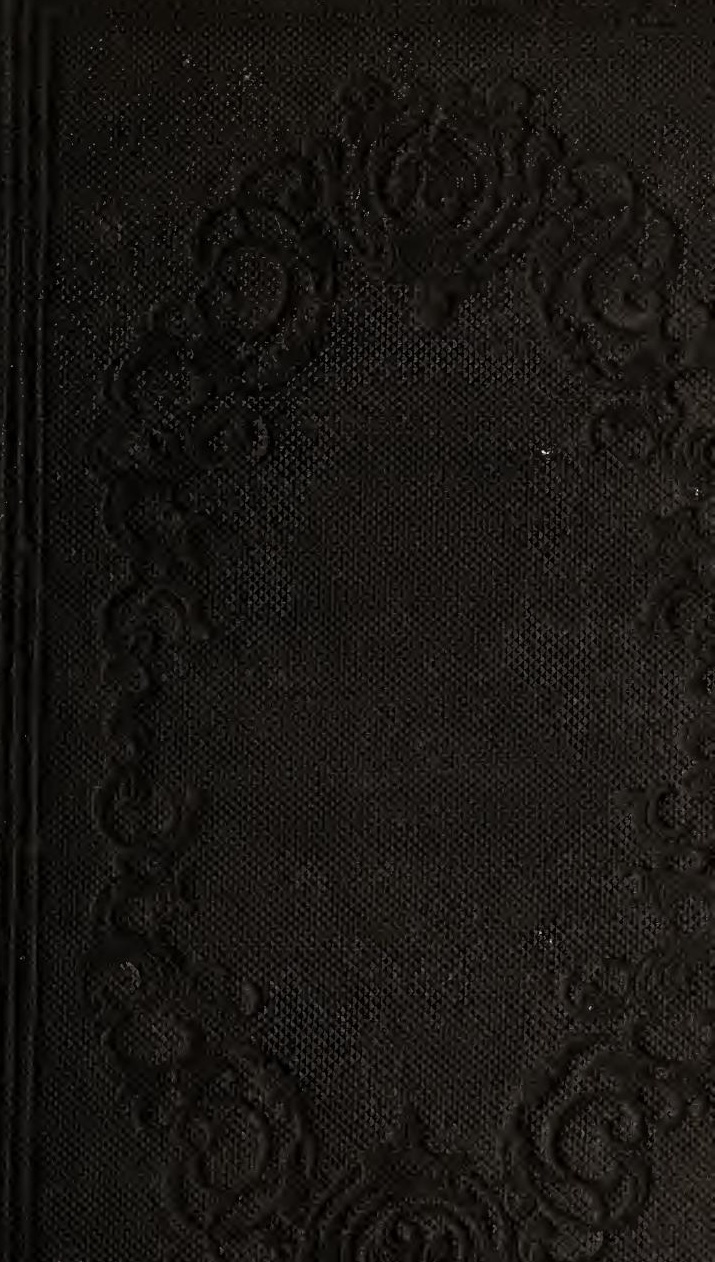




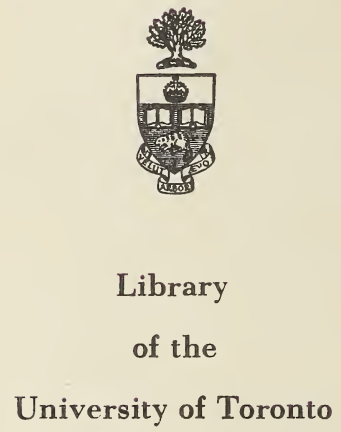


$-4$

$\therefore \quad 2$ 
Digitized by the Internet Archive in 2017 with funding from University of Toronto 


\section{NATURAL HISTORY.}

R E P T I L E S.

By P. H. GOSSE.

PUBLISHED UNDER THE DIRECTION OF THE COMMITTEE OF GENERAL IITERATURE AND EDUCATION, APPOINTED BY THE SOCIETY FOR PROMOTING CHRISTIAN KNOWLEDGE.

\section{O N D O N :}

PRINTED FOR THE SOCIETY FOR PROMOTING CHRISTIAN KNOWLEDGE;

SOLD AT THE DEPOSITORY,

GREAT QUDEN-STREET, LINCOLN'S INN-FIELDS, AND 4, ROTAL EXCHANGE;

AND BY ALL BOOKSELLERS.

1850. 
LONDON :

Printed by SaMUEL BentIII \& Co.

Bangor Elouse, Shoe Laze. 


\section{CONTENTS.}

\begin{tabular}{|c|c|c|c|c|c|}
\hline & & PAGE & & & PAGE \\
\hline ENOPLIA. & & & SAURIA continued. & & \\
\hline TESTUDINATA . & . & 8 & GECKOTIDA . & . & 82 \\
\hline Testudinid压 & . & 11 & Thecadactylus . & & 90 \\
\hline Testudo . & • & 13 & lavis & - & $i b$. \\
\hline nigra . & . & 14 & IGUANAD五. & & 93 \\
\hline EMYDIDA . & . & 18 & Iguana & . & 97 \\
\hline Emys & . & 19 & tuberculata & & 99 \\
\hline Cistudo Eur & ppea & $i b$. & $A G A M A D E$ & - & 106 \\
\hline TRIONYCHID & . & 22 & Phrynosoma . & & . 109 \\
\hline Trionyx . & . & 23 & orbiculare & . & $i b$. \\
\hline spiniferus & . & 24 & VARANIDAE & & . 111 \\
\hline SPHARGIDAE & - & 25 & Varanus & . & 115 \\
\hline Sphargis & . & 26 & albogularis & & $i b$. \\
\hline coriacea. & . & $i b$. & Teius & & . $\quad 117$ \\
\hline Cheloniadez . & - & 28 & teguixin & - & 119 \\
\hline Chelone. . & . & 33 & LACERTADE & & . 121 \\
\hline mydas . & . & 34 & Zootoca & . & 124 \\
\hline imbricata. & • & 44 & vivipara . & & $i b$. \\
\hline & & & SCINCInAE & . & 130 \\
\hline LORICATA & . & 50 & Celestus . & & - 134 \\
\hline Crocodilida & - & 53 & occiduus. & - & 135 \\
\hline Alligator . & . & 56 & Anguis . & & - 137 \\
\hline lucius & - & 59 & fragilis & . & ] 38 \\
\hline SAURIA . . & . & 66 & OPHIDIA . & & . 144 \\
\hline Chameleonide & • & 70 & AMPHISBAnadE & - & 157 \\
\hline Chamæleon . & - & 73 & Typhlops & & - 160 \\
\hline vulgaris . & • & $i$. & lumbricalis & 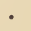 & $i b$. \\
\hline
\end{tabular}


OPHIDIA continued.

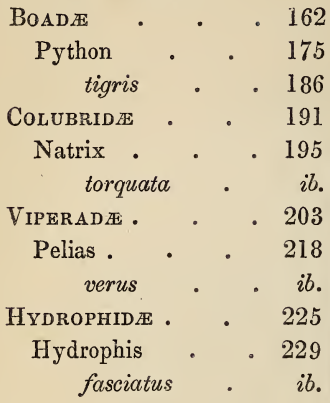

\section{AMPHIBIA.}

ANOURA • • . 238

RANADE . $\quad 239$

Rana . . . 242

temporaria . $i b$.

Hylade • • 247

Hyla . . . 250 viridis . . $i b$.

Bufonide . 254

Bufo • . . 255

vulgaris $\quad i b$.
PAGE

AMPHIBIA continued.

PIPADE $\quad$ • $\quad . \quad 259$

Pipa . . . $i b$.

Surinamensis . 260

URODELA • • 263

Salamandrade $\quad$. 265

Lissotriton . . 266

punctatus . . $i b$.

AMPHIPNEUSTA 271

Proteid . . $\quad 274$

Proteus . . 275

anguinus . $\quad 276$

ABRANCHIA - $\quad 282$

Amphiuma . 283

means . . 285

APODA • • . 286

Rhinatrema. . 290

bivittatum. . $i b$. 


\section{NATURAL HISTORY.}

\section{REPTILES.}

THE subjects of the present volume have been viewed in all countries and ages, with less of popular favour than other Classes of animals. Few of them are of the slightest use to man, either alive or dead; many of them are fatally poisonous, and others are terrible from their power and ferocity. The forms of some consist little with our ideas of beauty; and perhaps the coldness of their bodies when touched, the concealed situations which many of them inhabit, and the crawling motion generally observed in this Class, have also contributed to the suspicion and dislike with which they are commonly regarded. But when we discard prejudice, we find that the great majority of these animals are perfectly inoffensive; that many are clad in mail of the most brilliant polish, unsullied with spot or stain; that others are arrayed in rich and tastefully arranged colours; and that all afford, in the perfection of their structure, the skill and power displayed in the different contrivances of 
their organization, the varied instincts and habits with which they are endowed, their means of offence and defence, and the great diversity of form and structure which they exhibit, as rich a feast of intellectual gratification to the philosophic student of Nature, as any other of the wonderful works of God.

In this last respect the Class of Reptiles is eminently worthy of attention. "In Mammalogy and Ornithology, we find that the animals which are treated of under those branches are respectively formed according to one leading type, which, however modified, may be traced throughout the whole chain of beings with which those branches of Zoology are conversant. From an Elephant to a Mouse, from a Whale to a Porpoise, the same uniform principle of construction may be recognised. The same principle of organization governs the conformation of an Ostrich and a Humming-bird. But in Herpetology, we have various types or principles of structure. Not to dwell upon the more obvious differences in the organization of a Tortoise and a common Snake, we shall find in more cognate creatures, the Saurians for example, a striking variation in structure. The skeleton of a Crocodile differs widely from that of a Chameleon; ... and how widely are these again separated from the Frogs and Toads!"*

* Penny Cyclop. xix. 403. 
In one respect in which Reptiles agree among themselves, they agree also with the Classes of Birds and Fishes; the reproduction of their species is effected by means of eggs. For the most part these are encased in a calcareous covering, either hard and shelly as in the Tortoises, Crocodiles and some Saurians, or tough and leathery as in most of the Serpents : in the Amphibia, however, they are destitute of any covering. In a few instances, the young are brought forth alive; but these are rather apparent than real exceptions to the general rule, the eggs in such cases being hatched in the body of the parent, or ruptured in the act of deposition. Our native smaller Lizard, Viper, and Slow-worm, afford familiar examples of this peculiarity, Reptiles do not in general incubate their eggs ; but there is reason to believe that the Boas and Pythons are exceptions to this rule.

The heart in this Class is so constructed that at every pulsation only a part of the blood from the system is thrown into the lungs, the remaining portion returning into the circulation without being aërated. As animal heat is derived from the communication of oxygen to the blood, in its exposure to the air when passing through the lungs, it follows that the imperfect aëration of the blood in these animals is attended with a diminution of vital heat, and that they are what is called cold-blooded; in other words, the heat produced by respiration is so small, that the difference 
between the temperature of their bodies and that of the air or water in which they live, is not sensible to the touch. The Sub-class Amphibia, including the Frog-like Reptiles, pass through a sort of metamorphosis, breathing by means of gills in their early stages; and there are a few which have both gills and lungs through their entire existence.

The senses are in general well developed, though in various degrees in the different Orders: in some, however, the sense of sight appears to be nearly obliterated, as in Typhlops, and in Proteus. Their brain is comparatively small; and their sensations seem less referrible to a common centre, than in the higher Classes : life, and even voluntary motion, continues long after the brain is removed; the irritability of the muscular fibre is preserved for a considerable time after separation from the rest of the body; and the heart pulsates for many hours after it has been detached.

"The motion of Reptiles is as various as their structure, and exhibits a great diversity, particularly in the modes of progression. The slow march of the Land Tortoise, the paddling of the Turtles, the swimming and walking of the Crocodiles, the Newts, and the Protei, the agility of the Lizards, the rapid serpentine advance of the Snakes, the leaping of the Frogs, offer a widely extended scale of motion. If we add the vaulting of the 
Dragons, and the flying of the Pterodactyles, there is hardly any mode of animal progression which is not to be found among the Reptiles." *

The temperature of the blood does not require that the body should be clothed with a substance, such as hair or feathers, which might resist the abstraction of animal heat. Hence the skin is either quite naked, as in the Amphibia, or covered with a sort of mail, composed of plates or scales, for defence.

It is in the warmer regions of the globe that Reptiles most abound; both as to the number of species, and of the individuals which constitute them. There also they display the greatest variety of form and colour, the most gigantic bulk, and the highest amount of animal energy. The few species that inhabit temperate and cold countries, commonly retire into concealment and become torpid on the approach of winter. Yet it has been remarked that they can more easily bear the rigour of a severe winter, than suffer the want of a hot summer. "It is interesting to remark the manner in which, according to Berghaus, the number of species diminishes as we pass from the sunny regions of the East to the duller and more cloudy climes of Western Europe. Thus Italy with her islands can number forty-seven species; France has thirty-one;

* Penny Cyclop. xix. 410. 
Great Britain fourteen; and Ireland, it may be added, not more than five."*

We shall divide the Class Reptilia into two Sub-classes, Enoplia and Amphibia; containing nine Orders.

* Patterson's Zoology, 266.

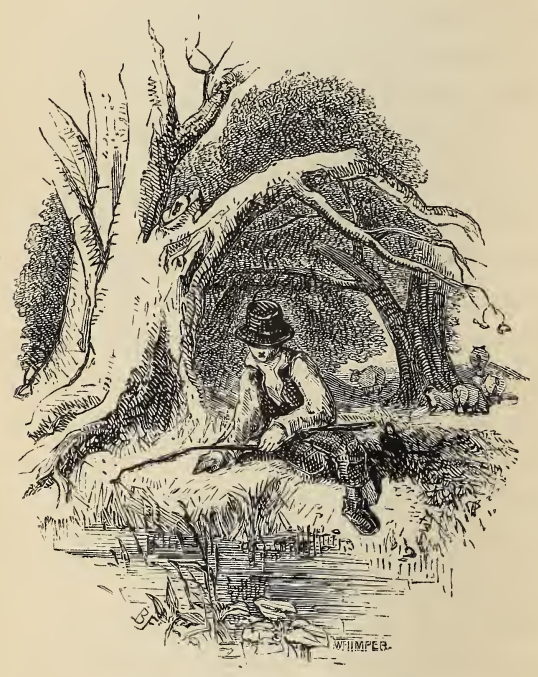




\section{SUB-CLASS I. ENOPLIA.}

\section{(Mailed Reptiles.)}

The Mailed or true Reptiles are principally distinguished by having the body encased in a series of plates of various degrees of hardness, sometimes imbedded, like stones in a pavement, into compact shields, at others forming overlapping scales, and yet again constituting a granular or tuberculous shagreen. In many particulars their anatomical organization is of a higher grade than that of the Amphibia; they have perfect ribs; and the occipital condyle, or joint by which the skull is connected with the spinal column, is single. They are subject to no metamorphosis, but are evolved from the egg in the form of the parents : gills (branchic) are never present in any stage, but respiration is performed entirely by means of lungs. The economy of reproduction partakes of the characters of that of Mammalia and Birds, and not that of Fishes; the eggs are always furnished with a calcareous covering, either shelly or coriaceous in texture.

The Enoplia are divided into four Orders, founded on diversities of form, the presence or absence of limbs, and the character of the mailed covering. These are named Testudinata, Loricata, Sauria, and Ophidia. 


\section{ORDER I. TESTUDINATA.}

\section{(Tortoises.)}

The appearance of an animal of this Order will naturally recal to the mind the mailed Armadillos among the Edentate Mammalia, as the Sauria will remind us of the Pangolins. The Tortoises are readily distinguished from other Reptiles by their body being inclosed in a double buckler, which admits only of a partial protrusion of the head, tail, and limbs. The bones of the skeleton, though essentially the same as those found in the preceding classes, are strangely modified. If we remove the convex shield, called the carapace, that covers the upper part of a Tortoise, and turn it up, we shall find on the inner surface the vertebral column imbedded into an immovable piece, and the ribs flattened and widened so as to touch each other at their edges. The vertebræ of the neck and of the tail alone are free. The lower plate or plastron, in like manner, is composed of pieces representing the breastbone or sternum, united by sutures.

The external surface of these shields is covered with a series of plates of a horny (or sometimes leathery) texture, of regular but varied forms, united at their edges, but sometimes overlapping posteriorly. The shoulder-blade and all the muscles of the arm and neck, instead of being attached to the exterior of the ribs and spine, 
as in other vertebrate animals, are all within, as are also the bones of the pelvis, and even the muscles of the thighs; so that a Tortoise has been described as an animal turned inside out. The

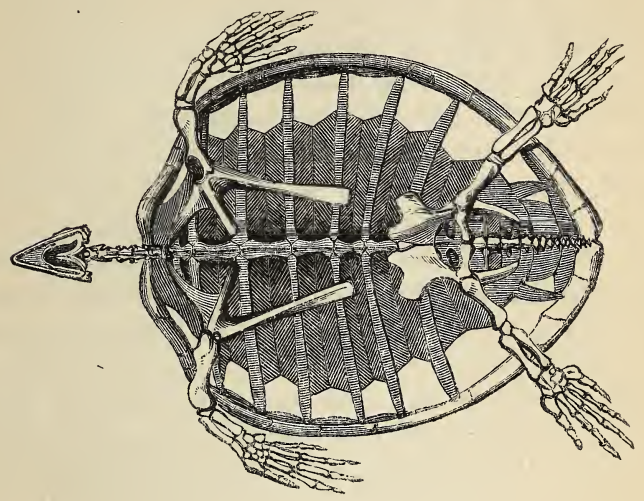

SKELETON OF TORTOISF.

jaws are destitute of teeth, but are invested with horn like those of birds, and form in fact a powerful beak. The head, neck, tail, and limbs, are clothed with a tough skin, in which are imbedded plates, either connected or detached.

The sphere of action of the Testudinata is either the land or the water. Of those which are aquatic, some inhabit marshes, pools, and rivers; others are exclusively marine. The walk of the terrestrial species is slow, even to a proverb; the legs are short, restricted in motion, and being placed at a distance from the centre, they form a sort of short crutches, able to drag the unwieldy 
body along, but unable to restore the prone position if the animal be laid on its back. The feet seem like stumps abruptly cut off, armed around the edge with a set of blunt nails, which serve as a sort of grapplings to hold on the surface of the ground and drag the body forwards. To an animal which feeds on herbs, the power of pursuit is useless; nor is it necessary that swiftness in escape should be conferred on one which can draw in its head and limbs on the approach of danger, presenting only a solid case of mail, in which it may defy every enemy but man.

On the other hand, the marine species swim with great rapidity, rushing along beneath the surface like a bird on the wing. The feet take the form of powerful fins, and the form of the body is flattened, and thinned to an edge, both of these provisions facilitating progression through a dense medium. "But the well-developed flipper that enables the Marine Tortoise to oar its way with swiftness, is even a worse organ for land-progression than the clumsy foot of a Land Tortoise. Not but that they will shuffle back to the sea, which they have only occasion to leave in order to deposit their eggs, at a good pace, and they will deal heavy blows with their flippers to those who attempt to stop them, (for they, as well as the Land Tortoises, are very strong, ) as those who have been foiled in turning Turtles have known to their cost."

The eggs are of an oval form, and are covered with a white calcareous shell, much resembling those of birds. Those of many of the species are eaten by man.

The food of the Testudinata is various: the 
terrestrial species are believed to subsist exclusively on vegetable diet; the marine species add to this the flesh of large shelled mollusks; the marsh and fresh-water kinds prey on fishes, young birds, insects, worms, and any other animals they can overcome.

About one hundred and twenty species are known to belong to the Order, of which twentyeight are terrestrial, eighty-four are fluviatile, and eight are marine. They are confined to the warmer regions of the earth; none of them being properly inhabitants of the British Islands; but occasional occurrences of some of the marine species on our shores are recorded, and a terrestrial Tortoise is imported in some numbers from the south of Europe, and kept as a pet in gardens.

We shall consider the Tortoises as comprised in five Families; Testudinida, Emydida, Trionychide, Sphargide, and Cheloniade.

\section{Family I. Testudinide.}

\section{(Land Tortoises.)}

In this Family the carapace is very high and convex, solid in structure, and covered with a horny shell. The general form may be illustrated by the common Greek Tortoise (Testudo Greca), familiar to most of our readers. But the principal and most remarkable peculiarity, and that which most perfectly indicates the manner of life common to the group, is the conformation of the limbs : the feet are short and stumpy, nearly of equal length, with toes scarcely distinct, immovable, united by a thick skin, and forming a sort 
of truncated mass, "callous in its periphery, on the outside of which one distinguishes only horny cases, a sort of hoofs, which for the most part

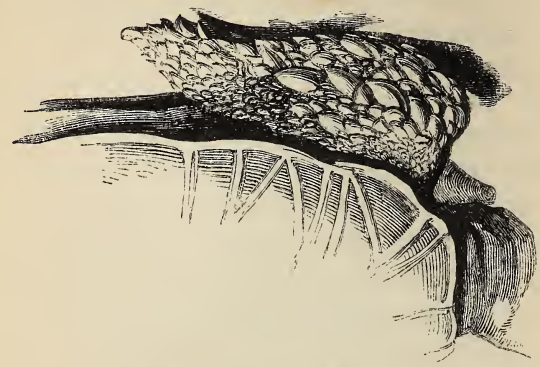

FOOT OF TORTOISE.

correspond with the last phalanges [or joints] they incase, and consequently shew that these animals live only on the land, never in the water." *

The feet, as well as the head, are capable of being completely drawn within the bony shell. Some of the species have the hinder part of the carapace flexible, so that it can be brought down to the plastron; while others have the front plates of the plastron jointed to the rest by an actual hinge, so that they can shut up the head as in a sort of box.

The food of the members of this Family consists exclusively of vegetables: their motions are slow and awkward: they live to an immense age, individuals having been ascertained to be above two hundred years old. In temperate climates, they burrow into the earth on the approach of winter, where they remain inert.

* Duméril et Bibron. 


\section{Genus Testudo. (Linn.)}

The technical characters of this genus are that the fore-feet are furnished with five toes each, the hind with four; the carapace is composed of a single piece; the anterior part of the plastron is not moveable. Above twenty species are described, principally inhabiting the tropical regions; many of these attain a gigantic size, to which our little European species present no approach.

One of the most interesting of these giant Tor-

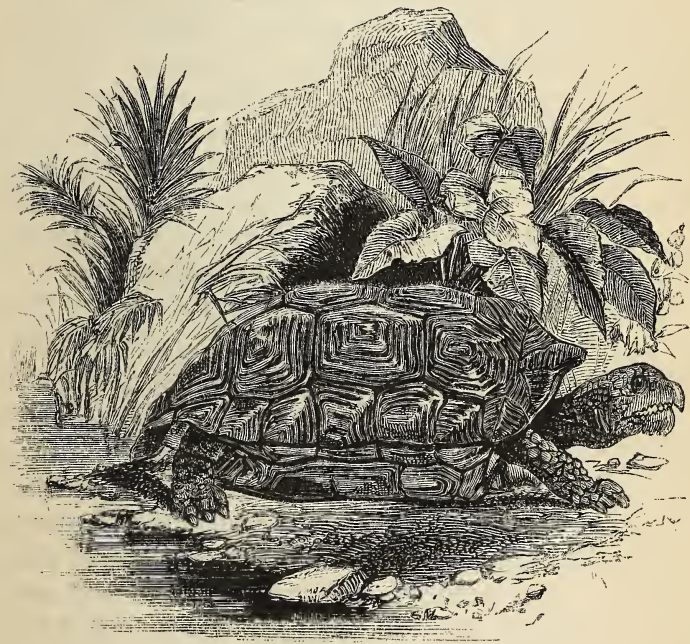

INDIAN TURTOISE.

toises is that described by $\mathrm{Mr}$. Darwin as inhabiting the Galapagos Islands. It is probably the 
Testudo nigra of Quoy and Gaimard. In these equinoctial islands it has been abundant from the time of Dampier, who observes, that five or six hundred men might subsist on them for several months without any other sort of provisions, adding, that they are so extraordinarily large and fat, and so sweet that no pullets eat more pleasantly.

The day on which Mr. Darwin visited the little craters in the Galapagos Archipelago was glowing hot, and the scrambling over the rough surface, and through the intricate thickets, was very fatiguing. "But," says Mr. Darwin, "I was well repaid by the Cyclopean scene. In my walk I met two large Tortoises, each of which must have weighed at least two hundred pounds. One was eating a piece of cactus, and when I approached it looked at me, and then quietly walked away; the other gave a deep hiss, and drew in his head. These huge reptiles, surrounded by the black lava, the leafless shrubs, and large cacti, appeared to my fancy like some antediluvian animals."

Mr. Darwin states his belief that these Tortoises are found in all the islands of the Archipelago ; certainly in the greater number; and thus continues his description:- " They frequent, in preference, the high damp parts, but likewise inhabit the lower and arid districts. Some individuals grow to an immense size. Mr. Lawson, an Englishman, who had, at the time of our visit, charge of the colony, told us that he had seen several so large that it required six or eight men to lift them from the ground, and that some had afforded as much as two hundred pounds of meat. The old males are the largest, the females rarely growing to so great a size. The male can readily 
be distinguished from the female by the greater length of its tail. The Tortoises which live on those islands where there is no water, or in the lower and arid parts of the others, chiefly feed on the succulent cactus. Those which frequent the higher and damper regions eat the leaves of various trees, a kind of berry (called guayavita), which is acid and austere, and likewise a pale green filamentous lichen, that hangs in tresses from the boughs of the trees. The Tortoise is very fond of water, drinking large quantities, and wallowing in the mud. The larger islands alone possess springs, and these are always situated towards the central parts, and at a considerable elevation. The Tortoises therefore, which frequent the lower districts, when thirsty, are obliged to travel from a long distance. Hence, broad and well-beaten paths radiate off in every direction from the wells even down to the sea-coast; and the Spaniards, by following them up, first discovered the watering places. When I landed at Chatham Island, I could not imagine what animal travelled so methodically along the well-chosen tracts. Near the springs it was a curious spectacle to behold many of these great monsters; one set eagerly travelling onwards with outstretched necks, and another set returning, after having drunk their fill. When the Tortoise arrives at the spring, quite regardless of any spectator, it buries its head in the water, above its eyes, and greedily swallows great mouthfuls, at the rate of about ten in a minute. The inhabitants say that each animal stays three or four days in the neighbourhood of the water, and then returns to the lower country; but they differed in their accounts 
respecting the frequency of these visits. The animal probably regulates them according to the nature of the food which it has consumed. It is, however, certain, that Tortoises can subsist even on those islands where there is no other water than what falls during a few rainy days in the year.

"I believe it is well ascertained, that the bladder of the frog acts as a reservoir for the moisture necessary to its existence : such seems to be the case with the Tortoise. For some time after a visit to the springs, the bladder of these animals is distended with fluid, which is said gradually to decrease in volume and to become less pure. The inhabitants, when walking in the lower district, and overcome with thirst, often take advantage of this circumstance, by killing a Tortoise, and if the bladder is full, drinking its contents. In one I saw killed, the fluid was quite limpid, and had only a very slightly bitter taste. The inhabitants, however, always drink first the water in the pericardium, which is described as being best. The Tortoises, when moving towards any definite point, travel by night and by day, and arrive at their journey's end much sooner than would be expected. The inhabitants, from observation on marked individuals, consider that they can move a distance of about eight miles in two or three days. One large Tortoise which I watched, I found walked at the rate of sixty yards in ten minutes, that is, three hundred and sixty in the hour, or four miles a day - allowing also a little time for it to eat on the road. They were at this time (October) laying their eggs. The female, where the soil is sand, deposits them together, and covers them up with sand; but where the ground 
is rocky, she drops them indiscriminately in any hollow. Mr. Bynoe found seven placed in a line in a fissure. The egg is white and spherical; one which I measured was seven inches and threeeighths in circumference. The young animals, as soon as they are hatched, fall a prey in great numbers to the buzzard with the habits of the caracara. The old ones seem generally to die from accidents, as from falling down precipices: at . least, several of the inhabitants told me they had never found one dead without some such apparent cause. The inhabitants believe that these animals are absolutely deaf; certainly they do not overhear a person walking close behind them. I was always amused, when, overtaking one of these great monsters as it was quietly pacing along, to see how suddenly, the instant I passed, it would draw in its head and legs, and uttering a deep hiss, fall to the ground with a heavy sound, as if struck dead. I frequently got on their backs, and then, upon giving a few raps on the hinder part of the shell, they would rise up and walk away; but I found it very difficult to keep my balance. The flesh of this animal is largely employed, both fresh and salted; and a beautifully clear oil is prepared from the fat. When a Tortoise is caught, the man makes a slit in the skin near its tail, so as to see, inside its body, whether the fat under the dorsal plate is thick. If it is not, the animal is liberated; and it is said to recover soon from this strange operation. In order to secure the Tortoises, it is not sufficient to turn them like Turtle, for they are often able to regain their upright position." *

* "Darwin"s" Journal. 


\section{:Family II. Emydide.}

\section{(Marsh Tortoises.)}

This is the most numerous in species of the Families of the Testudinata. MM. Duméril and Bibron observe, that America produces more Marsh Tortoises than all the rest of the world put together; for of the seventy-four species composing this family, forty-six are confined to that continent. The cause of this disproportion they attribute to the vast body of water in the form of immense lakes, marshes, and rivers with which the expanse of America is intersected. The continent of Africa, on the other hand, which offers in this respect so great a contrast to the former, presents us with but three species of Emydida, but is very rich in Testudinida.

The Marsh Tortoises, or Terrapins, have the body much flatter, the carapace being less arched, than the Land Tortoises. The toes are separated, or rather separately moveable, and are furnished with hooked claws; they are usually connected by a palmated membrane or web, and the hind feet are larger than the fore ones. They have twelve plates on the plastron; they withdraw the head and neck between the shields.

The habits of this Family differ much from those of other Tortoises. They swim with facility, and walk on land with a less slothful gait than the Testudinida. They inhabit marshes, stagnant ponds, lakes, and even small rivers whose course is gentle; feeding on small water-animals, such as frogs and newts, the young of web-footed fowl, 
fresh-water snails, and insects; nor does the flesh of larger creatures drowned in the lakes, or bogged in the marshes, come amiss to them. The eggs are rounded, with a hard, white, calcareous shell; they are deposited in shallow cavities scraped in the soft earth on the margins of the waters in which they reside, whence the young, hatched by the heat of the sun, readily find their way into their proper element.

\section{Genus Emys. (Brongn.)}

In this genus all the feet are furnished with five toes, but the inner toe of the hind foot is destitute of a nail: the plastron is wide, and oval, and is furnished with twelve plates; the marginal plates of the carapace are twenty-five. The jaws are strong and cutting, the mandibles notched, and toothed in a manner closely resembling the beak of a Falcon.

The most common European fresh-water Tortoise belongs to a genus allied to Emys, but distinguished by having the plastron attached to the buckler by a cartilage, allowing it some degree of mobility. It is named Cistudo Europaea, and is extended over the whole south-east of Europe, as far north as Prussia. It attains the length of nine or ten inches; the carapace is oval, of a blackish hue, marked with yellowish specks; the skin of the neck and breast is similarly spotted. It is a species of some elegance, but it is most esteemed for the excellence of its flesh, and is commonly sold in the markets of Germany. To improve its flavour, colonies of these animals, kept in ponds, are fattened upon let- 
tuce and other leaves, bread, \&c. "It may be even conveniently kept in a cellar, and fed on oats, which, being scattered on the floor, take root there, and as they begin to sprout up, afford a wholesome nutriment to this reptile." We are informed by Wolff that the peasants in Prussia keep numbers of these creatures in troughs for a year or two, and fatten them up.

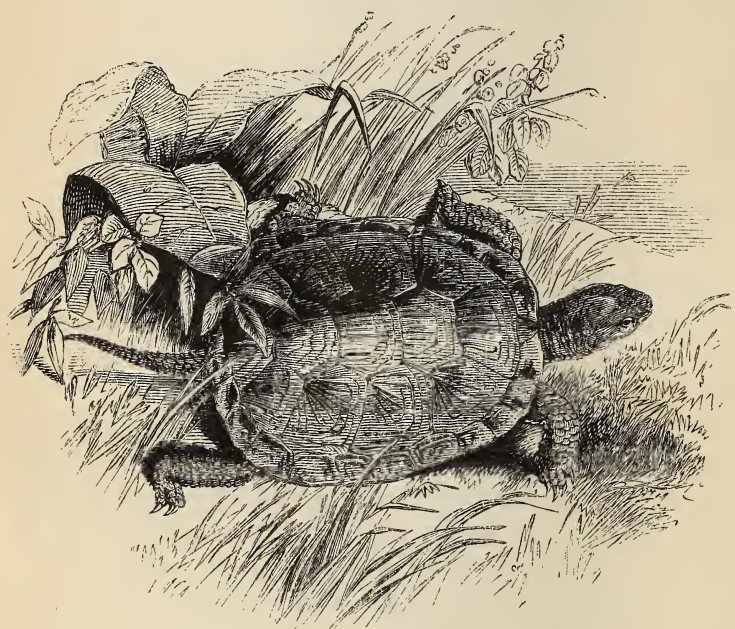

EUROPEAN MARSH TORTOISE.

On approaching a pond where these reptiles abound, numbers of them may be seen of various sizes, from that of a penny upwards, sitting motionless on the twigs and branches of fallen trees, or the projecting points of any other substance that is partly submerged. They are very 
watchful, and on the slightest alarm they drop almost imperceptibly into the water, and sink to the bottom, whence they soon emerge if all is quiet. They are voracious: their living prey is taken, by stealing slowly towards it, and seizing it with a sudden snap.

It is a curious fact that whenever this Tortoise eats a fish, it rejects the air-bladder; and the peasants, who seek these animals for the market, judge of the number that are to be found in any pond, by the number of fish-bladders floating on the surface. Professor Bell has mentioned to us that he had a Tortoise of this species in his possession, to which he once threw six small living fishes; the next morning there was one fish remaining, and five air-bladders on the surface, told the fate of the rest.

Several genera of fresh-water Tortoises are distinguished by their not being able entirely to retract the head between the shields; but they obtain a partial protection by bending the long neck to one side. In general the head in this group is depressed, and the eyes are seated somewhat on the upper surface, so as to look obliquely upwards instead of sidewise. These Tortoises are, by some Naturalists, considered to form a distinct Family by the name of Hydraspidae. 


\section{Family III. Trionychide.}

(Soft Tortoises.)

These are large Tortoises which have no horny shell, but the carapace and plastron are covered with a soft skin. The ribs do not reach to the border of the carapace, nor are they united through the whole of their length, the parts analogous to sternal ribs being replaced by a simple cartilage; and the sternal pieces are partly dentelated as in the Turtles, and do not cover the whole inferior surface. The feet, like those of the preceding family, are webbed, but not lengthened; only three toes of each foot are furnished with nails. The horny beak is covered on the outside with fleshy lips, and the muzzle is produced into a short trunk. The tail is short, and the anal orifice of the body is situated near its extremity.

The Soft Tortoises inhabit great rivers and lakes, where they live upon aquatic animals ; they are eminently carnivorous and voracious, and pursue with agility in the water, fishes, and especially young crocodiles. Notwithstanding the nature of their food, their flesh is esteemed for the table, and hence they are caught with a hook and line: it is necessary, however, as MM. Duméril and Bibron assert, that the hook should be baited with a living prey, or at least that the motion of apparent life should be communicated to it, if dead, as they are said never to touch a dead or immoveable prey. This does not apply, however, to the eggs of Crocodiles, which the 
Soft Tortoises devour greedily in the African and Indian rivers. In seizing their food, or defending themselves, they dart out their long neck with the sudden rapidity of an arrow. The grasp of their powerful and trenchant beak is sharp and deadly, nor is it relaxed until the piece is taken clean out; and as they are bold and ferocious, they are much dreaded even by those who fish for them.

Like the Emydes, the Soft Tortoises love to repose on the islets and points of rock, on the fallen trees at the rivers' margins, or on floating logs of timber, whence they drop into the water on the slightest alarm. They swim with ease and swiftness, both on and beneath the surface.

No species of this Family is found in any of the rivers of Europe. The Nile, the Niger, and the Senegal, the Euphrates, and the Ganges, the Mississippi, the Ohio, and their tributaries, and the great lakes of the St. Lawrence, are the localities known to be inhabited by various species of Trionychide.

\section{Genus TrIONYX. (Geoff.)}

The species belonging to this genus, which includes the majority of those known, are distinguished by the following characters. The carapace is surrounded by a cartilaginous circumference, very wide, floating behind, and deprived of bone externally. The hinder part of the plastron is too narrow to hide the posterior limbs completely, when the animal draws them up under the carapace.

The common Soft Tortoise of North America 
(Trionyx spiniferus, LESUEUR) inhabits the great lakes, and many of the rivers of that continent. It is a ferocious tyrant of the waters, devouring ducks and other fowl, the young of alligators, and fishes, with great voracity. It attains a large size.

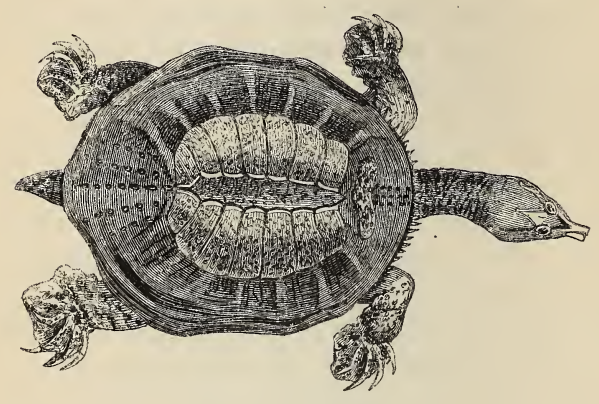

SOFT TORTOISE.

Pennant mentions some which weighed seventy pounds; one which he kept for three months weighed twenty pounds, and the buckler or carapace of this specimen was twenty inches in length, while the neck and head measured thirteen inches and a half more. The upper parts vary in tint, being brown or grey of various shades, irregularly marbled, and frequently studded with dots: the under surface is whitish, or of the same tint as the human nails.

Towards the end of April or May, according to M. Lesueur, the females of this species crawl out of the rivers, for the purpose of seeking out places suitable for the deposition of their eggs. Sandy spots exposed to the sun are chosen, and 
to obtain these they will often scale a steep bank that is ten or fifteen feet above the water's edge. The eggs are deposited in hollows, to the number of fifty or sixty, the old Tortoises laying more than young ones. They are spherical in form; the shell is calcareous but in a slight degree, and is therefore more fragile than that of the eggs of the Emydes that inhabit the same waters. M. Lesueur counted in the ovary of a female twenty ready for laying, and an immense number of others, varying in their dimensions, from the size of a pin's head to the full volume attained when they become covered with the calcareous shell. They are caught by persons who angle for them with a hook and line, baited with a small fish; when drawn on shore they are dangerous, darting the head to the right and left with incredible velocity; they often inflict severe bites on their captors, so that the prudent chop off their heads as soon as they draw them out of the water; the flesh is very delicate in flavour.

It is believed that the Soft Tortoises pair, and that the male remains constantly attached to the same female, two individuals of different sexes being commonly seen together in any given locality.

\section{Family IV. Sphargidæ.}

\section{(Leathery Turtles.)}

In this and the following Family, the carapace is very much depressed, and their two pairs of feet, which are of unequal length, are flattened into the form of oars or solid fins, their toes being 
united so as to be scarcely distinguishable, and incased in the common integument. They all inhabit the ocean, which they never leave except for the purpose of depositing their eggs.

The Sphargida, or Leatherbacks, have the bony structure of the carapace and plastron invested with a leathery skin instead of horny plates. In the young animal this is tuberculous, but in adults it is smooth, though marked with several ridges, slightly serrated, which run down through the whole length of the carapace and plastron.

\section{Genus Sphargis. (Illig.)}

The one or two species which belong to this genus compose the whole Family. Their remaining characters may be thus summed up : the carapace has seven longitudinal ridges, the plastron five; the paddles have no distinct nails; the muzzle is pointed; the jaws are of great power; the upper has a sharp tooth on each side near the tip, behind which is a deep notch, and another triangular notch in front separates the two teeth, which receives the sharp up-turned point of the lower mandible; the opening of the eyelids is almost vertical, and when closed the edge of the posterior (answering to what is ordinarily the lower) overlaps that of the anterior; the fore limbs are much more developed than the hind, and are of great length and breadth.

The species that inhabits the Mediterranean (Sphargis coriacea, LINN.) has occasionally strayed to the shores of our own islands. Some of the specimens taken here have weighed seven hundred 
and eight hundred pounds. Pennant relates that one taken off the coast of Scarborough was purchased by a family, who invited several persons to partake of its flesh. A gentleman present told the guests that it was unwholesome, but one person persisting to eat of it was seized with violent

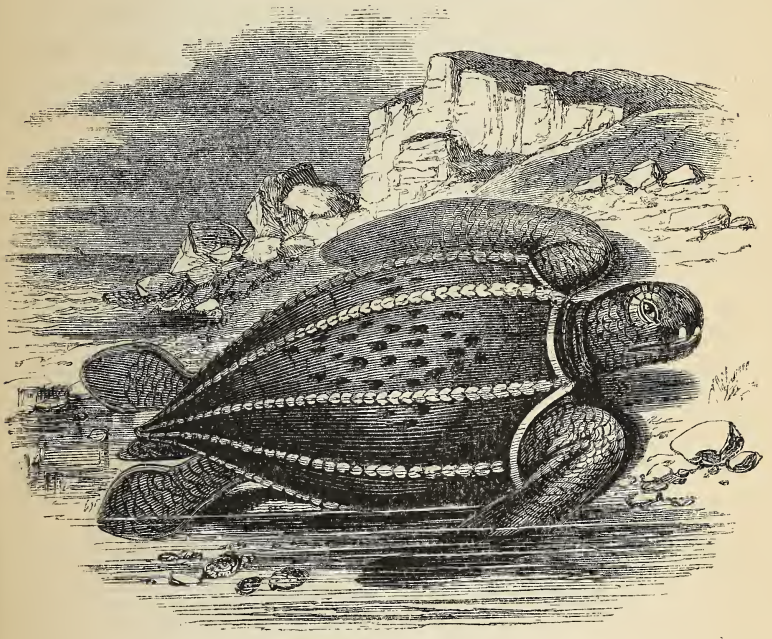

LEATHERY TURTLE.

purging and vomiting. This case, however, can hardly be considered conclusive as to its unwholesomeness, if what Pennant adds be correct, that the Carthusians are said to eat of the flesh of no other Turtle. The appearance of the meat is said to be coarse, and the flavour bad; though it is usually very fat. 
There is a species common on the tropical shores of the Atlantic Ocean, by some thought to be identical with the above, though distinguished by other zoologists. It regularly visits the Tortugas, or low sandy islets that lie off the point of Florida, for the purpose of depositing its eggs, arriving, according to Audubon, later than the other Turtles, and manifesting less caution in selecting a place adapted for their concealment. The number laid by each female amounts to about three hundred and fifty, deposited in two parcels. Individuals of this species, when sorely wounded, or hampered in nets, have been heard to utter loud bellowing cries, audible at the distance of nearly a mile.

This is the largest of all the T'estudinata known, sometimes attaining a length of nine or ten feet, and a weight of sixteen hundred pounds. Its carapace is of a dusky hue, and is marked over its surface into five or six-sided subdivisions, small and obscure, so as not to detract from its general smoothness.

\section{Family V. Cheloniade.}

\section{(Turtles.)}

The species of most importance to man are contained in this Family; one affording an abundant and esteemed article of diet, and another yielding a substance of much elegance, which, under the name of Tortoise-shell, is largely used in the arts. Their distinctive characters are, that the head, and particularly the feet, cannot be withdrawn between the carapace and plastron; 
that the feet are flattened into swimming-paddles, the toes being united, and enveloped in the same membrane: the anterior pair are greatly lengthened. Only the first two toes are furnished with claws, which are pointed; and one or other of these is apt to fall at a certain period of life. The pieces of which the plastron is composed do not form a continuous plate, but are variously dentelated, and leave wide inter-

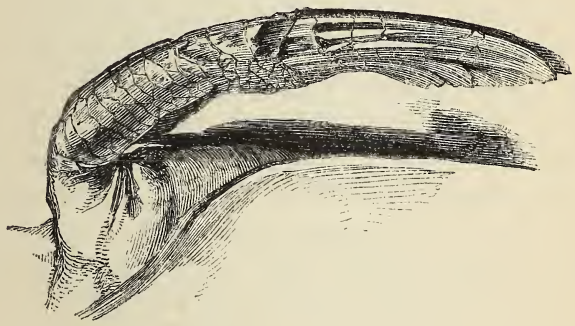

FOREFOOT OF HAWKSBILL TURTLE.

vals filled only by cartilage. The ribs are narrowed, and separated from each other at their external portion, but the entire circumference of the carapace is occupied by a circle of pieces corresponding to sternal ribs. The plates of the carapace are horny, and for the most part continuous at their edges, as in the majority of other Testudinata, but in some species, as that from which the beautiful Tortoise-shell is obtained, the posterior edge of each plate is produced, and overlaps the one that succeeds it.

The food of the Turtles consists chiefly of various kinds of sea-weeds, such as the Zostera 
or sea-grass, which grows in immense submerged fields at the bottom of the tropical seas. It has been stated that some species will crawl up the shores of desert islands during the night, and clamber up the cliffs of lone and isolated rocks far out at sea, for the purpose of browsing on certain favourite plants. But some species, such as the great Loggerhead Turtle (Chelone caouana), which diffuse a rank odour, feed largely on cuttles, and other mollusca, their powerful jaws crushing even such stony shells as those of the great Strombi and Cassides, as a man would crack a nut. The robust form of the jaws in these animals, their trenchant and frequently notched or toothed edges, the mode in which the lower mandible shuts into the upper, and the great strength of the muscles which move them, manifested in the force with which they snap together,-while they remind the beholder of the beak of a bird of prey, yet constitute an instrument of far greater power, and seem to intimate that it must be something more than grass that requires an apparatus so formidable.

The flattened form of the Marine Turtles presents little resistance to the fluid in which they move, and their broad oar-like feet enable them to swim and dive with great velocity and grace. Mr. Audubon speaks of some species shooting through the element with the arrowy fleetness of a bird on the wing. Except when they come on shore to lay their eggs on the sand, or clamber on the rocks, as intimated above, to browse on herbage, the Turtles never leave the sea; they may often be seen in fair weather in the tropics, floating motionless on the calm surface of the 
ocean, many hundred miles from land. They are supposed on such occasions to be asleep, but they are very vigilant, and will rarely allow a near approach without disappearing by diving. They remain a long time under water, as might be expected from the volume of their arbitrary lungs, enabling them to retain a sufficient quantity of air, while submerged.

The very peculiarities of conformation, however, which adapt them for swift progression in their own element, render them awkward and almost helpless when out of it. It is only with laborious efforts that they are enabled to shuffle along on land; and if once turned over on their backs, their great width and flattened form prevent their ever being able to regain their natural position.

The flesh of the herbivorous kinds is well known as an article of luxury in this country: to voyagers, however, it fills a much more important position, as it affords a most valuable resource in tropical climates, being abundant, easily kept fresh, and as nutritious as it is agreeable. The eggs of all the species are excellent, and are procured in immense numbers; the albumen, or that part which answers to the white, does not grow hard by the application of heat.

The various species seem to have no settled habitat, but are widely scattered over the whole ocean of the warmer regions of the globe. There are, however, favourite resorts, where they are procured in greater abundance, as low sandy coasts of uninhabited islands, or lonely spots on other shores. 'Thus in the Atlantic, the Cape Verd Isles, Ascension, and the Isles of the West In- 
dies; in the Indian Ocean, the Isle of France, Madagascar, Rodriguez, and the Seychelles; in the Pacific, the Galapagos, and the Sandwich Isles, are noted resorts of Turtle.

The reason of some shores being more frequented by Turtles than others, is their suitability for breeding-places. To reach the destined spot for the deposition of the eggs, "the females have often to traverse the sea for more than fifty leagues, and the males accompany them to the sandy beaches of those desert islands selected for the places of nidification. Arrived at the end of their voyage, they timidly come forth from the sea after sunset; and, as it is necessary to leave the eggs above high-water mark, they have often to drag themselves to a considerable distance before they can hollow out their nests (about two feet in diameter) during the night, and there lay at one sitting to the number of one hundred eggs. This laying is repeated thrice, at intervals of two or three weeks. The eggs vary in size, but are spherical, like tennis-balls; and when they are laid, their investing membrane is slightly flexible, although covered with a delicate calcareous layer. After slightly covering the nest with light sand, the parent returns to the sea, leaving the eggs to the fostering influence of a tropical sun. The eggs are said to be hatched from the fifteenth to the twenty-ninth day; and when the young Turtles come out, their shells are not yet formed, and they are white as if blanched. They instinctively make for the sea; but on their road, and as they pause before entering the water, the birds of prey that have been watching for the moment of their ap- 
pearance hasten to devour them; whilst those that have escaped their terrestrial persecutors by getting into the sea, have to encounter a host of voracious fishes and legions of ambushed crocodiles."*

\section{Genus Chelone. (Brongn.)}

If we consider the Green Turtle, the Loggerhead, and the Hawksbill, as constituting but so

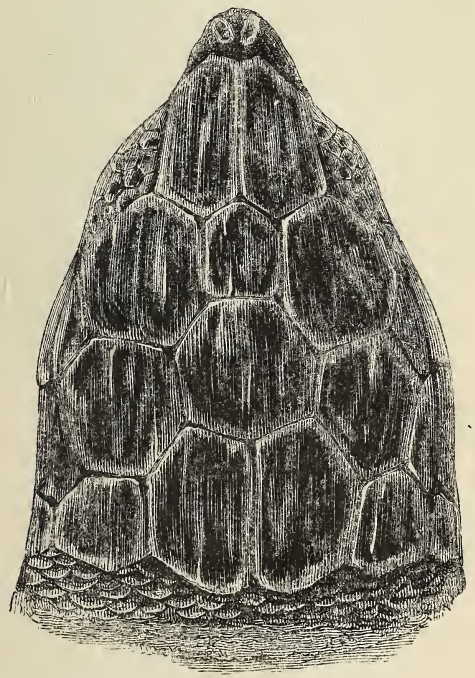

HEAD OF GREEN TURTLE.

many species of a single genus, the characters of that genus will be the same as those already

* Penny Cyclop. xxv. 76. 
enumerated as marking the Family: but if, with some zoologists, we treat the differences between these animals as generic and not specific, restricting the term Chelone to the Green Turtle and its allies ( $C$. mydas, maculosa, marmorata, $\& c$. ), we may give the following (from Duméril and Bibron) as the distinctive characteristics of this genus. The plates which compose the disk of the carapace are thirteen, not overlapping; the muzzle is short and rounded; the upper jaw has a slight notch in front, and small dentelations on the sides; the horny case of the lower jaw is formed of three pieces, and has its sides deeply dentelated; the first toe of each foot is furnished with a nail.

The Green Turtle (Chelone mydas, Lins.) is of an olive or greenish-brown hue above, and yellowish-white below. The carapace consists of twenty-five marginal plates, surrounding a disk of thirteen; the medial plates of the latter form almost perfect hexagons ; the whole shell is somewhat heart-shaped, being pointed at the posterior extremity. Its length is sometimes above six feet, and its weight six or seven hundred pounds. Dampier mentions one that was captured in the Bay of Campeachy, which was nearly six feet wide, and four feet thick. A son of Captain Roche, a boy of ten years old, went in the shell as a boat, from the shore to his father's ship, lying about a quarter of a mile distant. Pliny speaks of the Chelonophagi, dwelling on the shores of the Red Sea and the Indian Ocean, who not only subsisted on Turtles, but converted their enormous shells into roofs for their huts, and boats for their little voyages; and the inhabitants 
of some of the tropical islands at this day make these shells serve the same purposes, and others,

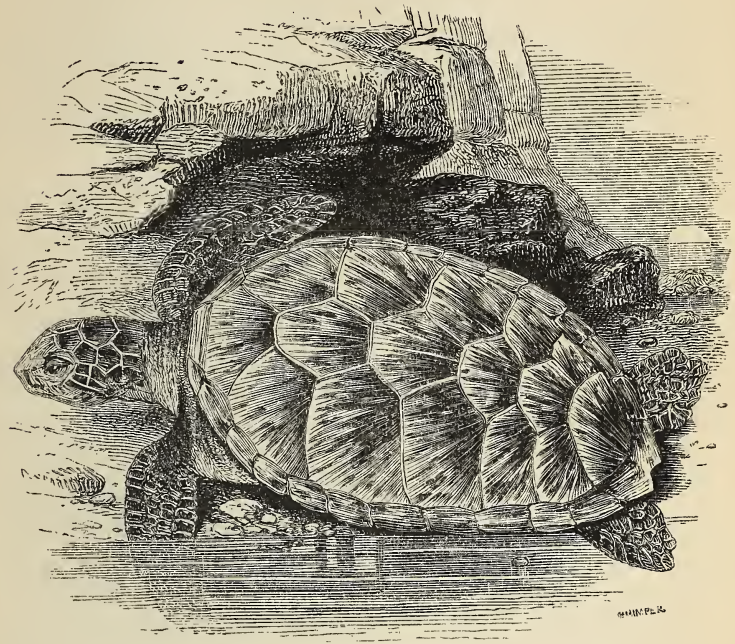

GREEN TURTLE.

such as drinking-troughs for their cattle, and baths for their children.

The West Indian Isles, particularly the Bahamas, and those little sandy spots off the end of Cuba, known as the Caymanas, the Isle of Ascension, and most of the islands of the Pacific, are favourite resorts of the Green Turtle. Specimens have been occasionally caught on the shores of Europe, driven hither by stress of weather. "In the year 1752," says Mr. Bingley, 
"one, six feet long and four feet broad, weighing betwixt eight and nine hundred pounds, was caught in the harbour of Dieppe after a storm. In 1754, a still larger one, upwards of eight feet long, was caught near Antioche, and was carried to the Abbey of Long-veau, near Vannes in Britany; and in the year 1810, I saw a small one which had been caught amongst the submarine rocks near Christchurch, Hants."*

This is the species the flesh of which is so highly esteemed, that it forms no unimportant article of commerce. Great numbers are imported every season for the supply of the London hotels and eating-houses, and these are chiefly brought from the West Indies and from Ascension Island. Ships proceeding on long voyages through the tropical seas always endeavour to recruit their supplies of fresh provisions, by calling at the islands where these animals are known to abound, and taking in a large number of living Turtle, as they are readily preserved in health for a long time with little trouble and without food.

The mode of taking Turtle is thus graphically described by Sir J. E. Alexander, as he witnessed it at Ascension, which island he calls the head-quarters of the finest Turtle in the world:-

"We walked down to the Turtle ponds, two large enclosures near the sea, which flowed in and out through a breakwater of large stones. A gallows was erected between the two ponds, where the Turtle are slaughtered for shipping, by suspending them by the hind flippers, and then

* Anim. Biog. iii. 147. This instance of its occurrence has probably been overlooked by Mr. Bell, who has not included the species in his beautiful "History of British Reptiles." 
cutting their throats. About three hundred Turtle, of four or five hundred pounds each, lay on the sand, or swam about in the ponds; a sight to set an alderman mad with delight.

"In the hot months of January, February, March, and April, the females land at night; and waddling over the sands in the various bays of

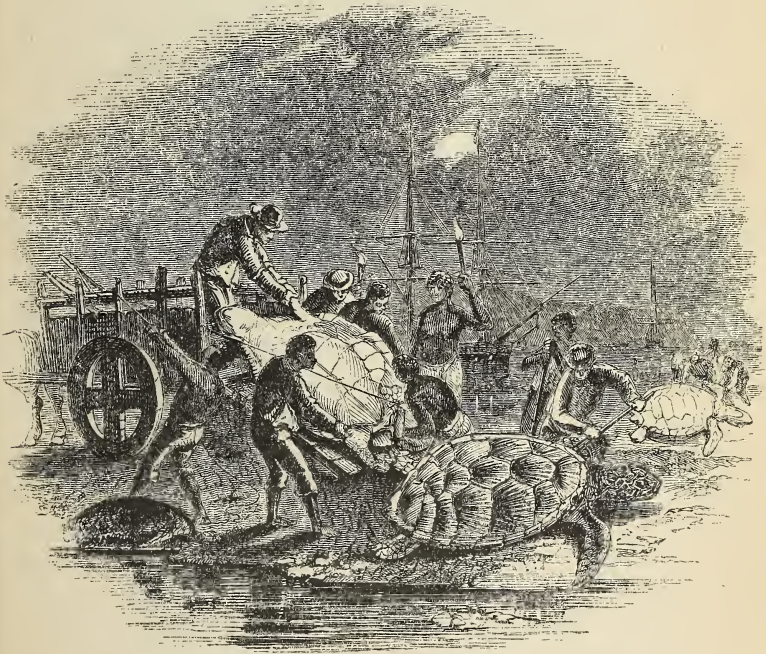

TURNING TURTLE.

the island far above high-water mark,-for by a pole in the ponds, the tide only rises here two feet,-they scrape up, by alternate scoops of their flippers, a hole deep enough to cover their bodies. Into this they get, sighing heavily, and deposit 
from one hundred and fifty to two hundred eggs ; cover them up, leave them to the sun to hatch, and then waddle again towards the sea. Two stout hands are, meanwhile, on the look out, watching the movements of the unfortunate Turtle; and running up to her after the completion of her task, one seizes a fore-flipper, and dexterously shoves it under her belly, to serve as a purchase, whilst the other, avoiding a stroke which might lame him, casts the Turtle over on her back, where she lies helpless. From fifteen to thirty are thus turned in a night; and six hundred had been so captured in the season of 1834. In the bays, where the surf, or heavy rollers, prevent the boats being beached to take on board the Turtle when caught, they are hauled out to them by ropes.

"No ships' crews are now allowed to turn Turtle, which is converted into a government monopoly; and two pounds ten shillings is the price for each. Strange to say, from the time that the young Turtle, the size of a dollar, are observed scuttling down to the water, they are never seen again here until they are four or five hundred pounds weight; and how long they take to attain this great size, and where they spend the intermediate time, is as yet a mystery. I was surprised to hear that Turtle are kept in the ponds for a year and upwards, without a morsel of food of any kind. They sometimes deposit their eggs in the sand, on the sides of the ponds; and in due time the little animals are allowed to make their escape to the sea. One old female, called 'Nelson,' because one of her flippers had been carried off by a shark, was kept, out of respect, 
for two or three years in the ponds. She contrived, however, one night to crawl round the enclosure, and make her escape; but she was turned next year in Clarence Bay. Another Turtle was also turned there, a short time since, on the back shell of which was carved the name of a mate of a British vessel, who had bought it and sailed with it three weeks before; it is probable that, imagining it to be dead, he had thrown it overboard. The best way to send home Turtle from Ascension, is to 'head them up' in a sealed cask, and have the water changed daily by the bung-hole and a cock. Turtle, though the extremes of heat and cold are injurious to them, should always arrive in hot weather in England. Thus, an unfortunate captain, on one occasion, took from Ascension two hundred Turtle, and timing his arrival badly, brought only four alive to Bristol!"

Catesby mentions a mode of capturing these animals besides turning them on the sands. The inhabitants of the Bahamas are very expert at the latter, and go in boats to the neighbouring coast of Cuba, where on moonlight nights they watch the passing of the female Turtles to and from their nests, and intercepting them, turn them on their backs. Leaving each as it is turned, they proceed along the shore, turning every one they meet with; knowing that they will find each on their return in the position in which it was left; for the Turtle, lying on its back, can never recover its feet by any efforts of its own. Some are so large, as to require three men to turn them. But the way in which these creatures are most commonly taken at the $\mathrm{Ba}$ - 
hamas, is by striking them with a sharp iron peg or spear-head of two inches long, set in a socket at the end of a staff twelve feet long. Two men set out on this employment in a light canoe, one to paddle noiselessly in the stern, while the other stands watchful in the bow, ready to strike. As soon as a Turtle is perceived, either swimming at the surface with the back exposed, or else crawling at the bottom in shoal water among the thick sea grass, the spear is darted at it. The sharp point enters the shell, and pierces the body, but is dislodged from the staff in the act; a slender line, however, fastened to the peg, is in the hand of the spearman, and though the Turtle speeds away, the canoe is enabled to keep up with him; his strength is soon spent, and he is hauled to the surface, and lifted into the boat.

In some of the isles of the Pacific, where the natives are almost as much at home in the sea as the Turtles themselves, a peculiarly dexterous method of capturing these animals is adopted. Two or three men go out in a canoe in smooth water, when the Turtles delight to sleep on the surface, basking in the sun. No sooner is one discovered, than the ready diver plunges into the sea, and coming up silently behind the animal, suddenly seizes the hinder edge of the carapace before it awakes, and pressing down the posterior part of the body in the water, obliges the fore parts to remain upright. Thus the terrified Turtle, now thoroughly awakened, is prevented from diving until the canoe coming up, the bold fisherman and his prey are both taken on board.

Mr. Darwin, in his very interesting Journal, describes a method of Turtle-catching not very 
dissimilar to the above, but superior in spirit and boldness. Keeling Island is the scene of his graphic description. He observes,

"I accompanied Captain Fitzroy to an island at the head of the lagoon; the channel was exceedingly intricate, winding through fields of delicately branched corals. We saw several Turtles, and two boats were then employed in catching them. The method is rather curious; the water is so clear and shallow, that although at first a Turtle quickly dives out of sight, yet in a canoe or boat under sail, the pursuers after no long chase come up to it. A man standing ready in the bows at this moment dashes through the water upon the Turtle's back, then clinging with both hands by the shell of the neck, he is carried away till the animal becomes exhausted and is secured. It was quite an interesting sight to see the two boats thus doubling about, and the men dashing into the water, trying to seize their prey."

But there is a mode of fishing for these animals, said to be practised on the coasts of China and Mozambique, which is still more remarkable; living fishes being trained for the purpose of capturing the Turtles. Columbus seems to have been aware of this fact, which has since been noticed by Commerson, as cited by Middleton and Salt. The fish used is a species of Echeneis or Remora, and the following is the method used by the natives of those parts. Their little boat is provided with tubs, in which are a number of these fishes, the top of whose head is covered with an oval plate, soft and fleshy at the circumference, but furnished in the middle with an apparatus of bony pieces, very complicated in its 
structure, arranged in two regular rows, somewhat resembling the laths of venetian blinds. In different species the number of these plates is varied, some not containing above fifteen, others as many as thirty-six. By muscular action, they are turned on their axis at the pleasure of the fish, and their free edges are provided with small hooks, which are raised all together like the points of a wool card. The tail of each of the trained fishes in the tubs is furnished with a ring, and to this is fastened a cord of fine texture but strong, and of considerable length. When the fishermen discover the Turtles basking on the surface of the water, not daring to disturb their intended prey, by making the least noise, they slip overboard one of their Remoras, secured by the long cord, and pay out the line according to their distance. The fish soon perceives the Turtle, and hastening to it, fixes itself so firmly on the floating reptile, that the fishermen can draw both together into their boat, where there is no difficulty in detaching the fish by pushing forwards its head from behind.

The deposition of eggs by the female of this species has been carefully watched and minutely recorded by an accurate observer of nature, who thus describes the process. "On nearing the shore," says Mr. Audubon, "and mostly on fine calm moonlight nights, the Turtle raises her head above the water, being still distant thirty or forty yards from the beach, looks around her, and attentively examines the objects on shore. Should she observe nothing likely to disturb her intended operations, she emits a loud hissing sound, by which such of her many enemies as are unaccus- 
tomed to it are startled, and so are apt to remove to another place, although unseen by her. Should she hear any more noise, or perceive any indications of danger, she instantly sinks and goes off to a considerable distance; but should everything be quiet, she advances slowly towards the beach, crawls over it, her head raised to the full stretch of her neck, and when she has reached a place fitted for her purpose, she gazes all round in silence. Finding all well, she proceeds to form a hole in the sand, which she effects by removing it from under her body with her hind flappers, scooping it out with so much dexterity that the sides seldom if ever fall in. The sand is raised alternately with each flapper, as with a large ladle, until it has accumulated behind her, when supporting herself with her head and forepart on the ground, she, with a spring from each flapper, sends the sand around her, scattering it to the distance of several feet. In this manner the hole is dug to the depth of eighteen inches, or sometimes more than two feet. This labour I have seen performed in the short period of nine minutes. The eggs are then dropped one by one, and disposed in regular layers, to the number of one hundred and fifty, or sometimes nearly two hundred. The whole time spent in this operation may be about twenty minutes. She now scrapes the loose sand back over the eggs, and so levels and smooths the surface, that few persons seeing the spot would imagine that anything had been done to it. This accomplished to her mind, she retreats to the water with all possible dispatch, leaving the hatching of the eggs to the heat of the sand. When a Turtle, a 
Loggerhead for example, is in the act of dropping her eggs, she will not move, although one should go up to her, or even seat himself on her back; but the moment it is finished, off she starts, nor would it then be possible for one, unless he were as strong as Hercules, to turn her over and secure her." **

The group to which the Hawksbill (Chelone

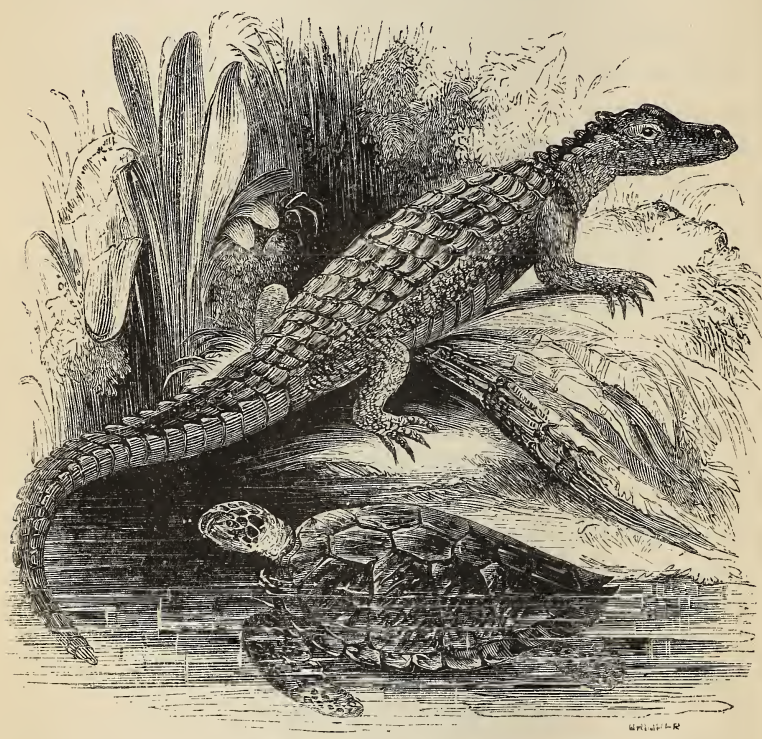

HAWKSBILL TURTLE.

imbricata, LINN.) belongs, with its ally C. virgata, Cuv., whether we regard it as of generic or sub-generic rank, may be thus characterised.

* Ornith. Biog. ii. 
The carapace is large, flat, and heart-shaped, composed of thirteen discal plates, and twentyfive marginal ones; the hinder margins of these are free, and overlap the succeeding plates, for nearly a third of their length; the muzzle is long and somewhat compressed; the jaws have straight edges, neither notched nor toothed, but curving towards each other at the extremities, where the lower shuts within the upper; each fin is furnished with two nails.

The fore-feet or paddles are larger in these species than in the rest of the Family, and it is said that the Hawksbill, unlike the Green Turtle, which is helpless when turned over on its back, can, by means of its long feet, recover its proper position.

The Hawksbill commonly grows to the length of three feet, and the width of two, but specimens are reported to have been seen of much greater size. Its flesh is of no estimation as food, being both ill-flavoured and unwholesome; its eggs, however, are highly valued. The species is not unimportant notwithstanding, for it produces almost exclusively that well known and beautiful material, so much used in the arts, called Tortoise-shell. In the luxurious ages of ancient Grecian and Roman art, this elegant substance was employed in embellishing articles of use and ornament, perhaps more copiously than with us; for they decorated their doors, the pillars of their houses, their beds, and the statues of their gods with it. Velleius Paterculus relates that when the city of Alexandria in Egypt was taken by Julius Cæesar, the warehouses were found to contain so large a quantity of this material, 
that he proposed to make it the principal ornament of his triumph, as he did subsequently with ivory, in his triumph at the close of the African war. In the present day the demand for it in the more costly sorts of cabinet work, in inlaying, in articles of virtù, and especially in the manufacture of combs, renders this substance an important article of commerce.

The plates of the carapace in this species are stronger, thicker, and clearer than in any other; they are nearly transparent, and most beautifully variegated with yellow, red, and dark brown clouds, often proceeding in radiations; and, being susceptible of a high polish, are well adapted for ornamental purposes. The comparative value of tortoise-shell is said to depend mainly on the thickness and size of the scales, and, but in a subordinate degree, on the clearness and brilliancy of the varying hues. The Indian Archipelago, and particularly the coasts of New Guinea, and the Spice Islands, are reputed to afford the best and finest specimens. A shell is considered of little value, if the animal from which it is taken, does not weigh at least a hundred and fifty pounds.

The ancients were not aware of any mode by which the layers of which the plates are composed could be separated from each other; they therefore had recourse to the tedious and wasteful plan of sawing them into thin leaves or veneers. A better method is now pursued; the whole carapace being taken from the animal, is filled with live coals, or placed with the inner part downwards, over a fire; when thoroughly heated, the plates start from the bony shield, and the constituent layers also gape apart at the edges, so as 
to be easily detached from each other. A plate varies in thickness from an eighth to a quarter of an inch, according to the size and age of the animal.

For the following account of the manner in which this beautiful material is rendered available to the many purposes of use and ornament which it subserves, we are indebted to the history of British Reptiles by Professor Bell.

"The scales, or plates, are in the first place separated by the application of heat. They are sold to the manufacturers in the rough state, in which they are uneven, fragile, opaque, and dirty; and it is the first object of the artificer to obviate these defects. The uneven surface, the irregular curvature, the unequal thickness of different parts, have all to be corrected: and not only can these objects be readily effected, but the substance can be rendered ductile, compressible, capable of receiving any impression, of being carved, moulded, and polished, and even extended by soldering pieces together by means of their own substance reduced to powder. The whole of these processes are performed by means of heat.

"The uneven curvature is first of all to be removed, and the plate rendered perfectly flat. This is effected by immersing it in hot water, and then allowing it to cool under heavy pressure, between smooth blocks of wood, or metallic plates. The surface is then rendered smooth, and the thickness equal, by scraping and filing away the rough and prominent parts. In this way each plate receives an equal and smooth surface. But it is in many cases desirable to employ larger pieces than can be obtained from single 
plates, and two pieces are then united together in the following manner :-The edges are bevelled off to the space of two or three lines, and the margins, when placed together, overlap each other to that extent. They are then pressed together by a metallic press, and the whole is submitted to the action of boiling water; and by this means the two pieces are so perfectly soldered together, as to leave no indication of the line of union. By the application of heat, also, the tortoise-shell may be made to receive any impression, by being pressed between metallic moulds.

"No portion of this precious substance is lost or useless. The filings and powder, which remain after these and the other processes to which the shell is submitted, are placed with any small fragments in metallic moulds, and by means of pressure, exercised whilst they are exposed to the heat of boiling water, they are formed into plates of any thickness which may be required."

The shell of the Turtle being so valuable, some ingenuity is well bestowed in the endeavour to avoid any waste of it. Accordingly, in manufacturing combs, a curious invention has been resorted to for this end. To make a comb six inches long, and one inch wide, one would naturally

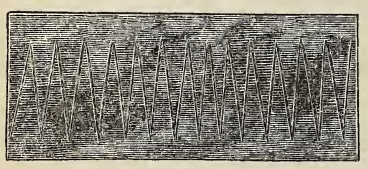

COMB-CUTTING. suppose that it would be needful to have a piece of shell of that size; and such is indeed the case. But two combs may be formed out of a piece of shell very little larger, by merely resorting to a very simple plan, which the accompany- 
ing diagram will clearly illustrate. The shell is cut by a circular saw, in the manner represented in the zigzag lines; thus, when the sawing is completed, the shell can be pulled in two, and the teeth of the combs will be cut out of one another, while the solid margins are left to form the backs.

Besides the localities already named as the resorts of the Hawksbill Turtle, we may mention the West Indian Isles, those of Bourbon and Mauritius, the Seychelles, and most of the situations enumerated in the notice of the Green Turtle. On three occasions it has occurred on the shores of our own country. Sibbald received the shell of one which came into Orkney. Fleming records its having been taken at Papa Stour, one of the West Zetland Isles; and Dr. Turton mentions one which was taken in the Severn in the year 1774, and placed in his father's fishponds, where it lived till the following winter.

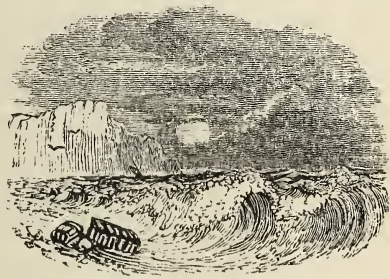




\section{ORDER II. LORICATA.}

(Crocodiles.)

The appellation by which this Order is distinguished, derived from the word lorica, signifying a coat of mail, expresses the most obvious peculiarity by which its members may be known, the ridged and bony armour in which they are invested. "The Crocodiles and Alligators of both worlds, and the Gavials of India, which constitute this order, are distinguished," observes Mr. Bell, "from the true Saurians or Lizard tribe, by several important characters. Of these the most tangible and obvious is that upon which the name of the Order is founded; the covering of the whole of the back part of the neck, body, and tail, with distinct series of bones, of modederate size, imbedded, as it were, in the substance of the skin, and covered externally with a thick cuticle. These dermal bones are usually furnished with a crest, which renders them exceedingly strong, and they altogether form a panoply of defence which can resist the attacks of the most powerful enemies of whatever kind."**

The general form of the Loricata agrees with that of the Lizards; but besides the important difference already mentioned, the bony plates run down the body in longitudinal lines, the structure of the skull is much more solid, and the posterior orifice of the body is longitudinal. The tail is

* British Reptiles, xix. 
flattened at the sides; there are five toes before and four behind, of which the innermost three on each foot are armed with claws; the toes are connected by intervening membranes, varying in extent. There is a single row of pointed teeth in each jaw; the tongue is fleshy, flat, and free only at the extreme edge; whence the Crocodile was vulgarly reputed to be without a tongue. The back and tail, as already intimated, are covered by large and strong scales of square form, elevated into a ridge in the middle; the tail is surmounted by a deeply notched or saw-like crest, which is double at the base; the scales of the belly are delicate and smooth. The nostrils are situated at the end of the muzzle, and open by small crescent-form slits, closed by valves; they lead through a long and straight canal pierced in the bones of the palate, to the back of the mouth. The lower jaw is prolonged behind the skull, and this structure causes the upper jaw to seem moveable; but this is simply an illusion. The external ear is closed at pleasure by means of two fleshy lips ; the eye is furnished with three lids: two small glandular orifices are placed beneath the throat, whence exudes a musky secretion, the odour of which strongly marks these animals even for years after their dried skins have been preserved in a museum.

The Reptiles of this Order are of large size and great strength; and as they are exclusively carnivorous and predaceous, and very ferocious, they are dreaded, not without reason, in the tropical countries which they chiefly inhabit. Yet these creatures, feared and hated as they are, were not created in vain. "In the grand policy 
of Nature," observes Prof. Jones, "the scavengers are by no means the least important agents. In hot climates, especially, where putrefaction advances with so much rapidity, were there not efficient and active officers continually employed in speedily removing all dead carcases and carrion, the air would be perpetually contaminated with pestilential effluvia, and entire regions rendered uninhabitable by the accumulation of putrefying flesh. Perhaps, however, no localities could be pointed out more obnoxious to such a frightful cause of pestilence, than the banks of tropical rivers-those gigantic streams, which, pouring their waters from realm to realm, daily roll down towards the sea the bloated remains of thousands of creatures which taint the atmosphere by their decomposition."*

Here, then, is the appointed dwelling-place of the Loricata. Lurking in the dense reeds, or tangled herbage that grows rank and teeming at the edges of rivers in hot climates, or under the mangroves that interweave their myriad roots in arches above the water, or concealed among the bleaching trunks and branches of trees that have fallen into the stream, these huge reptiles watch for the approach of a living prey, or feed at leisure on the putrid carcases with which the waters daily supply them. It is even affirmed that they prefer a condition of putrescence in their prey, and that their practice, when not pressed by immediate hunger, is, on seizing a living prey, to plunge into the stream in order to drown it, after which, it is dragged away to some hole, and stored until decomposition has commenced.

* General Outline, 559 . 
The subjects which compose this Order are few in number, and are all comprised in a single Family, which we shall presently describe more in detail. They are natives of both hemispheres, but are confined to the warmer regions of both, neither Europe nor Australia possessing any known species : they all inhabit fresh waters.

\section{Family I. Crocodilide。}

\section{(Crocodiles.)}

Messrs. Duméril and Bibron enumerate the following characters as proper to this family. The body is depressed, lengthened, protected on the back with solid and keeled scutcheons, or shields; the tail is longer than the trunk, compressed, the plates here set in rings, and rising into a ridge of pointed crests; the limbs are four in number, short; the toes of the hind feet united by a swimming membrane; three claws only on each foot; the head is flattened, lengthened into a muzzle, in the front of which are the nostrils, not far apart, upon a fleshy tubercle, furnished with moveable suckers; the gape opens beyond the base of the skull; the tongue is fleshy, entire, adherent, not protractile; the teeth are conical, simple, hollowed towards the root, unequal in length, but placed in a single row. The cavity at the root of each tooth serves as a case or sheath for the germ of the tooth des-

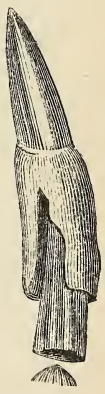

TOOTH OF CROCODILE. tined to replace it, which is to be of greater bulk; 
and each being thus gradually pushed out from below by a successor ready to supply its place, the jaws of the Crocodiles present, at all ages, their formidable array of pointed teeth in undiminished number.

The Crocodiles, as we have said, are fierce and voracious, and prove destructive, not only to quadrupeds, (and those of large size), but also to man himself. Cuvier states that they are unable to swallow in the water, but this seems to be unconfirmed. They do, however, commonly resort to the shore for the purpose of devouring those animals which they have seized and drowned, dragging them out again after they have begun to decay. On land their motions are stiff, ungainly, and embarrassed, and a peculiar structure of the vertebra precludes them from being able to turn themselves with facility. Yet they are able to bound forward with considerable agility, springing to a distance which would scarcely be expected from creatures so unwieldy.

In the water they swim with swiftness both upon and beneath the surface; here they know themselves to be at home, and usually leap into the water with precipitation if surprised on land by even the distant appearance of a man.

These are not only the largest of all reptiles, but are among the most gigantic of animals. Some are reported to have attained a length of twentyfive feet, and it seems probable that they are longlived, and that their bulk continues to increase with years. The mouth is enormous; and the numerous pointed teeth, thirty or more on each side of each jaw, are so disposed as to fit into the interstices of each other. As the lips are alto- 
gether wanting, the teeth are visible when the mouth is closed; hence the animal, even when tranquil, seems grinning with rage. A similar expression is communicated to the visage from the eyes, which are placed obliquely near each other, and have a peculiarly fiery glare.

The compressed and dentelated tail, though from its length and weight it impedes the motions of these animals on the land, is yet an organ of the utmost importance to them in the water, where it is a most powerful instrument of progression, and influences their aquatic habits much more than their webbed hind feet. The latter are indeed used, when the animal is paddling with a slow and gentle action; but in sudden and swift motion, as in escaping from an object of alarm, or in energetic pursuit of prey, alternate strokes with the tail upon the element give the powerful impulse. On land, also, the Crocodile is said to use this organ as an efficient weapon of offence, dashing it from side to side with swift contortions, when its weight, its hard rough surface, and especially its saw-like crests, render its strokes eminently formidable.

Like the Turtles, the Crocodiles lay their eggs in the sand, and leave them to be hatched by the heat of the sun. The general number is from eighty to a hundred: their size is about that of a goose's egg, but their form is more oblong. When we consider the vast bulk of the adult animal, we may affirm that no creature exhibits so great a disproportion between its youth and age. The eggs are covered with a hard calcareous shell, like that of birds' eggs, but more shining, harder, and more brittle. 


\section{Genus Alligator. (Cuv.)}

A broad obtuse muzzle, with uneven teeth, marks the genus before us; the fourth tooth on each side of the lower jaw enters into a cavity of the upper jaw, and not into an interspace of the opposite teeth; the webs of the hind feet are small, and extended only between the bases of the toes; the feet are not fringed or pectinated at the sides; and finally there are no holes, or very minute ones, in the skull, behind the orbits.

The five species which constitute this genus are peculiar to America, one being an inhabitant of the southern United States, and the four others of the tropical part of South America. It is worthy of remark, that while the islands of the West Indies possess species of the genus Crocodilus, which is common to both hemispheres, the Alligators are exclusively continental. The former are frequently seen in the brackish waters at the mouths of rivers, the latter never.

The term Alligator is commonly considered as a corruption of the Portuguese word lagarto, signifying a lizard; and it has been applied by the British colonists, not only to the species which inhabits the United States, but also to those inhabiting the West Indian Isles, though, as we have already intimated, the latter are genuine species of the restricted genus Crocodilus. Those of the South American continent bear the appellation of Caiman, which is probably a word of Indian origin.

In temperate climates, at least, the Alligators appear to hybernate; as winter draws near, they bury 
themselves in the mud, at the bottom of some stagnant pond, and there they remain hidden in a state of inactivity, till the return of milder weather. It is asserted by travellers, that they always avoid swiftly running streams and resort in preference to the creeks of large rivers or to stagnant ponds. In such localities they may be seen in immense numbers, and in the remote parts of South America which are unfrequented, they abound in incredible multitudes, protruding their great flat heads through the leaves of the aquatic plants, such as the nymphea and pontederia, which cover the surface of the water, and there watch for their prey : at other times they may be seen sleeping or basking on the sunny banks. It is only during the hottest part of the day that they ever venture on shore: before evening they return to the water, as night is their time for seeking their prey, in which they manifest much activity. Fishes constitute their chief food, and some physiologists have supposed that the musky fluid secreted by the glands under the throat, as noticed above, forms a sort of bait by which their prey is attracted towards them. It is very rare that the Alligators attack man, unless their eggs or their young are in danger; but it is said that the female of these reptiles manifests a much more tender care for her offspring than is exhibited by this class in general. She generally lays from fifty to sixty eggs in one place, which are about as large as those of the goose ; these she covers over with sand, leaving them to be hatched by the heat of the sun; but she never removes to any great distance from them. The young ones when they come forth from the shell are about 
five or six inches in length, and the female Alligator at once leads them to the water. In general at least half the brood perish before they reach the water; many while yet in the egg; some through the depredations of vultures, who watch the female Alligator when she repairs to the shore to lay; others are devoured by the adult males of their own species, and yet more by the

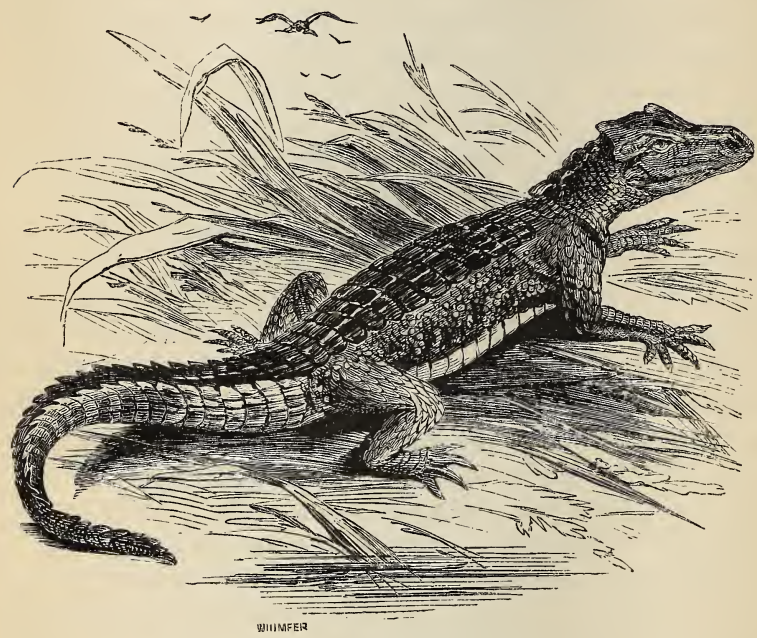

ALLIGATOR.

ravenous fishes and turtles that inhabit the same waters. Both the eggs and the flesh of these reptiles are eaten, though they diffuse a strong musky odour; some Europeans, however, have so far overcome their prejudices as to pronounce them savoury and agreeable. 
The Alligator is believed to be very long-lived, as its growth is very slow, and its ultimate bulk gigantic.

The species with whose economy we are best acquainted is that of which we have already spoken as inhabiting the rivers that flow through the Southern United States, and the dismal swamps that border them. In Louisiana and Florida, this Alligator (Alligator lucius, Cuv.) is particularly abundant, from the low and swampy character of those regions conjoined with their hot climate. The snout of this species is flattened above, and slightly turned upwards; the sides of the head are nearly parallel, and the nose forms a regular curve. The rim of the eye-orbits is large and protuberant, but not united by a transverse crest. The colour is a deep greenish-brown above, and pale yellow beneath; the sides are marked with these colours in alternate bands.

Some interesting details of the history of the Alligator are given with much graphic power by the eminent American ornithologist, $\mathrm{Mr}$. Audubon.

"In Louisiana," says this accurate observer, "all our lagoons, bayous, creeks, ponds, lakes, and rivers, are well stocked with them; they are found wherever there is a sufficient quantity of water to hide them, or to furnish them with food; and they continue thus, in great numbers, as high as the mouth of the Arkansas river, extending east to North Carolina, and as far west as I have penetrated. On the Red river, before it was navigated by steam-vessels, they were so extremely abundant, that to see hundreds at a time along the shores, or on the immense rafts of 
floating or stranded timber, was quite a common occurrence, the smaller on the backs of the larger, groaning and uttering their bellowing noise, like thousands of irritated bulls about to meet in fight; but all so careless of man, that, unless shot at, or positively disturbed, they remained motionless, suffering boats and canoes to pass within a few yards of them, without noticing them in the least. The shores are yet trampled by them in such a manner, that their large tracks are seen as plentiful as those of sheep in a fold. It was on that river particularly, that thousands of large ones were killed, while the mania of having shoes, boots, or saddle-seats, made of their hides lasted. It had become an article of trade, and many of the squatters and strolling Indians followed for a time no other business. The discovery that their skins are not sufficiently firm and close-grained to resist water and dampness long, put a stop to their general destruction, which had already become very apparent. The leather prepared from these skins was handsome and very pliant, exhibiting all the regular lozenges of the scales, and susceptible of the highest degree of polish and finishing. When Alligators are fishing, the flapping of their tails about the water may be heard at the distance of half a mile; but to describe this in a more graphic way, suffer me to take you along with me, in one of my hunting excursions, accompanied by friends and negroes.

"In the immediate neighbourhood of BayouSarah, on the Mississippi, are extensive shallow lakes and morasses; they are yearly overflowed by the dreadful floods of that river, and supplied with myriads of fishes of many kinds, amongst 
which trout are most abundant, white-perch, catfish, and alligator-gars, or devil-fish. Thither in the early part of autumn, when the heat of a southern sun has evaporated much of the water, the squatter, the planter, the hunter, all go in search of sport. The lakes then are about two feet deep, having a fine sandy bottom. Frequently much grass grows in them, bearing crops of seed, for which multitudes of water-fowl resort to those places. The edges of these lakes are deep swamps, muddy for some distance, overgrown with heavy large timber, principally cypress, hung with Spanish-beard, and tangled with different vines, creeping plants, and cane, so as to render them almost dark during the day. Here and there in the lakes are small islands, with clusters of the same trees, on which flocks of snake-birds, wood-ducks, and different species of herons, build their nests. Fishing-lines, guns, and rifles, some salt and some water, are all the hunters take. Two negroes precede them, the woods are crossed-the scampering deer is seen-the racoon and the opossum cross before you-the black, the grey, and the fox-squirrel are heard barking. As you proceed further on, the hunk, hunk, of the lesser ibis is heard from different parts, as they rise from the puddles that supply them with cray-fishes. At last the opening of the lake is seen. It has now become necessary to draw oneself along the deep mud, making the best of the way, with the head bent, through the small bushy growth, caring about nought but the lock of your gun. The long, narrow, Indian canoe, kept to hunt these lakes, and taken into them during the fresh, is soon launched, and the 
party, seated in the bottom, is paddled, or poled, in search of water-game. There, on a sudden, hundreds of Alligators are seen dispersed all over the lake, their head and all the upper part of their body floating like a log, and in many instances so resembling one, that it requires to be accustomed to see them, to know the distinction. Millions of the large wood-ibis are seen wading through the water, muddling it up, and striking deadly blows with their bills on the fish within. Here are a horde of blue herons ; the sand-hill crane rises with hoarse note; the snake-birds are perched here and there on the dead timber of the trees; the cormorants are fishing ; buzzards and carrion-crows exhibit a mourning train, patiently waiting for the water to dry, and leave food for them; and far in the horizon the eagle overtakes a devoted wood-duck, singled from the clouded flocks that have been bred there. It is then that you see and hear the Alligator, at his work; each lake has a spot deeper than the rest, rendered so by those animals, who work at it; and always situated at the lower end of the lake, near the connecting bayous, which, as drainers, pass through all these lakes, and discharge sometimes many miles below where the water had made its entrance above; thereby ensuring themselves water, as long as any will remain. This is called by the hunters the Alligator's hole. You see them there lying close together. The fish, that are already dying by thousands, through the insufferable heat and stench of the water, and the wounds of the different winged enemies constantly in pursuit of them, resort to the Alligator's hole to receive 
refreshment, with a hope of finding security also, and follow down the little current, flowing through the connecting sluices: but no! for, as the water recedes in the lake, they are here confined. The Alligators thrash them, and devour them whenever they feel hungry, while the ibis destroys all that make towards the shore.

"By looking attentively on this spot, you plainly see the tails of the Alligators moving to and fro, splashing, and now and then, when missing a fish, throwing it up in the air. The hunter anxious to prove the value of his rifle, marks one of the eyes of the largest Alligators, and as the hair-trigger is touched, the Alligator dies. Should the ball strike one inch astray from the eye, the animal flounces, rolls over and over, beating furiously about him with his tail, frightening all his companions, who sink immediately, whilst the fishes, like blades of burnished metal, leap in all directions out of the water, so terrified are they at this uproar. Another and another receives the shot in the eye and expires; yet those that do not feel the fatal bullet, pay no attention to the death of their companions, till the hunter approaches very close, when they hide themselves for a few moments, by sinking backwards."

The Alligator, like most other reptiles, is endowed with great powers of abstinence; and as stones and pieces of wood are frequently found in its stomach, it is supposed that these are swallowed to relieve the pangs of hunger, by the mechanical distension of that organ. Catesby, Dr. Brickell, and many other persons of veracity, have testified to the fact from personal observation. In some of these cases the lumps, from the 
wearing down of their angles, seemed to have lain in the stomach for several months.

The female Alligator lays her eggs in hollows in the sand near the margin of the water, amassing for their reception a quantity of decaying leaves and other vegetable matters, and separating the different layers of eggs by layers of the same materials. The fermentation of the heap, when the whole is covered again with sand, is supposed to aid the heat of the sun, in the production of the young. Fifty or sixty eggs are laid in a season, in two or three batches. The mother keeps watch over the place, and after the young are excluded, tends them for months afterwards with much affection and care.

Though most abundant in the southern rivers, the Alligator extends far enough north to be within the influence of severe winters. Buried beneath the mud, however, at the bottom of his river or pool, he sleeps unconscious of the frost. If exposed at such times, sensation is found to be completely suspended, so that the body of the animal may be cut up without arousing him from his torpidity. It is not, however, frozen, and a few hours' warm weather, or the beams of the sun, are sufficient to restore his suspended animation.

Mr. Swainson's opinion of the comparative inoffensiveness of these huge reptiles seems to be contradicted by well-authenticated instances, in which their ferocity has been fatal to man.

Mr. Waterton thus records the fatal ferocity of an allied species, the Cayman of Surinam (Alligator palpebrosus, Cuv.), which is commonly reputed to be less bold than the former. "One Sunday 
evening, some years ago, as I was walking with Don Felipe de Ynciarte, governor of Angustura, on the bank of the Oroonoque, "Stop here a minute or two, Don Carlos,' said he to me, 'while I recount a sad accident. One fine evening last year, as the people of Angustura were sauntering up and down here, in the Alameda, I was within twenty yards of this place, when I saw a large Cayman rush out of the river, seize a man, and carry him down, before any one had power to assist him. The screams of the poor fellow were terrible as the Cayman was running off with him. He plunged into the river with his prey; we instantly lost sight of him, and never saw or heard him more." "*

* Wanderings in South America.

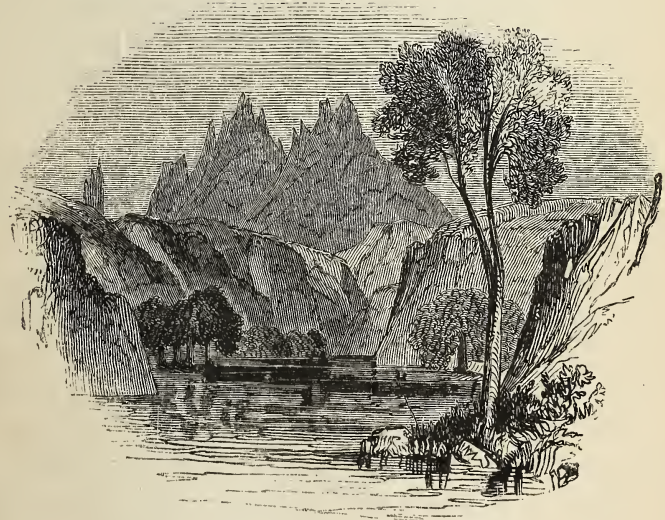




\section{ORDER III. SAURIA.}

\section{(Lizards.)}

The Sauria or true Lizards, resemble the Crocodiles in their external form, the body being: lengthened and tapering to the tail, which is likewise long, in the possession of four limbs (at least in most cases), and in the presence of numerous teeth. They have a moderate number of perfect and moveable ribs, capable of being raised for the purpose of respiration. The lung extends more or less towards the hind part of the body, often penetrating into the abdomen. Their skin is covered with scales, which in many overlap at the hinder edges; in others are flat, with the edges in common contact, and in some are so minute as to impart a kind of granulated or shagreened surface. "The eyes are furnished with eyelids; the ear in some protected by a simple valve, in others by scales rather larger than the surrounding ones, and in others the tympanum is on a level with the surface of the skin."

The ordinary mode of reproduction is by eggs, which are coated with a calcareous, brittle shell: those of the Chameleon, however, have the covering tough, resembling parchment. In the extensive Family of the Skinks, all the species, as we believe, are ovoviviparous, as are also some of the Lizards proper, for example, our own little Zootoca. The young come into existence in the same form which they retain through life. 
"The passage from the Lizard tribe to the Serpents," observes Mr. Bell, "is by a succession of very gradual modifications of development. In the lower forms of the Saurian group, the body becomes gradually elongated and serpentiform: its ribs increase in number, the anterior and posm terior limbs are removed farther and farther from each other, and diminish in size and power, exhibiting in some forms the anterior, and in others the posterior only, external to the integument, until at length they cease to appear, being merely rudimentary, and wholly covered by the skin. Of this transition state we have an example in the common Slow-worm (Anguis fragilis), which, though completely serpentiform in its external appearance, yet possesses the minute rudiments of limbs entirely concealed under the integuments. Notwithstanding this general form of the Serpent, they have not the expansible jaws of the true Serpents: nor is the character of the ears the same, the tympanic membrane not being superficial, nor the auditory passage covered by integument; the eyes, also, like those of the Lizards, are furnished with moveable eyelids, which are wholly wanting in the true Serpents." . . .

"The movements of the Saurian reptiles are effected principally by means of their feet, and in some of the higher forms exclusively so; but as they descend towards the more elongated form of the Skinks and other genera, in which these organs become more and more subordinate, they are greatly assisted by the lateral motion of their bodies, different parts of which are brought into alternate contact with, and pressure upon either the roughness of the ground or the shrubs and herbage 
through which they pass. A comparison of the progression of these, however, and even of the Slow-worm, with that of the true Snakes, will show that the latter only employ the free termination of their ribs as organs of locomotion. In these the ribs serve absolutely and perfectly the function of feet, and with the exception of their being covered with integument, their action is exactly that of the multitudinous feet in the Scolopendra or Julus, the whole series of ribs coming into contact in succession. At the same time, it is upon the lateral pressure of successive portions of it, that the Serpents mainly depend for the rapidity of their progression." *

The Sauria are, we believe, exclusively landanimals, none of them being fitted for inhabiting the water, though some are able to swim, in emergency. Most of them are terrestrial, but not a few are arboreal, more or less entirely, from the Chameleon, which, with his opposible toes, climbs about the branches of trees, to the little Anoles, which run about the trunks and leap from leaf to leaf; and some, as the Geckos, inhabit the crevices of old buildings, among the rafters of which they crawl in all positions, frequently with the back downward. These last are rather slow in their motions, and the Chameleons are still more deliberate ; but the characteristic of the Order is extreme agility, and some of the ground Lizards dart to and fro, and skim the surface of the earth with the rapidity of a bird. In one genus, Draco, the skin of the sides is stretched upon a prolongation of the ribs, and acts as a parachute, or as the

* British Reptiles, Introd. xx. 
membrane of the Flying Squirrels, enabling them to take long leaps from tree to tree.

The food of this Order consists principally of insects, but the Monitors of tropical America, which approach the Crocodiles in size, and in some other peculiarities, are said to prey upon other reptiles, the eggs of birds, \&c.; and the Iguanas feed on fruit, as does also the Gallywasp of the West Indies, one of the Scincida, as we know from personal observation. Mr. Darwin mentions a species of Amblyrhynchus, a native of the Galapagos Islands, which swims out to sea, in order to feed on the sea-weeds that grow at the bottom.

Several of the foreign species are used as human food; Humboldt asserts that all the South American kinds within the tropics, that inhabit dry regions, are esteemed delicacies for the table. The flesh is white, and is said to resemble that of chicken. The Iguanas of the West Indies have always been prized by the Spanish settlers, though the English have commonly rejected them from prejudice.

The tropical regions of the globe swarm with Lizards, the species of which are very numerous; the grassy turf, the sandy plain, the sunny bank, the trees and bushes, the dilapidated wall, every heap of stones, and even the houses of the inhabitants, have their Lizards; some of which are of pleasing forms, most are distinguished for agile and graceful motions, and many are arrayed either in burnished mail, or in various brilliant hues. The colours of some, as the Chameleons, and the Anoles, are subject to changes, not produced by the play of light, as from the iridescent scales of 
some Serpents, but by actual alteration of tint, at the will of the animal. Most of them throw off the cuticle, at periodical intervals, which retains the form of every scale and plate, impressed convexly on the outer surface, and concavely on the inner. After the sloughing, the new surface is more brilliant than the old. The swift and brighteyed little Lizards darting and leaping everywhere, in tropical countries, form an attractive feature of the scene, and are not regarded with the fear and disgust with which reptiles are foolishly regarded too often with us. Moore alludes to the beauty of these little creatures,-

"Gay Lizards glittering on the walls Of ruin'd shrines, busy and bright, As they were all alive with light."

The Families of the Sauria have been greatly multiplied by some zoologists : we shall prefer to consider them as seven in number; Chamaleonide, Geckotida, Iguanade, Agamade, Varanida, Lacertada, and Scincida.

\section{Family I. Chamæleonide.}

\section{(Chameleons.)}

This small but compact and well-defined Family is not only the most anomalous among Reptiles, but perhaps even amongst the whole range of Vertebrate animals. They are distinguished at once by the character of their feet, which is strictly Scansorial, and recalls the form which those organs assume in the Monkeys among Mammalia, and in the Parrots and Woodpeckers among Birds. The 
toes are five, as in the majority of Saurians, but these are arranged in two sets, three in one set, and two in the other, each set being enveloped in the common skin as far as the claws. These two parcels of toes are opposible to each other, and thus each foot forms a true grasping hand, and is used in the manner which this structure indicates; the Chameleon moving with slow and deliberate steps, always grasping with a firm hold the branch on which it is creeping, before the other feet are relaxed for a fresh step. The tail is round and prehensile at the tip, like that of the American Monkeys ; its under surface is roughened, with small granulated papille, as is that of

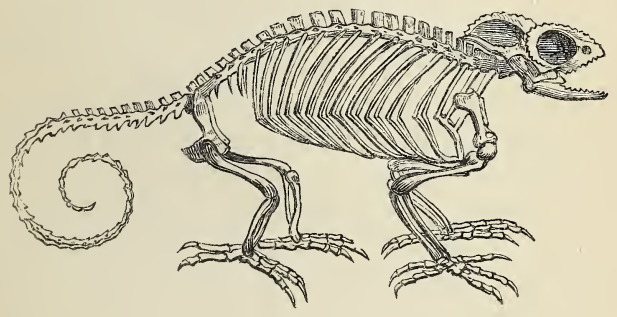

SKELETON OF CHAMELEON.

the toes also, probably for the more delicate perception of the surface grasped. The tongue affords an analogy to the same organ in the Woodpeckers, no less singular than that of the feet; for though ordinarily concealed within the mouth, it is capam ble of being darted forward at its insect prey, and being furnished with a glutinous secretion, secures it by its adhesiveness. 
One of the most remarkable features in the physiognomy of the Chameleons is the peculiarity of their eyes ; these are large, full, and prominent, entirely covered with the common shagreened integument, except a small round aperture opposite to the pupil. Unlike all other vertebrate animals, their eyes act independently of each other, so that one may be directed to an object before, while the other remains still, or is looking behind.*

The head in the Chameleons is large, somewhat triangular in outline, and appears set upon the shoulders without the intervention of a neck; it is very broad across the occiput, where it is surmounted by an elevated process, greatly developed in some of the species; ridges also proceed over the eyes, which meet at the muzzle, and are sometimes much prolonged.

The Chameleons, though constituting but a single genus, comprise numerous species, which are scattered over the warmer regions of the eastern hemisphere, from the south of Spain, and the countries bordering the Mediterranean, to Australia. No species is known to exist in America, where the genus seems to be replaced by Anolis and its allies.

* " These most singular creatures are particularly remarkable for the diminished sympathy of the two sides of their whole frame, one of which may be asleep and the other awake, one of one colour and the other of another, \&c. : the separate movement of their eyes being merely another phase of the same phenomenon. Hence it is remarkable, that unlike most other animals, the Chameleon is totally unable to swim, from the incapability of its limbs of acting in due concert."-BLY'rH's Cuvier, 278. 


\section{Genus Chameleon. (Cuv.)}

As the peculiarities of this genus have already been traced at some length in our account of the Family which it alone constitutes, we need not recapitulate them, but shall confine ourselves to some particulars of the history of the best known species, and an examination of some interesting phenomena, which are displayed by the whole tribe.

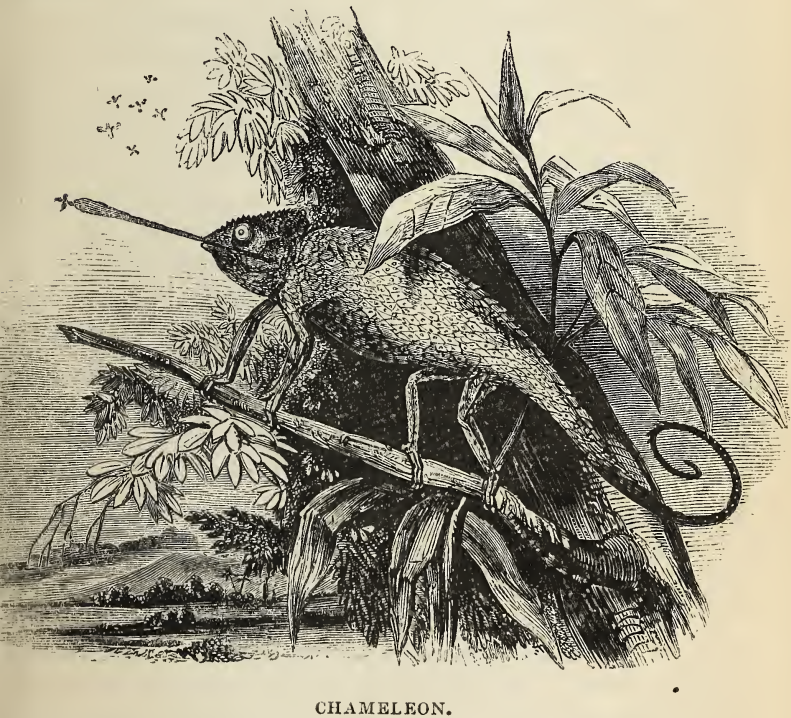

The Common Chameleon (Chamaleon vulgaris, Cuv.) is about ten inches in length ; the occiput is arched and compressed. It is distinguished 
from a species found in Central Africa by the occipital keel reaching forward to the centre of the eye, by the back of the head being only slightly lobed, and by the frontal scales being tubercular. It is spread over the whole north of Africa, and the south of Asia, and is said to extend even into Spain.

The changes of colour to which this reptile is subject are so curious as to have attracted popular observation from early times; and though much of fable has been mingled with the descriptions of the phenomenon, it is still exceedingly interesting; and not the less so because of the obscurity which has huug over the causes of the changes, baffling the researches of acute physiologists, and giving rise to many diverse theories. The popular notion is that the Chameleon assumes the tint of the surface on which it rests, becoming green on a leaf, brown on the branch of a tree, white on a stone, \&c., but this opinion is at variance with fact, and is now universally exploded by naturalists. Hasselquist, who considers the changes to be the result of a kind of disease, remarks, that he never observed the Chameleon assume the colour of an external object presented to its view, although he made several experiments for the purpose. He says that its natural colour is an iron grey, or black mixed with a little grey. This it sometimes changes, and it becomes entirely of a brimstone yellow, which, except the former, is the colour it most frequently assumes. It sometimes takes a darker or greenish yellow, and sometimes a lighter. $\mathrm{He}$ did not observe it assume any other colours, such as blue, red, purple, \&c. When changing 
from black to yellow, the soles of its feet, its head, and the bag under its throat, were the first tinged; and then by degrees that colour spread over the rest of the body. He several times saw it marked with large spots of both colours all over its body, which gave it an elegant appearance. When it became of an irongrey it dilated its skin, and became plump and handsome; but as soon as it turned yellow, it contracted itself, and appeared empty, lean, and ugly; and the nearer it approached in colour to white, the more empty and ugly it appeared; but its shape was always the most unpleasant when it was speckled. Mr. Hasselquist kept a Chameleon for nearly a month. During the whole time it was very lively, climbing up and down its cage, fond of being near the light; and constantly rolling about its large eyes. It took no food during the whole of this time, so that it became lean, and evidently suffered from hunger. At length, through weakness, it fell from its cage upon the floor, when a turtle that was in the same room, bit it, and hastened its death.

M. d'Obsonville's account differs somewhat from the above, and he considers that he has discovered the secret cause of the changes in the blood. "The colour of the Chameleon," he observes, " is naturally green; but it is susceptible of many shades, and particularly of three very distinct ones; Saxon green, deep green, and a shade bordering on blue and yellow green. When free, in health, and at ease, it is of a beautiful green; some parts excepted, where the skin being thicker and more rough, produces gradations of brown, red, or light grey. When the animal is provoked 
in open air, and well fed, it becomes a blue green, but when feeble, or deprived of free air, the prevailing tint is yellow green. Under other circumstances, and especially at the approach of one of its own species, no matter of which sex, or when surrounded and teased by a number of insects thrown upon him, he then almost in a moment takes alternately the three different tints of green. If he be dying, particularly of hunger, the yellow is at first predominant; but in the first stage of putrefaction this changes to the colour of dead leaves.

"The causes of these changes are various; and first, the blood of the Chameleon is of a violet blue, which colour it will preserve for some minutes on linen or paper, especially on such as have been steeped in alum-water. In the second place, the different tunicles of the vessels are yellow, as well in their trunks as in their ramifications. The epidermis, or exterior skin, when separated, is transparent, without any colour; and the second skin is yellow, as are all the little vessels that touch it. Hence it is probable that the change of colour depends upon the mixtures of blue and yellow, from which result different shades of green. Thus, when the animal, healthy and well-fed, is provoked, its blood is carried in greater abundance from the heart towards the extremities; and swelling the vessels that are spread over the skin, its blue colour subsides, and with the yellow of the vessels, produces a blue green, that is seen through the epidermis. When, on the contrary, the animal is impoverished, and deprived of free air, the exterior vessels being more empty, their colour prevails, and the animal 
becomes of a yellow green, till it recovers its liberty, is well nourished, and without pain, when it regains its former colour ; this being the consequence of an equilibrium in the liquids, and of a due proportion of them in the vessels."

To mention the various hypotheses by which these interesting changes of colour have been attempted to be explained, would not suit our pages; we content ourselves with adding the conclusions of Dr. Milne Edwards, who, in an elaborate memoir on the subject, is considered by some to have solved the problem. We have room only for the results at which he arrives, which he embodies in the following propositions:

1. That the change in the colour of Chameleons does not depend essentially either on the more or less considerable swelling of their bodies, or the changes which might hence result to the condition of their blood or circulation; nor does it depend on the greater or less distance which may exist between the several cutaneous tubercles, although it is not to be denied that these circumstances probably exercise some influence upon the phenomenon.

2. That there exists in the skins of these animals two layers of membraneous pigment, placed the one above the other, but disposed in such a way as to appear simultaneously under the cuticle, and sometimes in such a manner that the one may hide the other.

3. That everything remarkable in the changes of colour that manifest themselves in the Chameleon, may be explained by the appearance of the pigment of the deeper layer to an extent more or less considerable, in the midst of the pigment of 
the superficial layer, or from its disappearance beneath this layer.

4. That these displacements of the deeper pigment do in reality occur; and it is a probable consequence that the Chameleon's colour changes during life, and may continue to change even after death.

5. That there exists a close analogy between the mechanism by the help of which the changes of colour appear to take place in these reptiles, and that which determines the successive appearance and disappearance of coloured spots in the mantles of several of the Cephalopods.*

Whether this learned zoologist has set the question completely at rest in these observations or not, we may be permitted to doubt; and to inquire with Mr. Martin, "how the mechanical admixture of two pigments can produce the various tints, exhibited at various times by the skin of the Chameleon, as primary yellow, and red, yellowish-grey, brown, and violet, or dull inky blue?"

The Chameleon is vulgarly reputed to feed on air; which absurd notion may have arisen from its habit of frequently inflating its body to an extraordinary degree, when it appears plump and well-fed. The air penetrates even into the feet and tail, increasing the bulk of the animal to double its former size. At other times it becomes quite flaccid, and then has a dreadful appearance of leanness, like that of a skeleton enclosed in a loose skin. In this state the lungs are very small, but when fully inflated, their vesicles cover almost the whole of the viscera. It feeds, like most other Lizards, on insects, to * Ann. des Sci. Nat. ; 1834. 
capture which it has no powers of pursuit, for its motions are slow in the extreme. To this slowness there is indeed one exception, without which the creature would starve. Its habit is to lie in ambush, as it were, among the leaves, and watch for flies and other insects that may by chance alight or crawl within reach of its tongue. This organ, as we have said, is capable of being projected to a great length with great rapidity and precision; its tip, which is dilated, is somewhat tubular, and secretes a glutinous fluid, to which, when suddenly launched, the prey adheres, and is in an instant retracted into the mouth.

Some interesting details of the action of this organ, as observed in a state of captivity, are given in a paper by Mr. Houlston, published in the "Transactions of the Irish Society :" " When a fly, so maimed as not to be able to escape, but still sufficiently vigorous to move its legs and wings, was so placed that its fluttering might attract the Chameleon's attention, the animal advanced slowly until within tongue's reach of it; then, steadying itself like a pointer, sometimes stretching out its tail, sometimes fixing it against an adjacent body, and directing both eyes steadfastly on the prey, it slowly opened its mouth and suddenly darted forth its tongue, which advancing in a straight line, seldom failed of striking, with its glutinous cupped extremity, the object aimed at. Near the point of the tongue there is a small gland, which secretes a glutinous fluid, but even when the point happened to err, the prey did not always escape, sometimes adhering to the sides of the tongue. The tongue thus laden, then retired into the mouth, but somewhat more 
tardily than in its advance. When projected, the tongue acquired a thickness equal to the largest swan-quill, and a length not less, sometimes, than six or seven inches. Its consistence I attempted on one occasion to ascertain, by catching it between my fingers, when it imparted the feel of an elastic body, yielding slightly when pressed on, and expanding as soon as the pressure was removed. The experiment only caused a short delay in its progress, but neither altered its form or course, nor unfastened the prey from its extremity.

"The tongue is probably the sole agent of the Chameleon in obtaining food. Flies have often rested on its body, and though it has looked wistfully at them, it has had no means of taking them. I have frequently observed them on its very lips, without any attempt being made to seize them. Even when placed before it, if not sufficiently distant to afford room for the necessary evolution of the tongue, the Chameleon was under the necessity of retiring for the purpose.

"If the fly happened to be on a flat surface, so placed as to oblige the creature to direct its tongue perpendicularly against the surface, the cupped extremity would adhere, for a short time, in the same manner as a child's leather-sucker does to a stone. But the animal seemed most annoyed when seizing its prey on the sides of its cage, which was made of paper, the down of the paper sticking to the mucus on the tongue. On one occasion when two Chameleons attempted at the same moment to catch a fly placed between them, their tongues struck against each other, and remained connected for a short time." 
In Loudon's "Magazine of Natural History" are recorded some particulars of two Chameleons, which were sent from Malaga, in Spain, and which lived in the possession of Mr. Slight several months. They were kept unconfined in a wicker-basket in a bow-window, and slept many hours in the day, lying on a projecting ridge of the wicker-work. During sunshine, they flattened themselves, to expose a larger surface to its influence, when they were usually of a greenish stone-colour, and pale. If disturbed, they contracted their abdomen, expanding the ribs, and often became instantly of a dark green, or even indigo green. Sometimes only one side changed colour. The larger was vigorous, and in health; when awake, its eye (of a dark colour and very lustrous) was turned in every direction, the motions being by a kind of jerk, and very rapid, as if in search of prey. Mr. Slight was accustomed to put six or seven cockroaches in a shallow tin vessel, and the Chameleon on its edge, with its head projecting over the brim. After making a circuit round a portion of the vessel it would distend the throat-pouch, and stretching forward its body on the fore-legs, it would suddenly dart out its tongue with such force as to make a very sensible ring on the opposite side of the tin. It would catch the insect in the trumpet-shaped extremity of the tongue, which was retracted quick as lightning, and mastication and swallowing followed. In this manner it would take three or four insects from the vessel, but fed only once in three or four days, and would not eat hard-shelled beetles. They generally slept on the top of the basket, their heads pro- 
jecting over the edge, and their tails curled round one of the small divisions of the wicker-work, and it was curious to observe the firmness of their hold in this way. On going in with a candle, they always appeared of a pale ashy stone-colour or a spectral blue, like the tint cast upon the face by coming opposite a blue bottle in a chemist's window. Their motions were exceedingly slow, always firmly attaching one foot before letting go with the other. They were lost several times, and Mr. Slight was afraid to step about the room, lest he should tread on them, but they were generally found in the folds of the curtain, not on the blue lining, but on the chintz. One side was often seen nearly of a stone colour, while the other was blackish green; the changes of hue were always rapid, and attended by either elevation or depression of the ribs.

\section{Family II. Geckotide.}

(Geckos.)

The Geckos form a numerous but well-defined Family, widely diffused over the hot regions of both hemispheres. They are all of small size, but of somewhat uncouth proportions, and of repulsive appearance; the head being large and flat, the neck short, the body stout and protuberant, with the line of the back rather depressed than ridged. The eyes are full and large, and being destitute of visible eyelids, always appear staring; the pupil is, for the most part, a perpendicular line by day, with notched edges. The feet are nearly equal, short, stout, and terminated 
by five toes, differing little in length, which radiate as if from a centre, so as to form twothirds of a circle. The under surface of the toes is, in most of the genera, much widened, and furnished with small plates, or laminæ, overlapping each other in a regular manner, which varies in different genera and species. The toes are frequently united by a membrane at their base.

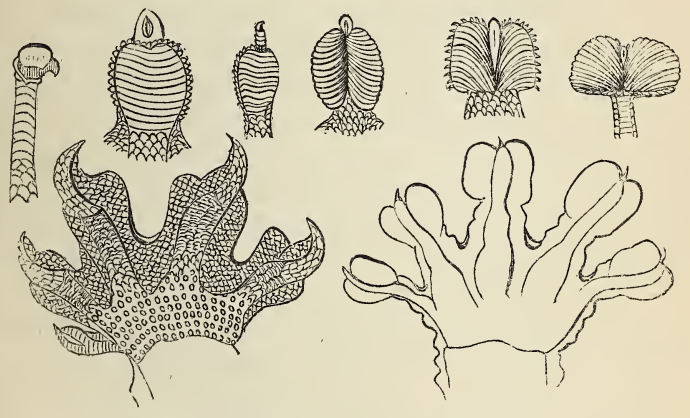

FEET OF GECKOS.

The claws are pointed, hooked, and kept constantly sharp, by an apparatus by which they are capable of retraction, like those of the cat. In some genera, however, the claws are wanting. The jaws of the Geckos are armed all round with a single row of minute teeth, which are compressed, with cutting edges, implanted in the interior surface of the jaw-bone; the palate is destitute of teeth. The mouth is wide; the tongue is thick and fleshy; slightly extensile, with the extremity sometimes notched. The ears are situated on the sides of the head, the tym- 
panum or drum, a membrane sunk considerably below the general surface, the orifice bordered by two folds of skin. The skin is very loosely attached to the muscles, weak, and easily torn : it is roughened with minute granular scales, which, on the sides and hinder parts become more inclined, and overlapping, and on the under parts take the form of regular scales. The tail varies in length, but never exceeds that of the body; like that of most Lizards, it is very brittle, and liable to be separated by accident; it is, however, soon replaced. In some species, the sides of the body, the tail, and the limbs, are furnished with expansions of the skin, sometimes fringed or vandyked in a singular manner. The males have femoral pores more frequently than the females, but not invariably.

"The skull of the Geckotide is marked by some peculiar characters. The bones are welldefined, nor do the
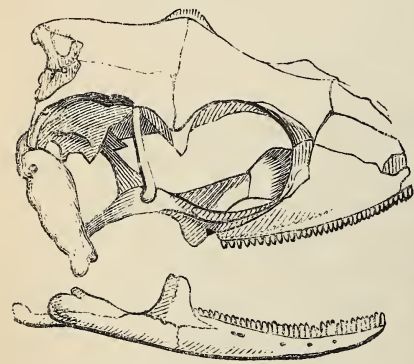

SKULL OF GECKח. sutures seem to be obliterated by age. In general contour it approaches the skull of the Crocodilide by its width, its flatness, and its length ; its particular resemblances to the same part in that Family are to be found in the disposition of the orbits, and the articulation of the jaws. The excavations for the eyes are very large, and apparently incomplete, inasmuch as the orbital frame is not 
entirely bony in its back part, nor has it, so to speak, any flooring; so that when deprived of the softer parts, the cavity communicates with the mouth. The articulation of the jaw is quite backward." * The spinal column is destitute of any bony processes or projections; the vertebræ are said to be hollowed out, on their anterior and posterior surfaces, into conical cavities, somewhat like the vertebræ of fishes. The number of ribs varies according to the species.

We have said that the skin is easily detached; when held up to the light, it is seen to be regularly furnished with small, delicate, rounded, escutcheon-like bodies, set in its substance. The form and distribution of these bodies are different in different species, and they are found in the skin of the belly, the neck, the head, the thighs, and the tail.

The colours of the Geckos are commonly sombre, and even lurid; frequently various shades of grey and brown, more or less irregularly clouded or mottled; they have the power in some degree of changing their hues, the colours being darker or paler, and the markings becoming visible or evanescent, at will. Some of the small species are marked with bright colours, which are not mutable. Wagler was informed by some travellers, that certain Geckotide of India become luminous or phosphorescent during the night; but we know not how far this information is to be depended on. The skin is moulted or sloughed off, at certain times, when that which envelops the head and fore parts of the body is detached first, the separation proceeding gradually to

$$
\text { * Penny Cyclop،, xi. } 102 .
$$


the tail. During the process, which lasts for a day or two, the half-detached skin hangs about the animal in loose folds, resembling the finest muslin, apparently to its great annoyance. The colours of the body after this shedding of the cuticle are much brighter and more definite.

By means of the singular lamellated structure on the under surface of the toes, the Geckos, or at least many of them, are enabled to cling to vertical or even inverted surfaces, as house-flies do. The mode in which this is effected, we do not thoroughly understand; but we may conjecture that it is by the raising of these imbricated plates by muscular action, so as to form a vacuum beneath the sole, when the pressure of the external air causes the toe to adhere firmly to the surface. The similarity of the structure to that of the coronal sucker in the Remora, suggests this explanation. A familiar illustration of the principle is seen in the leathern suckers which children make, which adhere so firmly that large stones are lifted by them.

M. Duméril has noticed a peculiarity in the cesophagus or gullet of this Family, which is the more extraordinary, since the part is not exposed to the light. In many species, both living and dead, which he examined, he found the interior of this tube, which is very wide, strongly coloured with different shades, uniform in the same individual, sometimes orange-yellow, but more generally deep black. We have observed something analogous to this in the rich vermillion hue of the whole interior of the mouth and vomer of some West Indian fishes.

The names Gecko, Geitje, Tockaie, \&c., by 
which these reptiles have been called in different localities, are derived from the sounds emitted by them, which are supposed to resemble these words. M. Duméril is unable to account for the production of this voice, the more especially as they are destitute of the dewlap, or goître, which we find in the Iguanade. He suggests, however, that the movement of the tongue may bear a part in its emission, and the reception of that organ in the concavity of the palate; perhaps in a similar way to that in which the cracking sound is produced by a rider, when he stimulates his horse, - the tongue being applied to the palate, and quickly withdrawn. The goître of the Anoles does not appear to us to be in any way connected with the emission of sounds.

The motions of the Geckos are slow and stealthy: they creep along with an almost imperceptible step, with the chin and belly resting on the surface on which they move; yet on alarm they display surprising agility. They watch, the whole day long, at the mouth of some hole or crevice, the head peeping out; and if they do venture to travel, rarely wander far from their retreat, into which they vanish in an instant, if disturbed. Their senses seem acute, and to be exercised by day, though night is the season of their activity.

The following summary of the habits of these animals we extract from the elaborate article on this Family in the Penny Cyclopædia, though a few of the remarks we have already anticipated, and though we cannot fully agree with some of the conclusions :-

"The Geckotide are none of them large in 
size, and the greatest number feed on small animals, such as insects, their larvæ and pupæ. These they catch either by lying in ambush, or by pursuing their feeble prey in the holes and dark crevices to which it retires. The structure of their feet enables them to run in every direction over the smoothest surfaces, and they can even remain suspended beneath the large leaves which a luxuriant tropical vegetation so frequently puts forth. The sharp or retractile nails with which the feet of the greater number are armed enable them to cling to and make rapid progress on trees with the smoothest bark, or penetrate the holes of rocks, and to climb walls. Of sombre or varying colours, adapted generally to the locality where their lot is cast, they will often remain for hours in positions as extraordinary as the flies and insects for which they watch; the wonderful apparatus with which their feet are furnished enabling them to overcome the general law of gravity, and without which they would instantly fall to the earth. The hues of their skins thus render them less objects of suspicion to the little animals for which they lie in wait, and also serve to dodge even the acute eye of the bird of prey that seeks to destroy them. Their eyes enable them to discern objects in the dark, and are at the same time capable of bearing the rays of a bright sun; for many insects are nocturnal or crepuscular, while the great mass of them are diurnal. The pursuit of their prey leads them near the habitations of man, whose dwelling always attracts certain kinds of insects, and they sometimes fall victims to their appearance, which frequently inspires terror, and often dis- 
gust. A Gecko, confident in his powers of flight, appears boldly to await his adversary, and his sudden disappearance at a nearer approach adds to the horror which his uncouth form inspires. The poor Geckos, too, have a bad name. They are supposed to poison whatever they touch, be it animate or inanimate, and their saliva is said to vex the skin of those on whom it falls with foul eruptions. Many of these cuticular irritations, when they have actually existed from the intervention of these animals, may have arisen from the extremely sharp claws of a Gecko running over a sleeping man, or small blisters may have been raised by the adherent apparatus at the bottom of its feet."

The explanation here given of the baneful effects supposed to be produced by the feet of some species of this Family, though repeated in most works on the subject, seems to us futile and unsatisfactory. We do not believe that the adhesion of the suckers of the toes of these minute animals would produce the smallest appreciable result on the skin of a man, in the way of raising blisters, nor that the muscular power with which the little claws are moved would be sufficient to pierce the flesh.

The genera and species which compose the Family are rather numerous, and are scattered over all the great divisions of the globe. Europe, however, has but two, neither of which is found in the British Isles. To Asia, Africa, America, and Australasia, the remainder are distributed in about equal proportions, each of these regions having twelve or fourteen species; the whole amounting to between fifty and sixty. 


\section{Genus Thecadactylus (Cuv.).}

The claw in this genus is completely retractile; the toes, which are widened throughout their length, being furnished with transverse plates beneath, which are divided by a deep longitudinal groove, to receive the claw. Those known have the innermost toe destitute of a claw, they have no femoral pores, and the tail is clothed with minute scales on both the upper and under surfaces.

The Smooth Sheath-claw (Thecadactylus lavis, Cuv.) has the transverse scales beneath the toes numerous : it is about nine inches in length, of a stout form, of a pale reddish hue, marked with transverse bands of brown; the sides are spotted with red, and there is over each shoulder a black patch with a white dot in the centre. The tail is vertically compressed towards the tip; but this organ is readily detached, not only by violence, but by the convulsive action of the reptile itself, if put alive into spirits. In this latter case the separated tail sometimes contracts and assumes an almost globular form. From having been seen in collections in this state, it has been supposed to be a distinct species, and has been named the Turnip-tailed Gecko (Gecko rapicauda). If the animal escape after having thrown off its tail, a new one will be reproduced in a short time, soon assuming the size and appearance of the old one, and leaving scarcely any trace of the misfortune, as we have proved in specimens in our own possession in captivity.

The Smooth Sheath-claw is a native of Jamaica, 
where it is very common. From its singular voice, uttered on the approach of night, and continued at intervals through the darkness, it is there called the Croaking Lizard. The sound which it emits might rather be called cackling than croaking, having some resemblance to the

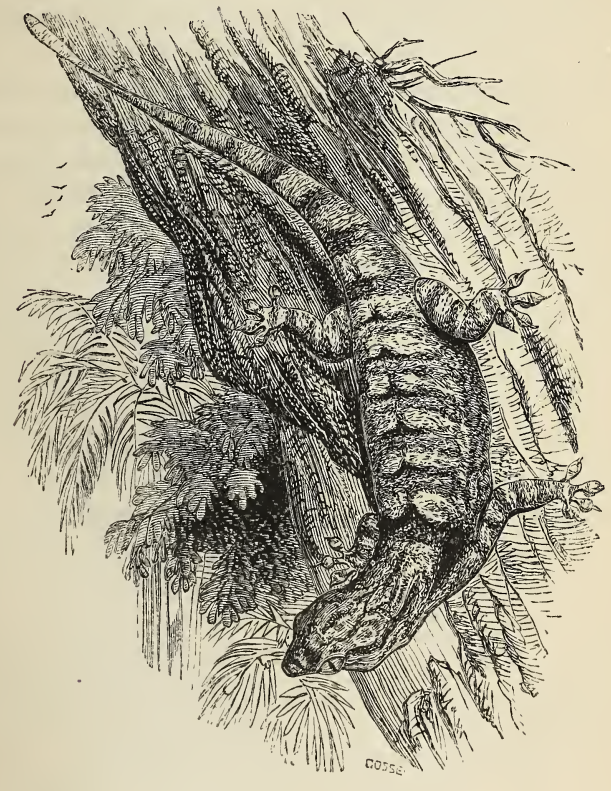

SMOOTH SHFATH-CLAW.

noise produced by drawing a stick across the teeth of a comb. It frequents hollow trees, and the roofs and rafters of deserted houses, a pair generally living together; one or both 
may commonly be seen, day after day, at the same spot, frequently peeping out of a crevice, and remaining perfectly still for hours. They move with excessive deliberation, but are easily alarmed, when they dart into their hole with inconceivable rapidity. They may often be observed crawling on the vertical side of a beam, but we have never seen one actually inverted.

The food of this species principally consists of insects; but we have frequently found in its stomach substances of a vegetable nature also, as pulpy berries, and seeds of various kinds. Its eggs, which are about half-an-inch in length, irregularly oval and flattened, are laid in any crevice; they are covered with a hard and brittle calcareous shell. The young, when excluded, are exactly like the adult, but have the hues much more brilliant: they are able to run with agility the moment they leave the shell.

The sombre and lurid appearance of this Lizard, its stealthy motions, its nocturnal activity, and singular harsh cry, and especially a certain sinister aspect, produced by its large globular eye, unprotected by an eyelid, and divided by its linear pupil, have doubtless combined to give to it in the popular mind a character for evil, which its fellows in other regions possess, but to which it seems to have no rightful claim; for though dreaded, and vulgarly reputed poisonous, we have every reason to believe that it is a perfectly innocuous reptile. 


\section{Family III. Iguanade.}

\section{(Iguanas.)}

Some of the largest and some of the smallest of the Lizards are found in this Family, for while the true Iguanas sometimes measure six feet in length, there are some of the Anoles which scarcely attain half as many inches. It comprises many genera and species, which, with scarcely an exception, are confined to the warmer parts of the American continent and the adjacent islands. They are marked by a long and slender body, and greatly lengthened tail; by having five toes on each foot, which are very unequal in length, those of the hind feet particularly so ; by the eye being protected by eyelids, meeting in a longitudinal line; by the tympanum or drum of the ear being membranous, and but little beneath the surface; by the tongue being thick, fleshy, and not extensile, and notched only at the tip; by teeth in the palate; and by numerous others

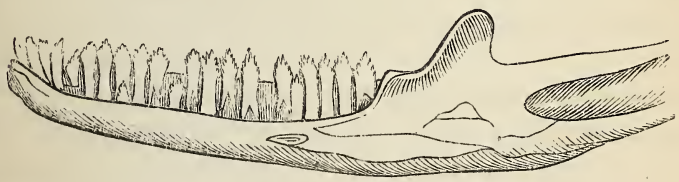

TEETH OF IGUANA.

attached to the inner edge of the jawbone, which for the most part are lobed or dilated, and have a crenated or notched edge. Besides these distinctions, the body is covered with scales or tu- 
bercles, often ridged or spinous, always horny in texture, not bony: those of the head frequently take the form of many-sided plates, more or less large, and those of the belly are square and overlapping. The scales of the back are generally elevated into spinous processes, forming a sawlike crest, which runs down the back and tail in various degrees. The toes are always free, commonly slender; but in some genera, as Anolis, Dactyloa, \&c., they have the dilated and lamellated tips of the Geckotida. These have the power of crawling with ease and rapidity on perpendicular surfaces, and haunt out-buildings, and even dwelling-houses in the hot parts of America and the West Indies, running with great agility about the walls, and leaping from place to place; while others run and leap with equal sprightliness among the twigs and leaves of low shrubs in pursuit of insects. These have the faculty of changing their colours, which is effected with a rapidity and to an extent scarcely inferior to what we see in the Chameleons. All the genera appear to be more or less arboreal; the larger species, or true Iguanas, living almost entirely on trees: these are reported to be able to swim with ease, but their feet do not manifest any structural adaptation to aquatic habits, and we doubt whether they ever take to the water except in an emergency, or impelled by some unusual motive.

Most of the species in this Family have some expansion of loose skin about the neck. In the Iguanas it hangs down in a permanent sort of dewlap, but in the Anoles it is ordinarily contracted and consequently invisible, but is ex- 
panded broadly during excitement. It does not, however, form a bag, nor is it susceptible of inflation, as commonly represented, but is simply extended by means of the branches of the tonguebone (os hyoïdes), which in repose pass down longitudinally beneath the skin. Under the influence of excitement, the tips of this bony fork are drawn downward and forward, stretching the skin with them, in an elliptical form, the two inner surfaces of the skin being in contact.* This

* The apparatus by which this extension is effected was thus described as long ago as 1825, by Professor Bell. "The frame-work of this structure consists of a remarkable developement of the os hyoides or bone of the tongue. This bone is situated immediately under the larynx. It has two long, slender, bony processes on each side, which, for the sake of distinction, I shall term the anterior and posterior lateral processes, - a small one which is filiform, given off from the anterior part of the bone, and closely connected with the under part of the tongue,-and a very long, delicate, and elastic cartilage, extending from the body of the bone, nearly to the middle of the abdomen, immediately beneath the skin, to the internal surface of which it is attached by condensed cellular tissue. In its form it is slightly flattened and tapering to its extremity, where it is extremely slight and. flexible.

"The anterior lateral process extends backwards to the angle of the lower jaw, over the muscles of which it is curved upwards. The posterior lateral process is placed in a similar direction, but does not take the same curve over the edge of the jaw. These two processes run parallel to each other through almost their whole length, but at a small distance apart.

"There are several pairs of muscles attached to these little bones, by the action of which the phænomena are produced, which it is my object to explain. Of these the following are the principal. A broad strong muscle arises from the whole edge of the posterior lateral process, and is inserted into the clavicle. It is consequently of considerable length; and by its contraction the whole bony frame-work is drawn back and a little downwards, so that the distance between the two extremities of the long elastic cartilage being diminished, this organ is thrown into a curve, and the skin of the throat and belly is stretched upon it, exactly as the silk is strained upon the whale-bone ribs of an opened umbrella. The parts are restored to their natural state by the action of [counteracting] muscles." (Zool. Journ.ii. 12.) 
goître is almost always of bright colours, usually some tint of orange or red, and is not susceptible

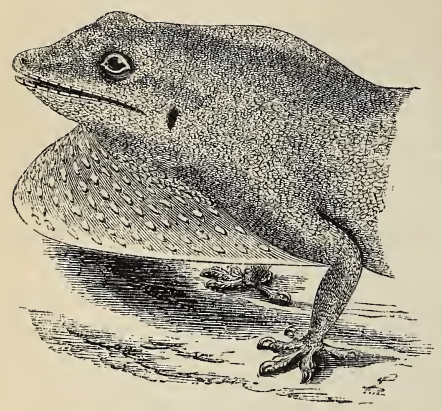

HEAD OF ANOLIS. of change in hue, as has been erroneously stated even when the colours of the body are mutable.

The food of the smaller species of the Iguanade consists chiefly of insects, in the capture of which they display great agility. We have,

however, seen specimens of the genus Dactyloa (allied to Anolis) engaged in feeding on pulpy berries; and MM. Duméril and Bibron state that in their dissections of many of the larger species they have found the stomach filled with vegetable matters, such as flowers, leaves, and seeds, in considerable quantities, and hence these herpetologists conclude that most of the species are herbivorous. The true Iguanas are said, however, to feed voraciously on animal matters also, such as the eggs of birds, the intestines of fowls, and insects.

An interesting anecdote recorded by Professor Bell of one of the smallest of the Iguanada shows that insectivorous animals may be exposed to danger from the noxious qualities of the insects which they attack. "Some years since," observes this zoologist, "I had in my possession two living specimens of the beautiful little green Anolis 
of the West Indies, a lizard about the size of our own smallest species. I was in the habit of feeding them with flies and other insects, and having one day placed in the cage with them a very large garden spider, Epeira diadema, one of the lizards darted at it, but seized it only by the leg. The spider instantly ran round and round the creature's mouth, weaving a very thick web round both jaws, and then gave it a severe bite in the lip, just as this species of spider usually does with any large insect which it has taken. The lizard was greatly distressed, and I removed the spider, and rubbed off the web, the confinement of which appeared to give it great annoyance; but in a few days it died, though previously in as perfect health as its companion, which lived for a long time afterwards." *

\section{Genus IgUANA (Laur.).}

To this genus, which is very restricted in extent, belong the largest species of the Family, and almost of the Order. They are marked by a prolongation of the skin, which stretching under the whole surface of the head and neck, forms a very thin, but very deep dewlap or pouch, the border of which describes a curve, and is set along its front edge with spinous processes like the teeth of a saw. The skin is irregularly folded on the sides of this dewlap, behind which there is another transverse fold passing obliquely over each shoulder. On the sides of the neck and body, also, the skin has a tendency to form loose folds. The head is rather large, and has * "British. Reptiles." Intr. xx. 
somewhat of the form of a four-sided pyramid. The neck is compressed, the body rounded, but flattened on the under surface. The toes are long, and very unequal, increasing rapidly in length from the innermost to the fourth, which is longest, the fifth being short: their edges are notched. The tail is long, slender, compressed, and tapered to a fine point.

The general surface of the body is covered with small square or lozenge-form scales, keeled along the middle, which slightly overlap each other; those of the tail present at regular intervals verticillations or rings, produced by every fourth or fifth series being a little larger than the others, but this structure ceases to be perceptible towards the tip. The line of scales which runs down the middle of the back and tail, forms a saw-like crest, commencing from the hindhead, and reaching the extremity of the tail. It is composed of strongly compressed scales, which are pointed and curved backwards, and which gradually diminish in height towards the end of the tail. On the top and sides of the head the scales are larger than the rest, but varying in size, many-sided, some flat, some convex, and some ridged: the lips are covered with large four-sided plates. The under surface of the thighs has a single row of pores, surrounded by small scales disposed like the petals of a flower around its disk.*

We have already mentioned MM. Duméril and Bibron's conclusions of the nature of these Reptiles' food from anatomical investigation. These are confirmed by a fact related of a living Iguana,

* Dum. et Bibr. 
which was kept in a hot-house near Bristol. It had refused to eat insects and other kinds of animal food, until happening to be near some kidney-bean plants, it began to eat their leaves, and was thenceforward supplied with these plants. Other accounts, as we shall presently see, describe them in their native regions as feeding on fruits.

Some writers have enumerated many species of this genus, but the eminent herpetologists above mentioned reduce the whole to three, all of which are widely spread over South America and the

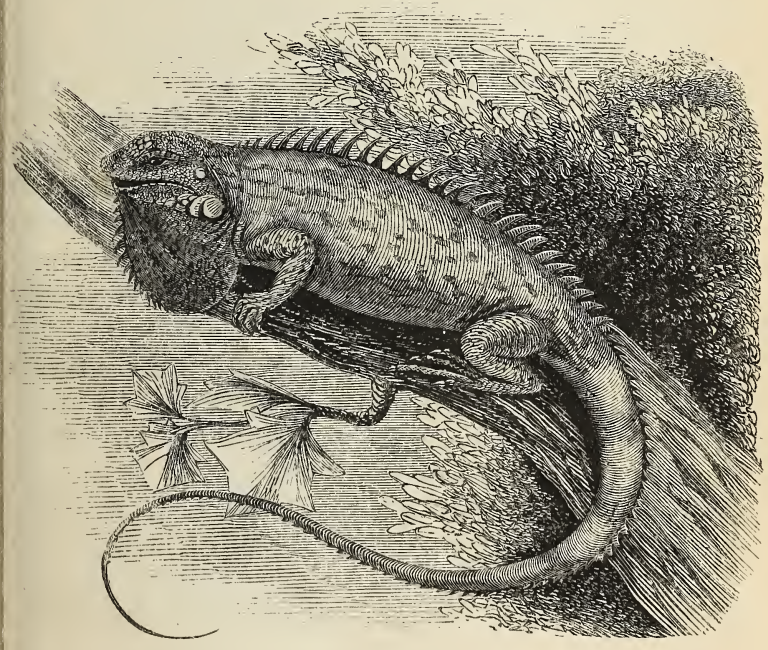

IGUANA.

Antilles. The most common is Iguana tuberculata (LAURENTI), which, in five stages of its life, has 
been described and figured by Spix, in his magnificent work on the Zoology of Brazil, under five different names.

This is the common Iguana or Guana of the European colonies, a name which seems to be of Indian origin, and which was probably that by which the reptile was distinguished at the time of the discovery of America. It is said to have been common in the West Indian Isles in former years, but it seems to have disappeared, at least from Jamaica; it is possible, however, that some large species of Cyclura, an allied genus, inhabiting that island, and provincially called by the name of Guana, may have been mistaken for it.

The Green Iguana attains a length of five or six feet; its general hue is green, more or less deep, sometimes merging into blue : the sides are marked with oblique stripes of brown, edged with yellow; a line of yellow frequently appears over the shoulder; the tail is crossed by broad bands of brown, alternating with the green. In some specimens, the sides and limbs are variously clouded or spotted with brown.

The esteem in which the flesh of this reptile is held in the countries which it inhabits is spoken of by most writers who mention its existence. Delicatissima and sapidissima are among the numerous specific names which have been assigned to it. Excellent, however, as is its flavour, it is not considered very wholesome, and to persons labouring under certain diseases it is highly injurious.

In Paramaribo, where the Iguana is considered one of the most delicious animals brought to the daily market, it is always in request and sells 
at a high price, being immoderately esteemed by those epicures who consider a fricaseed frog preferable to a chicken. The eggs, which are spoken of as very agreeable in flavour, and which are constantly sought after in Surinam and Guiana, have common qualities with those of the Turtle, especially those taken from the gravid Turtle killed for the market; - a yolk that never boils hard, and a slight envelope of albumen that never whitens. They are described as being as large as, but a little longer than, pigeons' eggs ; equally thick at both ends, but soft, with powdery crystals of carbonate of lime, and therefore differing from the egg of the Alligator, which they resemble in shape, but which has a shell unusually thick and compact. They are found deposited in sand, some six dozen together.*

Goldsmith gives a very graphic description of the manner of pursuing and taking the Iguana as a pastime. From his speaking of the Mapou, the Colonial-French for the Eriodendron, or silk cotton-tree, it is probable he derived his account from Father Labat's amusing notices of tropical natural history. After repeating that its flesh is considered the greatest delicacy of America, he represents the sportsmen of the tropics as going out to hunt this Lizard with the same sort of preparation for success that an English poacher makes for the seizure of the pheasant or the hare. "In the beginning of the season," he says, "when the great floods of the tropical climates are passed

* At Aritaka, on the Essequibo, Schomburghk relates that south of the rapids, numerous sandbanks rising out of the water serve as a depository for the eggs of the Guana; in a very short time they took some hundreds. 
away, and vegetation starts into universal verdure, the sportsmen are seen with a noose and a stick wandering along the sides of the river to take the Iguana. The animal, though apparently formed for combat, is the most harmless creature of all the forest: it lives among the trees, or sports on the water, without ever offering to offend; there having fed upon the flowers of the Mahot (Hibiscus tiliaceus), and the leaves of the Mapou (Eriodendron anfractuosum), that grow along the banks of the stream, it goes to repose upon the branches of the trees that hang over the water. Upon the land the animal is swift of foot; but when once in possession of a tree, it seems conscious of the security of its situation, and never offers to stir. There the sportsman easily finds it, and as easily fastens his noose round its neck: if the head be placed in such a manner that the noose cannot readily be fastened, by hitting the animal a blow on the nose with a stick, it lifts the head, and offers it in some measure to the noose. In this manner, and also by the tail, the Iguana is dragged from the tree and killed by repeated blows on the head." *

The mode in which the animal is induced to permit the placing of the fatal noose over its head has been described as follows; and we can in some measure confirm its credibility from personal experience, having often captured Dactyloa Edwardsii, and other West Indian Iguanadae by this very artifice. "They are in the habit of sitting on the branches of trees, facing the sun, with only the front part of their head exposed. On these occasions the following method is re* "Animated Nature," book ii., chap. 3. 
sorted to by the huntsman. He approaches gently, whistling as he advances; this attracts the attention of the reptile, and appears to please it, for it advances its head further from its retreat. When the huntsman is come sufficiently near, he gently rubs the end of his pole against the sides and throat of the Iguana, who not only suffers this sort of caress without resistance, but appears to return and enjoy it. The huntsman continuing to employ these means, induces his victim to expose its head sufficiently to allow him to pass a loop, which is fastened to the end of his pole, over the head and round the neck of the reptile; and this accomplished, he brings it to the ground with a violent jerk, and places his foot on its body. The Iguana now proves itself less passive than usual, for when it finds its confidence deceived, and itself captured, it exerts itself with violence, rolls its sparkling eyes, and inflates its throat; but such efforts are useless, the huntsman manages to tie its fore-feet together, and to secure them under the creature's throat, so that it can neither fly nor fight. If taken alive, it appears at first sullen and intractable, but after a time becomes domesticated, and runs about the house and garden with as much confidence as a cat."

Catesby's account of the Iguana was probably derived from personal acquaintance with it in the Bahama Islands. He says,-

" These reptiles nestle in hollow trees; their eggs have not a hard shell like those of alligators, but a skin only, like those of a turtle, and are esteemed good food. They lay a great number of eggs at a time in the earth, which are hatched by the sun's heat. The Guanas furnish 
a great part of the subsistence of the inhabitants of the Bahama Islands; for which purpose they visit many of the remote kayes and islands in their sloops to catch them, which they do by dogs trained up for that purpose, and which are so dexterous as not often to kill them. If they do so, however, the Guanas serve only for present use; if otherwise, they sew up their mouths to prevent their biting, and put them into the hold of their sloop, until they have obtained a sufficient number, which they either carry alive for sale to Carolina, or salt and barrel up for the use of their families at home. These Guanas feed wholly on vegetables and fruit, especially on a particular kind of fungus growing at the roots of trees, and on the fruits of the different kinds of Ananas : their flesh is easy of digestion, delicate, and well tasted. They are sometimes roasted, but the more common mode is to boil them, taking out the fat, which is melted and clarified and put into a dish, into which they dip the flesh of the Guana as they eat it. Though not amphibious, they are said to keep under water above an hour. They cannot run fast, and their holes are a greater security to them than their heels. They are so impatient of cold that they rarely appear out of their holes but when the sun shines."

Brown, in his "History of Jamaica" (1756), says that the Guana lives for a considerable time without food, and changes its colour with the weather, or the natural moisture of its place of residence. "I have kept," he adds, "a grown Guana about the house for more than two months : it was very fierce and ill-natured at the beginning, * "Natural History of Carolina," \&c. 
but after some few days it grew more tame, and would at length pass the greatest part of the day upon the bed or couch, but always went out at night. The flesh of this creature is liked by many people, and frequently served up in fricassees at their tables, in which state it is often preferred to the best fowls. When taken young, the Guana is easily tamed, and is both a harmless and beautiful creature in that state."

In the unpublished MSS. of Dr. Robinson on the Natural History of Jamaica, preserved in the Library of the Jamaica Society, the Iguana is spoken of as familiarly known in that island. After some descriptive notes, he observes,-

"They are said to be inoffensive animals, and meddle with no living creature, unless first attacked, when they bite hard. One of them bit a cat's paw quite off, that was held to it; and I have seen the above snap at a stick that has been held towards it, with great tokens of wrath, sullenness, and fierceness. They are found in Salt Pond Hills, where they live upon vegetables and fruit; and can by the help of their open toes climb upon trees and shrubs. They hide themselves in holes among the rocks, and are hunted with small dogs by the negroes, who sell them in the towns to many people who admire them as a great delicacy. Their flesh is said to be very white, tender, and well tasted, and even superior to that of a chicken; but for my part I never had an opportunity of tasting this animal's flesh. The fat is said to be good to cleanse iron utensils with, and preserve them from rust."

We think it very probable, however, that both these notes of Robinson's, and those already 
cited from Brown, belong to the Cyclura, which we know to be an inhabitant of the district mentioned by the former. In another passage, however, it appears to have been a true Iguana, which he speaks of as having been brought from the Isle of Pines, "of a wonderful size, being, as they judged, between six and seven feet in length. . - The hind quarter weighed five pounds, whence they concluded that the Iguana must have weighed twenty pounds."

\section{Family IV. Agamade.}

\section{(Agamas.)}

The subjects of the present group are by some zoologists (among whom are the great French herpetologists we have so often cited) considered as forming a division of the Iguanada; but they are by others elevated to the rank of a Family, and as such we prefer to treat of them. Their most important distinctions are to be found in the teeth; these are entirely wanting in the palate; and those of the jaw, instead of being implanted on its inner side, are seated on the ridge of the jaw-bone, to which they are soldered, and of which they appear to be a continuation.

In the form of the head and of the teeth the Agamadae resemble the true Lizards, but differ from them in the imbricated scales with which their tails are clothed. The body is for the most part thicker and shorter than the usual proportions ; the skin is loose and capable of being inflated with air at pleasure; the head is short, flat, and broad, particularly behind; the neck 
also is short, and the tail seldom longer than the body. From these peculiarities the Agamas are sometimes called frog-lizards. The whole head, body, and limbs, are commonly covered with lozenge-form or hexagonal scales, which are often prolonged into little spines, which bristle up formidably, when the body is distended with air.

Some of the species, indeed, are so armed with spinous processes of various forms and lengths, as

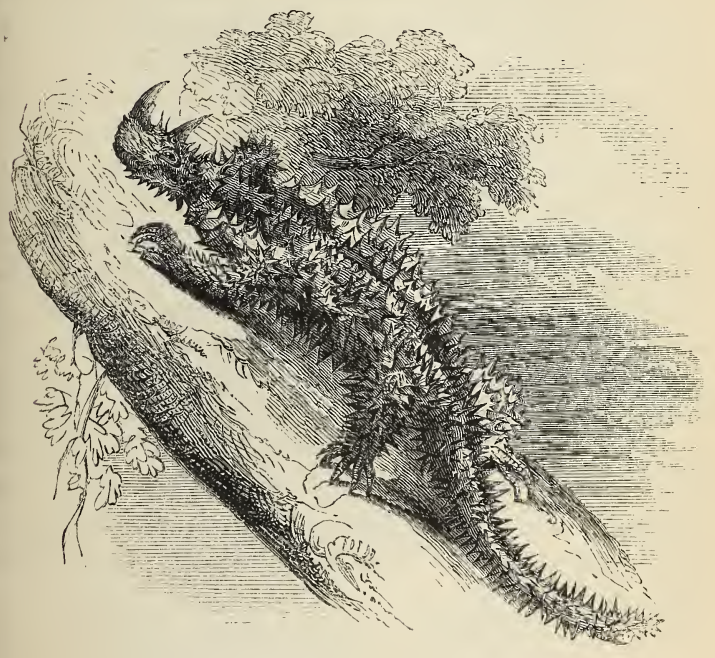

MOLOCH LIZARD.

to present a truly frightful appearance; such as, for example, the Moloch Lizard of Australia (Moloch horridus).

"Some of the most singular shapes among the existing races of reptiles," observes Mr. Swainson, 
"will be found in this Family. The Phrynosoma, with its fat body and short tail, immediately reminds us of a toad. Megalochilus has much of the same shape, but seems to have a large pair of rounded ears standing out from the sides of the head. Those of the sub-genera of Draco are most extraordinary reptiles; the Sitana has an enormous pouch under the throat, which it can swell out so as to appear like a Tetraodon, or porcupine fish. Chlamydosaurus, again, is provided with an immense fringe round the throat, perfectly resembling the broad collars worn by ladies of the present day. The flying lizards (Draco), however, even surpass these, for they possess a distinct pair of wings, attached to the sides of their body, supported by rays, and capable of being expanded or folded at pleasure. These extraordinary reptiles, however, are by no means formidable; they are all of a comparatively small size, live in trees, and feed only upon insects. Of their peculiar habits, however, in other respects, we unfortunately are at present ignorant. There can be no doubt that these wings are used to support them in the air, when leaping from bough to bough, much in the same manner as the loose skin that performs that office among the flying squirrels." "*

The Agamade are spread over both hemispheres, but are most numerous in the tropical regions of Asia and Africa. They feed chiefly on insects, but some are said to be herbivorous; and seem to affect dry, stony places.

* "Classification. of Reptiles," ii. 161. 


\section{Genus $P_{\text {hrynosoma }}$ (Wiegm.).}

In this singular genus, whose orbicular form scarcely recals the idea of a lizard, the tail is flattened, and shorter than the body; the whole form greatly depressed; the body nearly globular; the scales on the belly, limbs, and tail, are small and overlapping; those of the upper parts rather larger, and interspersed with longitudinal rows of spines; the hind head is set with large spines.

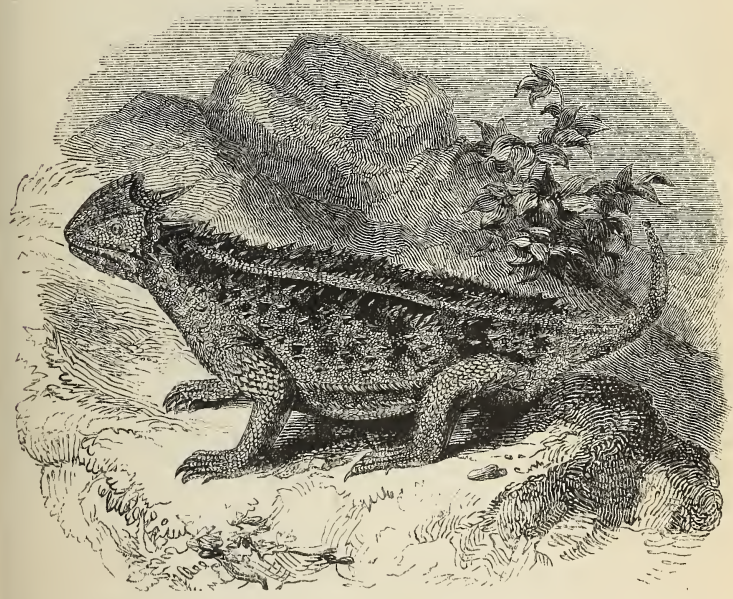

TAPAYAXIN.

The best known species is the Tapayaxin of Mexico (Phrynosoma orbiculare, W AGL.), sometimes called the Spinous Toad. "The extraordinary figure of this reptile, approaching almost 
to the form of a perfect sphere, its broad flat head, its skin covered with small tubercles or warts interspersed among the scales, and the faculty which it possesses of distending its body with air, and to a certain degree assuming different shades of colour, have caused it to be sometimes compared to a toad, and sometimes to a chameleon; but the truth is, that it has no actual relation or affinity to either of these animals, but is indebted solely to its naturally disgusting aspect for the calumnies which the early Spanish writers have heaped upon it. The scales of this species are small, pointed, and rough on the upper parts, smooth and flat beneath; on various parts of the back they are elevated into insulated spines, ranged in six or eight longitudinal rows, but without much regularity: the ground-colour is dark grey above, with irregular brown blotches, and beneath yellowish red, speckled with small black spots. The legs are short and thick, and the toes of equal length both before and behind. The Tapayaxin inhabits the mountainous and rocky parts of South America, from the Isthmus of Darien to Patagonia ; according to Ray, it is capable of domestication, and even recognises and shews a kind of attachment to those who feed it."*

* "Penny Cyclop." i. 193. 


\section{Family V. Varanide.}

\section{(Monitors.)}

These are Lizards of large size, in some respeets approaching the Crocodiles. MM. Duméril and Bibron, who designate them by the appellation of Broad-backed Saurians, assign to them the following characters. They have the body very much elongated, rounded, and without a dorsal crest, supported on strong legs and feet, with distinct and very long, but unequal toes. The tail is slightly compressed, and at least twice as long as the trunk. The skin is furnished with enchased scales, which are tuberculous, projecting, rounded upon the head, as well as upon the back and sides, always distributed in rings or circular bands, parallel under the belly and round the tail. The tongue is protractile, fleshy, and similar to that of the Serpents, - that is to say, capable of elongation, and of being withdrawn into a sheath,-narrow and flattened at the base, and deeply divided and separated at the extremity into two points.

They are distinguished from the other Families by evident and easily seized peculiarities. From the Crocodilida, in the toes which are all furnished with claws, and never palmated at the base ; in the cutaneous tubercles, which are neither square nor furnished with projecting ridges; in the protractile tongue; in the form of the teeth, the pupils, the auditory conduits, and especially in the male genital organs, which are double. From the Chameleonida, because their tongue is 
forked at the point; their eyes furnished with two distinct lids, in addition to the auditory conduits; their body depressed instead of being compressed; and on account of the relative length of their tail, which is never prehensile. From the Geckotida, in the form and inequality of the length of the toes, the movements of the tongue, and the presence of movable lids. From the Iguanada, in the scales of the trunk, the absence of a dorsal crest, and the vaginal conformation of the tongue. From the Lacertada, in the difference of the teguments of the head and body, and the form of the teeth. Finally, from the Chalcidida and the Scincida, in the non-rounded form of the trunk, and the distinct origin of the tail, the structure of the tongue, and especially in the form and disposition of the scales.

The teeth of the Varanidae are always flattened at the root, which is lodged in the length of a

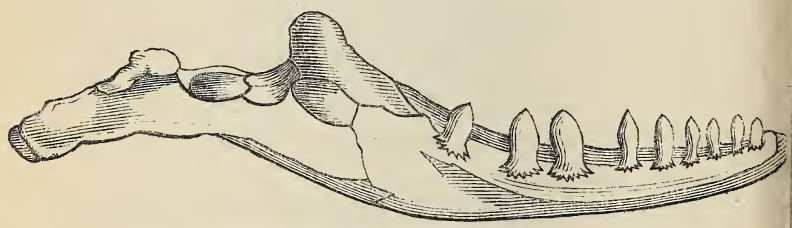

UNDER JAW OF MONITOR.

furrow constituting a common alveolus or socket, having no internal border. The crowns or free portions of the teeth are most commonly pointed and curved backwards. There are no teeth in the palate. The neck is longer in proportion than in other Lizards, which gives them an unusual aspect. 
The whole surface of the body is covered with tubercles, which do not overlap, but are most frequently arranged in transverse series. Some species have the scales of the back set with a ring of small projecting points, the regularity of which is highly ornamental. Those of the lower parts are flat, lengthened, and somewhat sixsided. There is no collar of great scales beneath the neck, but there is a transverse fold of the skin.

The colours of these Lizards vary from black to green more or less deép, with spots which seem to depend on the tubercles, the tints of which, variously grouped, present more or less regular designs, resembling Mosaic work; so that the skin of the Monitors may be employed in the arts like shagreen.

The tongue, unlike that organ in the Families we have described, is fleshy, and very extensile, so that it can be thrown forth to a length double that of the head. The greater part is cylindrical, but the terminal fourth is split into two conical, horny, very flexible points. When retracted, more than half the length is encased in a sort of sheath; and the portion that remains exposed is frequently tinged with bright colours, so as to be easily distinguished by its hue, even when not protruded.

The Monitors are found in both hemispheres; and with the exception of Europe and North America, neither of which have any, the species are equally divided among the great divisions of the globe: viz., four in Africa, four in Asia, four in Australasia, and four in South America.

These are divided into two groups, the ter- 
restrial and the aquatic Monitors, the habits of which differ much from each other. The former have the tail conical and nearly round, and these live in sandy districts or among dry rocks, never frequenting water. They run with rapidity, with a serpentine motion, a mode of progression produced by the long and muscular tail, which helps to push them forward, and aids them in leaping on the prey which they pursue. Some of these were known to the ancients, who regarded them as terrestrial Crocodiles, probably from their size and ferocity.

The aquatic Monitors, which are by far the more numerous, have the tail, which is very muscular and strong, compressed through its whole length ; it thus forms a powerful organ of progression in swimming, especially as its upper surface is frequently surmounted with one or two rows of flattened scales forming an elevated crest. These frequent the banks of lakes and rivers, which they traverse by swimming, and into which they are said to drag their living prey, when they have seized it, in the manner of the Crocodiles.

The food of the Varanidae consists, it appears, of any animals which they have size and strength sufficient to overcome. The terrestrial species hunt after large insects, such as cockroaches, locusts, and beetles; the eggs of ground-building birds, and small vertebrate animals. The aquatic species are still more formidable, for, besides fishes, tortoises, chameleons, and the eggs of birds and of crocodiles, they are said to prey on quadrupeds of considerable size and strength. M. Leschenault de Latour asserts that they associate in bands, and watch at the margins of the rivers to 
attack quadrupeds that come to quench their thirst; and that he has seen them attack a young stag as he attempted to swim across a river, in order to drown him. He even declares that he found the thigh-bone of a sheep in the stomach of one which he dissected. Inhabiting, in many cases, waters which are likewise tenanted by Crocodiles and Alligators, they are vulgarly believed to be beneficial to mankind by giving warning of the proximity of these much-dreaded creatures. This, it is asserted, they do by a hissing, or whistling sound; and though, probably, having little foundation in truth, this reputation has procured them the names of Monitors, Sauvegardes, \&c., and has caused them to be regarded with a measure of popular respect.

\section{Genus Varanus. (Merr.)}

The scales of the body in this genus are set side by side in the skin, and are each surrounded by a ring of small and close-set tubercles: the upper edge of the tail is more or less sharp, and there is a fold beneath the neck, passing transversely in front of the breast.

We illustrate the terrestrial Monitors by the White-throated Varan of South Africa, (Varanus albogularis, KUHL, ) a species the locality of which was unknown, till it was met with by Dr. A. Smith in his late zoological expedition into the interior of that continent. Though he did not obtain any specimens of this Lizard south of Latakoo, yet there is reason to believe that it has been occasionally seen within the limits of he Cape Colony; and the Doctor supposes that 
it is the reptile which is called das Adder by the Boors, and which is so much dreaded from its reputed venomous qualities.

The specimen from which Dr. Smith's description was taken was no more than two feet eight inches in length; but specimens occur which have attained a size nearly double of this. The ground-colour is yellow, variously banded, blotched, and spotted with brown, so as to produce a rich and beautiful effect.

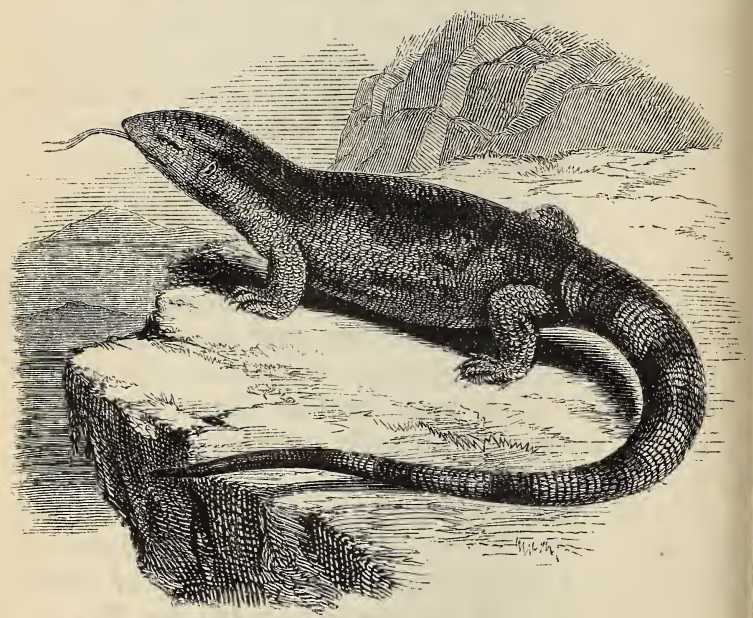

WHITE-THROATED VARAN.

The enterprising zoologist who discovered this reptile thus describes its manners :- "' It is usually met with in rocky precipices, or on low stony hills, and, when surprised, seeks concealment in 
the chinks of the former, or in the irregular cavities of the latter; and when any irregularities exist upon the surface of the rocks or stones, it clasps them so firmly with its toes, that it becomes a task of no small difficulty to dislodge it, even though it can be easily reached. Under such circumstances the strength of no one man is able to withdraw a full-grown individual; and I have seen two persons required to pull a specimen out of a position it had attained, even with the assistance of a rope fixed in front of its hinder legs. The moment it was dislodged it flew with fury at its enemies, who by flight only saved themselves from being bitten. After it was killed it was discovered that the points of all the nails had been broken previously, or at the moment it lost its hold. It feeds upon frogs, crabs, and small quadrupeds; and from its partiality to the two former, it is often found among rocks near to springs or running streams; which fact having been observed by the natives, has led them to regard it as sacred, and not to be injured without danger of drought." *

\section{Genus Teius. (Merr.)}

This limited genus of large Lizards is by some zoologists made the type of a separate Family; but they seem to have so many affinities with the Monitors of the Old World as to be rightly associated with them. In many of their habits they agree with the aquatic forms we have just described, and partake of a similar name and reputation, being commonly known as Sauvegardes.

* Illust. Zool. S. Afr. 
The scales of the back are small, angular, smooth, not overlapping, disposed in transverse bands; those of the belly are flat, four-sided, longer than broad. The tail is rounded, but somewhat four-sided, a little compressed towards the tip. The skin of the throat and breast forms two or three transverse folds. There are femoral pores. The head is covered with large plates or shields: the palate is destitute of teeth; those of the jaw are notched at the summit; the tongue is very long, capable of great protrusion, sheathed at the base, and divided at the tip into two long and slender filaments.

The Sauvegardes are Lizards of imposing appearance; they are stoutly built, and richly coloured; being marked with spots of rich yellow on deep black, or vice versâ.

These Lizards are natives of the tropical parts of America. They attain a considerable size, frequently measuring four or five feet in length. According to MM. Duméril and Bibron, they generally inhabit the fields and borders of woods, but never climb trees; they appear also to frequent sandy arid tracts, and it is said they excavate burrows, in which they lay themselves up for the winter. Sometimes, in their efforts to elude pursuit, they come upon a lake, pond, or river, when, as we are informed by D'Azara, in order to avoid the danger that menaces them, they plunge in and do not leave the water till all fear of harm is past. These Lizards have not indeed webbed feet, as MM. Duméril and Bibron observe, but under these circumstances their long and compressed tail becomes without doubt a sort of oar, which well answers their purpose. 
D'Azara states that they feed on fruits and insects, as well as on toads, serpents, young chickens, and eggs; also that they are fond of honey; and that in order to procure it without fear of the bees, they come forward at intervals, and each time as they run away, they give the hive a blow with their tail, till by repeated attacks they weary out the industrious insects, and drive them from their home.* It is not certain that the Sauveguardes are frugivorous; but there is no doubt that they feed on insects, for MM. Duméril and Bibron found remains of them in the stomachs of all the individuals which they opened. In one they found the fragments of Coleoptera and the remains of caterpillars; in another, portions of skin and bones which had certainly belonged to a common Ameiva.

But two species of this genus are recognised, of which we select for illustration the Teguixin (Teius teguixin, LINN.), as the longest and best known. It is well figured in Madame Merian's splendid but not always faithful plates on the insects, \&c., of Surinam, whence some naturalists, in honour of that lady, have distinguished the species by her name Monitor Merianc.

This noble Lizard is reported to attain the length of four or even five feet, and a thickness proportionate. Its ground-colour is a deep velvety black, beautifully varied with rich yellow spots, sometimes irregularly scattered, sometimes arranged in transverse bands, and sometimes in two longitudinal stripes running the whole length of the body. The face and whole under parts are yellow banded with black, and the posterior

* This sagacity seems somewhat apocryphal. 
half of the tail is ringed with alternate bands of the same colours.

The Teguixin is spread over the greater part of South America, from Guiana to Brazil ; it is also attributed to the West Indies, but we think erroneously, though it may possibly occur in

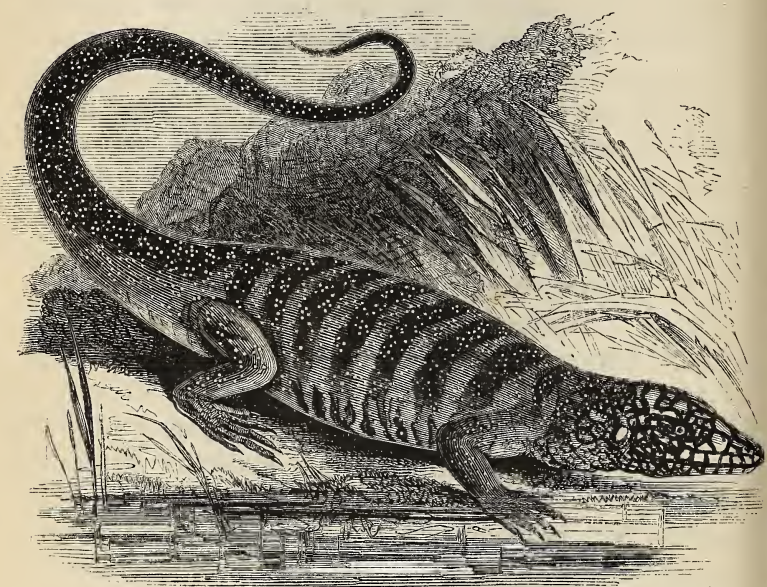

WHWWER

TEGUIXIN.

Trinidad. Our knowledge of its habits is principally derived from the great naturalist of South America, D'Azara. He asserts that though it readily takes to the water as a refuge from danger, it does not swim, but sinks and walks along at the bottom. It fights with resolute courage when attacked or captured, biting with great severity and maintaining its grasp with inflexible 
pertinacity. It manifests much ferocity also in the seizure of its animal prey. Its flesh is eaten, and highly esteemed; nor are its excellences esteemed only by the epicure; for a medical value is attached to rings of the skin stripped from its tail, which are worn by the simple natives of those regions as preventives of paralysis, and curatives of painful humours.

\section{Family VI. Lacertade.}

\section{(Lizards.)}

The two species which constitute the only British representatives of the vast Saurian Order are members of this Family, which is known by the following characters :-

The body is long, slender, and elegant, without spines on any part; the toes are free, long, and very unequal; the tongue long, extensile, sheathed at the base, and terminating in two long slender points; there is a collar round the neck, formed by a transverse range of broad scales, separated from those of the breast by a space covered with minute ones, and overlapping them; a part of the bones of the skull projects over the temples and orbits; the palate is in general furnished with minute teeth, and those of the jaw are placed on the same line, and have a cutting edge.

The upper parts of the body are covered with small overlapping scales; the top of the head and the temples are covered with broad plates or shields, of various but regular forms, the margins of which are in contact. On the slight 
variations of form or relative position in these plates, generic distinctions often rest, and hence, for the sake of perspicuity in description, these have received names, which we here enumerate, copying the accompanying illustration from Professor Bell's beautiful work on British Reptiles.

The plate marked 1 is termed the rostral ; 2 , the

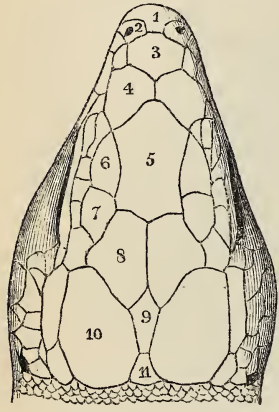

HEAD OF LIZARD. nasal ; 3, internasal; 4, fronto-nasal ; 5 , frontal ; 6 , anterior palpebral; 7 , posterior palpebral ; 8, frontoparietal ; 9, inter-parietal ; 10, parietal ; 11, occipital.

The scales of the tail, which are arranged in distinct rings or transverse bands, are long and narrow, especially towards the tip of this organ. The lower parts of the body are clothed with broad plate arranged lengthwise in several rows; not overlapping, but in contact at their margins.

The femoral pores, which we have before mentioned, either as present or absent, in other Saurian groups, are always found in the Lacertada. " They consist, probably," observes Professor Bell, "of very small follicular glands, each placed in a scale, the middle of which is pierced by the opening of the follicle. In some, the scale is very little larger than the pore, and appears almost like a minute tube; in others, the scale is larger and triangular. The use of these pores 
is not known. They vary exceedingly in number, even in the same species: in this respect, therefore, they afford no distinctive characters."

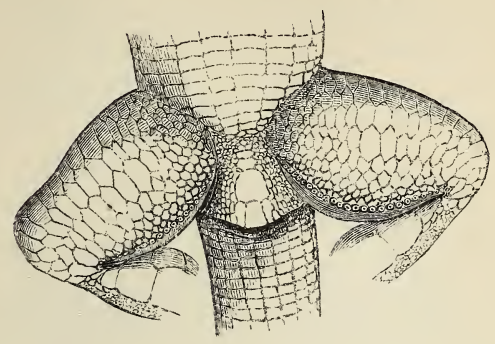

FEMORAL PORES OF AMEIVA.

The Lizards are confined to the Old World, where the species are numerous. None of them attain a large size, but the colours of most are elegant and beautiful, and some shine in the most gem-like radiance of green and gold. Their graceful slender forms, rapid motions, and gay tints, associated with the fairest weather of summer, and the sunniest spots of the country, cause them to be generally looked upon not only without alarm, but even with admiration; and, we may add, that there is an expression so meek and gentle in the countenance of the Lacerta, that physiognomy would be greatly at fault if it were found connected with poisonous fangs, or ferocious propensities. Indeed their bright eyes as they timidly peep from under the overhanging leaves, and the rustling that their fleet steps make as they dart away among the herbage, are felt to be as poetical accompaniments of rural 
scenes as the flowers and the birds. Thus Byron says, -

$$
\text { “— The green hills }
$$

Are clothed with early blossoms; through the grass

The quick-eyed Lizard rustles, and the bills

Of summer-birds sing welcome, as ye pass."

And Moore, whose poetry so faithfully reflects the beautiful in nature, speaks of

"Gay Lizards glittering on the walls Of ruin'd shrines, busy and bright, As they were all alive with light."

\section{Genus Zootoca. (WagL.)}

The distinctive characters of this genus are the following. The throat is furnished with a distinct collar; the nostrils are placed near the outer and lower margin of the nasal plates; there is a bony plate over the orbits; the temples are covered not with plates, but with close-pressed scales; the scales of the back are lengthened and six-sided; the palate is destitute of teeth; the femoral pores are small and round, so as almost to form tubes. The young are produced alive; the membrane of the egg, answering to the shell, being ruptured either immediately before, or in the moment of, birth.

The most common of our native Lizards is of this genus, the Nimble or Viviparous Lizard (Zootoca vivipara, JACQ.), whose history Professor Bell thus pleasingly records :--

"This agile and pretty little creature is the common inhabitant of almost all our heaths and banks in most of the districts of England, and extending even into Scotland: it is also one of 
it. Thus it will often take a great number of the smaller insects, preferring those of the dipterous order ; though it will not refuse many of the coleoptera or orthoptera, if they be not too large. "Instead of depositing her eggs in the sand to be hatched by the warmth of the sun, the female of the present species retains the eggs within the oviduct until the young are ready to leave them, and they are produced alive. As in all the ovo-viviparous reptiles, the covering of the egg is very thin, and merely membranous. In this respect they differ from those which deposit their eggs before the embryo is formed. In the latter case a more efficient protection is necessary, and the covering is either calcareous, as in the Tortoises and Crocodiles, or of a substance resembling parchment, as those of the Snakes and most Lizards. In the Viper, which also produces its young alive, the covering, as in the present animal, is extremely thin and very easily torn; and there is reason to believe that the laceration of this membrane and the emancipation of the young take place in, and are occasioned by, the very act of parturition.

"As the young ones are occasionally found with the mother, there is some reason to believe that these little animals are not wholly devoid of the instinct of parental care and tendance; but it is scarcely probable that the exercise of this feeling is ever very powerful, or that it endures for any considerable period. The young, when brought forth, are fully formed and capable of running about, and very shortly afterwards of taking their own food. The usual number is from three to six. 
"Although I have alluded to the sun's influence as being the means of hastening the evolution of the embryo in the oviparous reptiles, it is not to be concluded that the same source of warmth is unnecessary in the present and similar instances. The only difference is, that in the ovo-viviparous species the solar heat is communicated to the embryo through the medium of the mother; and hence we often see the pregnant female, about the month of June, constantly basking in the sun, and lying in such a position as to expose the body most fully to his influence. Every one who has watched the habits of our native reptiles must have seen the same circumstance in the gravid female of the Common Viper, and may have observed how much more reluctantly and tardily she leaves the genial spot than the male." *

Mr. W. C. L. Martin also thus speaks of the agile movements of this pretty and familiar little reptile:- "It is astonishing to see how rapidly, when alarmed, these agile little creatures gain their burrows, or disappear from view, diving beneath the intertangled vegetation: they seem gone in the twinkling of an eye. Not less prompt and rapid are they in catching their prey; the moment an insect comes near them, or settles on a leaf within due distance, their bright eyes mark it; the next instant it is seized and swallowed: the act is wonderfully quick and instantaneous. The sight of these animals is indeed very acute, and their hearing appears also to be by no means deficient; we have seen them on the slightest noise, on the snapping of a branch, or a rustle made among the leaves, dart off to their burrows,

* Brit. Rept. 34 . 
and after a little time cautiously make their reappearance, and on the least alarm again seek refuge in their retreat." *

Few persons can have paid any attention to these reptiles without having been struck with a phenomenon which, when observed for the first time, seems singular in the extreme,-- the facility with which the tail breaks off on the slightest violence. We well remember the astonishment with which we first witnessed the circumstance, and the painful feeling of compunction with which we regarded the writhing fragment left in our fingers, with its white projecting muscle, slightly bleeding, and thought of the involuntary mutilation that we had committed. We were not then aware of the rapidity with which the lost organ would be reproduced.

Dr. Drummond has described his surprise at a similar incident:-" Being on the sea-shore at Pulo Bay, in Sardinia, and searching for specimens of natural history, I observed a large Lizard running for shelter under a heap of stones. I was just in time to seize it by the end of the tail, but suddenly the resistance made by the animal to my attempt to drag it from its hiding-place ceased, and I gave it up for lost; but I as suddenly had cause for alarm myself on seeing what appeared to be a small Snake leaping with great agility about my feet, and springing as high as my knee. I instantly started out of its way, and watched it at a respectful distance, when I found that it was the tail of the animal, which I was not before aware could so easily separate." $\rightarrow$

This singular phenomenon is doubtless depend* Pict. Museum. ii. 94. * First Steps to Anatomy, 86. 
ent on a peculiarity of structure no less singular, first noticed by Cuvier. That illustrious physiologist considers it a very interesting fact that a great number of the vertebræ of the tail in the common Lizards are divided in the middle in a vertical plane into two portions; and that these portions are separated with even more facility than two contiguous vertebræ at the point of articulation; and this for the simple reason that the articulation is complicated, formed of many irregularities of surface (apophyses), and strengthened by ligaments, while the adhesion of the two parts of each vertebra is retained only by the continuous periosteum (or membrane that invests the bone), and by the surrounding tendons. This structure he had observed besides in the Iguance and the Anoles, and is of opinion that it would be found in all the genera which, like those mentioned, are subject to the rupture of the tail. "Every one knows," adds this anatomist, "that the tail shoots out again after having been broken, but neither the skeleton nor its integuments are, in that case, the same as before the rupture. The scales of the skin are generally small, without ridges and without spines, though they may have had the contrary qualities in the original tail; and internally, instead of the numerous vertebræ, with all their apparatus of apophyses and ligaments, there is nothing but a long cartilaginous cone of one piece, which only presents annular wrinkles, numerous indeed, but scarcely at all elevated." We have some reasons for thinking, however, that in time the reproduced tail would assume at least the exterior appearance, if not the interior structure of the original member. 
Like most of the tribe, the Viviparous Lizard varies considerably in its colours and markings. The most common variety is of an olive hue, with a line of dark brown down the back, and a band of the same down each side, with rows of black spots between; the under parts are, in the male, bright orange, spotted with black,-in the female pale greyish-green, without spots. Six inches is the average length of the adult male.

\section{Family VII.-ScINCIDA.}

\section{(Snake-Lizards.)}

There is not perhaps in the whole circle of zoology, a more beautiful example of the gradation between forms whose extremities are widely distinct from each other, than is presented by the gradual and almost imperceptible transition of the Lizards into the Serpents. If we look at a Chameleon, or an Iguana on the one hand, and then at a Rattlesnake or a Cobra di Capello on the other, they seem almost as remotely separated as animals of the same class can be; and yet so minute are the steps by which we are led from one to the other, that it is impossible with any satisfaction to draw a line that shall divide them, other than such as is merely conventional and arbitrary. Pressed by this difficulty, while some zoologists, as Mr. Gray, separate the Lizards from the Serpents by a third order, called Saurophidia, constituted expressly for the reception of these intermediate and transition forms, others, with Merrem have preferred to consider the whole of the scaled reptiles as forming but a single Order. 
Some of the steps of this beautiful gradation, by which the four long-toed and muscular limbs that mark the Lizard pass away, and leave no trace in the lithe cylindrical Serpent, are thus graphically enumerated by Professor Bell. "From the well-known family of the Scinks (Scincida), with their true legs and five-toed feet, down to the Slow-worm (Anguis fragilis) and its immediate congeners, every possible gradation is to be found in the development of the anterior and posterior extremities. Agreeing, as they all do, in the Saurian character of the structure of the head, the consolidation of the bones of the cranium and jaws, and the narrow and confined gape, so different from those parts in the true Serpents, they yet approach the latter in the comparative length of the bodies, and in the gradual diminution and ultimate disappearance of the extremities. In the genus Scincus, for instance, the limbs are already less robust than those of the true Saurians; the two pairs are also more distant from each other, in consequence of the greater comparative elongation of the body. There are as yet five perfect toes on each foot, which, however, are shorter and more even in their relative proportions than in the true Saurians. These deviations become increased in the genus Chalcides, and still more in Seps, which has a very elongated body, the limbs extremely small, and the toes only four or three on each foot. In Monodactylus a further reduction takes place in the development of the limbs, which have dwinlled to a mere little undivided finger; they are till, however, four in number; but in the genus Bipes the anterior ones have wholly disappeared, 
and are found in a rudimentary state under the integument, the posterior ones constituting only small undivided processes. These also being removed, the Ophidian form of the present genus, [Anguis] and those of Tortix, Typhlops, and others, with all the Amphisbanida, succeed, in which the bones of the shoulder, the sternum, and the pelvis, exist in a more or less rudimentary condition; and lead us towards the true Snakes, in which all these parts are lost, excepting the rudiments of a posterior extremity, which in the Boa appears externally in the form of a small horny hook, or holder, on each side of the vent. In the Serpents, the gape, too, has assumed its extreme power of extension, from the bones of the jaws and other parts of the face being separate; and in most of them the scales, which in the former groups were similar on the upper and under parts of the body and tail, are small and imbricated above, whilst beneath they assume the form of broad transverse plates." **

The Scinks have the head covered with large horny plates, of angular forms, in contact with each other at their edges, with the sutures or divisions always distinct: the neck is of the same size as the breast; the body and limbs are clothed with scales, more or less angular, frequently wide, with a somewhat rounded edge, disposed in quincunx (or like the meshes of a net), and overlapping each other, much like the scales of a fish. The back is rounded, without any crest; the belly is also more or less rounded, and covered with scales similar to those of the back. The tongue is free, fleshy, not very thick, slightly

\section{* Brit. Reptiles, 40 .}


notched at the tip, and covered either totally or partially with scaly papillæ.

Thus the Scincide are at once distinguishable from all the Saurian Orders, except the Lacertade, by the broad plates which cover the head; and from the latter by the belly being clothed with scales not diverse from those which cover the rest of the trunk.

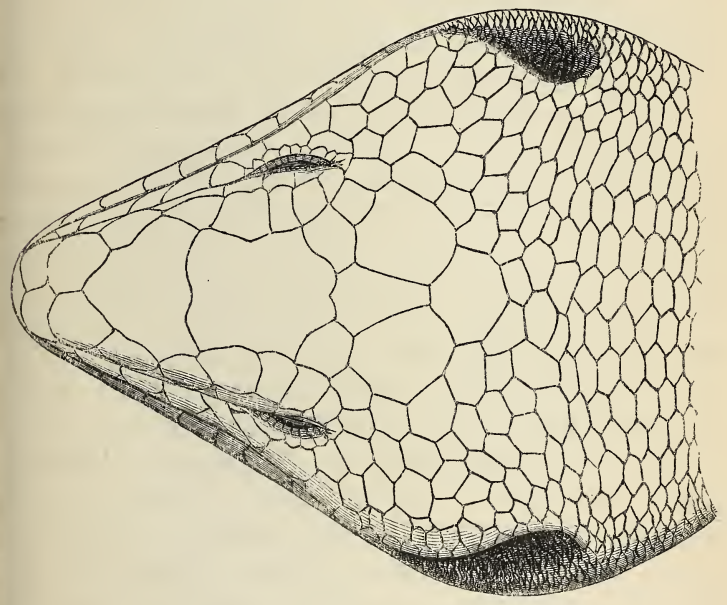

HEAD OF GALLY-WASP.

The Scinks are a harmless race, for the most part living upon insects, slugs, and worms; but one of the most typical species, the great Gallywasp of Jamaica, we have found to feed on fruits and other vegetable substances. Of their reproduction little seems known, but as the Gallywasps, the Mabouyas, and the Slow-worm are 
viviparous, perhaps the same is true of the whole Family. They are commonly agile creatures, and the shortness of their limbs, and the smoothness of their scales, enable them to glide through small apertures with facility.

The geographical range of the species is very wide, they being spread, as MM. Duméril and Bibron observe, over nearly the whole surface of the globe, for they are found in very high latitudes, even in countries where the lowness of the temperature would seem to forbid the existence of Reptiles; thus the Slow-worm ( $A n$ guis fragilis), for example, is found as far north as Sweden, and perhaps farther. Their geographical distribution is otherwise remarkable. Europe does not possess a single species which is peculiar to itself, for though seven species are found there, they are all shared with Africa, and two of them also with Australia and Polynesia. Africa, besides these, has eighteen of its own; seventeen are peculiar to Asia, and three others it shares with America or Polynesia. Sixteen species are American, but one of these is also Asiatic, and another is cosmopolite. Australia and Polynesia are the regions richest in the Scincida, for they possess forty species, four only of which are common to other divisions; and it is remarkable that all the other Saurian Families are comparatively deficient there.

\section{Genus Celestus. (Gray.)}

The nostrils in this genus open on the sides of the muzzle, in the nasal plate; the tongue is notched at the tip, clothed with papillæ, which 
are scale-shaped in front, and slender or bristleshaped behind; the teeth are conical or rounded; the palate is not furnished with teeth, but is furrowed lengthwise; the muzzle is somewhat obtuse; there are four feet, each terminating in five unequal toes, which are compressed, not toothed at their edges, and furnished with claws; the palms and soles of the feet are set with tubercles; the tail is conical, or slightly compressed, and sharp-pointed; the scales are marked with numerous stria, or delicate lines.

One of the largest species of the

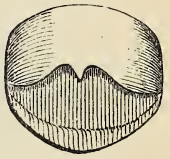

SCALE OF Family is the Gally-wasp or GullyGALLY-WASP. asp of Jamaica (Celestus occiduus, GraY), which grows to about two feet in length, and nine inches in circumference. Its head is large, and somewhat triangular, being pointed at the muzzle and swollen at the occiput; the legs and feet are very small, but perfectly formed. Its hue is pale yellow, irregularly spotted and dashed with brown, but the head is black.

The Gally-wasp inhabits marshy lowlands in the island above named, where it forms burrows in the soft earth by means of its short paws. These excavations resemble those of the Landcrab (Gecarcinus ruricola), but are deeper and more tortuous. The animal is nocturnal, rarely coming forth till after the heat of the day has begun to abate. It is not very timid, but will sit in the mouth of its hole, and retracting the skin of its lips, show its teeth at an intruder like a dog. Great dread is entertained of the bite of this reptile, which is held to be venomous. 
That its muscular powers are great, there is no doubt, and that its blunt teeth would painfully bruise the flesh, and produce an injury perhaps more difficult to be healed than even a lacerated

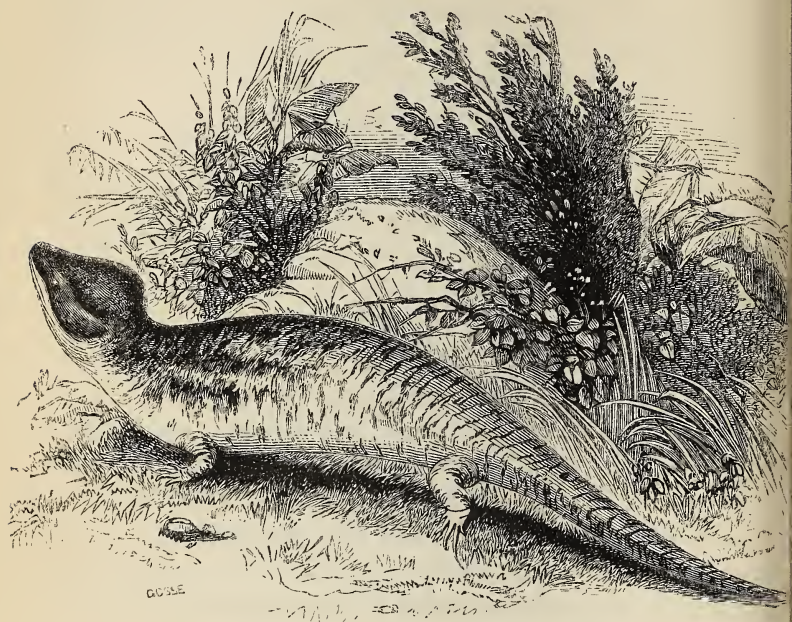

GALLY-WASP.

wound, is not improbable. With all our inquiries made in the island, we have never been able to trace any direct accounts of serious mischief done by this animal; and those which seemed most circumstantial of second-hand narratives are such as in a great degree may be accounted for by the imagination,-the fears of the patient, in the case of a bite, being very highly excited. The creature is acknowledged, however, to be inoffensive, biting only in self-defence, when accidentally trodden on, or attacked. 
In the stomachs of such individuals as we have dissected, we found only vegetable food; fragments of large fruits, bitten off but not masticated; and the soft white bases of the spongy leaves of bulrush were conspicuous. The flesh has been cooked and eaten by those who could overcome the general aversion with which the animal is viewed, and it was found to be excellent.

The female brings forth her young alive; these are numerous, for we have taken seventeen young, perfectly formed and nearly ready for the birth, from the body of one mother. These were about five inches in total length, of which much more than half belonged to the tail, a proportion very different from that of the adult.

\section{Genus $A_{\text {NGUIS. }}$ (Linn.)}

The great disparity of form which we have already alluded to between the genera of the Family before us, induces us to select two examples for its illustration. In the genus Celestus, the limbs, though small, are perfectly formed, and furnished with the full number of perfect toes; the body is thick and stout, and the whole appearance Lizard-like. In the genus Anguis, there is not the slightest appearance of any external limbs, the body is very long, slender, and cylindrical, and the whole appearance is Snake-like. Indeed so completely is this the case, that not only by unscientific observers, but by such men as Linnæus, Cuvier, and other illustrious zoologists, the Slow-worms have been arranged with the Serpents. Yet the agreement is merely superficial; they certainly form, as 
already remarked, a beautiful and interesting link between the Lizards and the Snakes; but their whole anatomical structure, and other peculiarities manifest that their true affinities are with the former rather than the latter.

The technical characters of the genus Anguis are as follows: the body and tail are cylindrical and obtuse; the scales are smooth, overlapping, nearly equal on the upper and under parts; the head is covered with about nine larger plates; the drum of the ear (tympa-

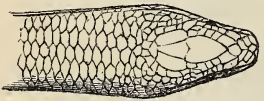
num) is concealed beneath the skin, but communicating with the air, according to MM. Duméril and Bibron, by a minute linear orifice; the teeth of the

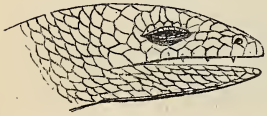
jaws are hooked and compressed; there are none on the palate; the eyes are furnished with three lids; there is no Head of sLow-worm. external trace of limbs, but the bones of the shoulders and of the pelvis exist in a rudimentary form.

The common Slow-worm (Anguis fragilis, Linn.) is often called the Blind-worm, from the minuteness of its eyes, which are, however, sharp and brilliant. The former appellation refers to the sluggishness of its movements, and the specific term fragilis, to the brittleness of its body, when the muscles are contracted from sudden fear. If laid hold of and pursued, instead of attempting to escape or to defend itself, it contracts itself to such a degree of rigidity as to be easily snapped in two.

Twelve inches may be considered the average 
length attained by this reptile, though it has been known considerably longer. It is nearly of equal thickness throughout, but rather more slender towards the tail, the tip of which is abrupt. The colour is brownish grey, with a silvery gloss;

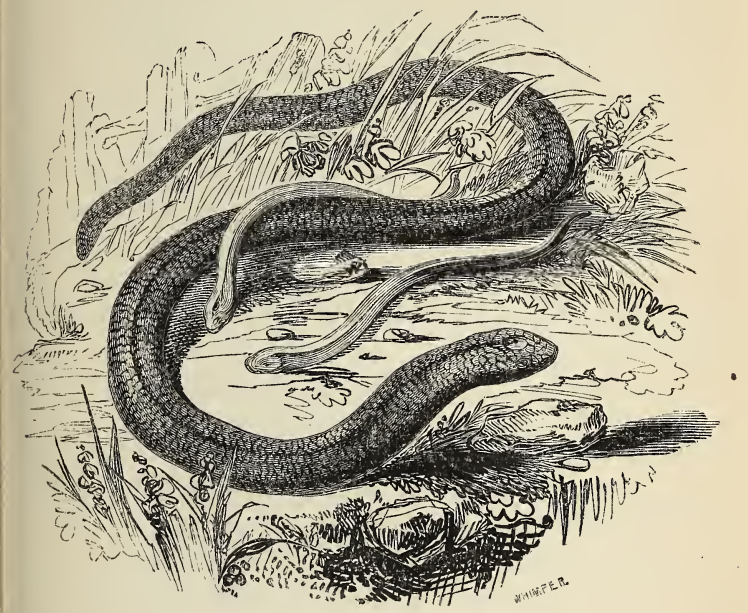

SLOW-WORM.

several rows of obscure dark dots run down the sides, and a black line down the middle of the back. In some varieties, however, these marks are scarcely visible. The under-parts are bluish-black.

The Slow-worm is spread over nearly the whole of Europe, from Sweden and Russia to the shores of the Mediterranean: it is found in the Swiss Alps at an elevation of nearly 6000 feet; it is well known in every part of Great Britain, but 
has not been found in Ireland. With the common propensity to attach venomous qualities to all reptiles, the vulgar in our own country suppose the inoffensive little Slow-worm to be highly poisonous, and this false notion is shared by many whose powers and opportunities of observation should have taught them better. Shakspeare talks of it as "the eyeless venom'd worm," and speaks of "the blind-worm's sting" among the horrors which are to be boiled " $i$ " the charmed pot" of the witches. Dr. Borlase, as cited by Pennant, speaks from hearsay of a man in Oxfordshire who had lost his life by the bite of a Slow-worm, which, however, the reptile could not have been, from the description which he himself gives.

No animal, in fact, can possibly be more harmless than the vilified Slow-worm. "Even when handled roughly," observes Professor Bell, "it rarely attempts to bite; and when it is irritated so as to induce it to seize upon the finger, the teeth are so small as scarcely to make an impression."

Like all the other reptiles that inhabit these islands, the Slow-worm retires to a place of security on the approach of winter, which it passes in a state of insensibility. Sometimes it contents itself with hiding under a compact mass of decaying leaves in a sheltered situation, but more commonly it penetrates into the soft earth, where it is covered with heath or brushwood, forming burrows by means of its smooth muzzle and polished body, to the depth of three or four feet, describing in its course "different circuits, and having several issues." It comes forth earlier in the spring than any other of our Snakes or 
Lizards; but Lacépède asserts that it continues to live in its burrow, coming up to obtain air and food, when it raises its head out of its hole ready to retreat on any alarm. "Even in the winter," says Mr. Martin, "it sometimes does this, though snow may be on the ground, if the sun be shining with a warm though transient gleam." * In summer it may frequently be seen on sunny banks and beneath hedges, enjoying the warmth and basking in the genial beam: it is easily captured, and as easily killed, for its fright produces the rigid brittleness already described, instead of quickening its efforts to escape.

The food of the Slow-worm must of necessity be very small, for the mouth not being dilatable, as in the true Snakes, it cannot possibly receive such prey as Frogs, Toads, and Rats, which have been absurdly assigned to it. Professor Bell has found insects in its stomach, and M. de Sept Fontaines asserts that it will readily feed on earth-worms, even of six or seven inches in length. But yet another prey seems to be still more acceptable, according to the following very interesting note by Mr. Daniel.

"A Blind-worm that I kept alive for nine weeks, would, when touched, turn and bite, although not very sharply: its bite was not sufficient to draw blood, but it always retained its hold until released. It drank sparingly of milk, raising its head when drinking. It fed upon the little white slug (Limax agrestis, LrNn.) so common in fields and gardens, eating six or seven of them, one after another; but it did not eat every day. It 
invariably took them in one position. Elevating its head slowly above its victim, it would suddenly seize the slug by the middle, in the same way that a ferret or dog will generally take a rat by the loins; it would then hold it thus sometimes for more than a minute, when it would pass its prey through its jaws, and swallow the slug head foremost. It refused the larger slugs, and would not touch either young frogs or mice. Snakes kept in the same cage took both frogs and mice. The Blind-worm avoided the water; the Snakes, on the contrary, coiled themselves in the pan containing water which was put into the cage, and appeared to delight in it. The Blind-worm was a remarkably fine one, measuring fifteen inches in length. It cast its slough whilst in my keeping. The skin came off in separate pieces, the largest of which was two inches in length; splitting first on the belly, and the peeling from the head being completed the last." *

For some other details of the history of this little reptile, we quote Professor Bell, from whose elegant work on British Herpetology, most of the above particulars have been gleaned. "One very interesting point in its habits, is its being ovo-viviparous. Like the Zootoca vivipara, the young of this animal are hatched before they come into the world, and it is probable that in this case, as in that of the species just named, as well as in the Viper and the Rattlesnake, the rupture of the membrane of the egg takes place during parturition. The female is said to go with young

* White's " Nat. Hist. of Selborne " (Bennett's edit.) 
about six weeks or two months: there can be no doubt, however, that the duration of this period must depend upon the temperature to which the animal is exposed. They are produced in June or July. The number of young ones produced at one birth varies from seven to twelve or thirteen. When brought forth, they are from eighteen to twenty-two lines in length. The young become very active almost immediately after their birth, and soon learn to feed upon small soft insects, and probably small worms, snails, or slugs.

"The shedding of its skin is performed by this species in the same manner as by most of the true Ophidians. It is, in fact, taken off in one piece, when the animal is at liberty and strong enough to effect this; and, like the others, it leaves its skin turned inside out, attached to the brushwood, or other substance which it has employed to entangle or secure it as it was coming off. It is, however, stated, that in some cases it is inverted only as far as the vent, and that the tail slips out of its covering 'like a sword out of its scabbard." "*

* Brit. Rept. 44. 


\section{ORDER IV. OPHIDIA.}

\section{(Serpents.)}

The appearance of the animals of this Order is, for the most part, exceedingly beautiful. The smooth roundness of the body, unbroken by any projections; its slenderness tapering gradually away to a point; the cleanness and polished surface of the gleaming scales with which they are clothed, together with their symmetry and the closeness with which they overlap each other; the hues almost always gay, and often brilliant, often finely contrasted and arranged in varied and tasteful patterns, and often reflecting an opalescent lustre; and, above all, the lithe and graceful motions throwing the animals into the most elegant curves and spires, cannot be contemplated by an observer, unblinded by prejudice or dread, without admiration. Yet it cannot be denied that there is another side to the picture: the knowledge that many kinds are armed with a most deadly potency of mischief; the difficulty of knowing (at first sight, and by the unskilled, at least) how to discriminate between the venomous and the innocent; the fierce boldness and preparedness for war which almost all manifest, if disturbed; and the threatening aspect with which, open-mouthed, they face an adversary, combine with a something of malignity in the eye and physiognomy, more or less observable in all, to inspire fear and aversion. 
Perhaps this last feature depends on the flattened form of the head, the glare of the eye, which is not furnished with eyelids, and frequently has the pupil linear), and the extreme width of the gape.

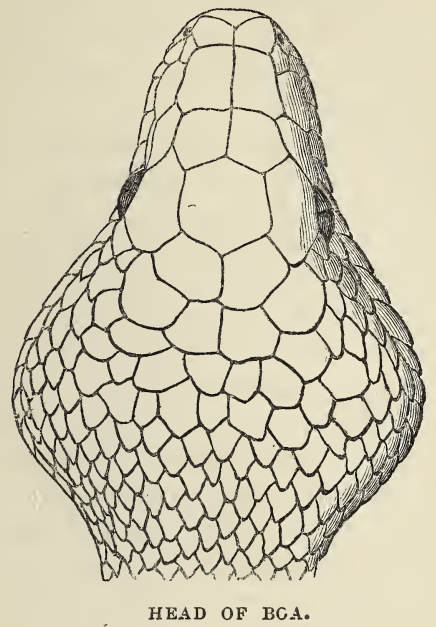

In the Serpents, the four limbs which we have een gradually to become obsolete in the latest orms of the Saurian group, are no longer found, ither in external projections or in internal bones; here is neither breast-bone, nor pelvis, nor houlder. In one Family, however, there are two 1orny spurs or hooks on the hinder part of the ody, which are connected with minute bones mbedded in the flesh, and seem to be the rudinentary representatives of posterior limbs; they re, however, of no use in progression, but answer 
another purpose in the animal's economy. The ribs are immensely numerous and encircle a great part of the trunk; and the free extremities of these form, as we shall presently describe, the ordinary instruments of progressive motion in this Order. The vertebra, or joints of the spine, are connected not by two hollow facets, filled up with cartilage, but by one convex face, filling that which is concave.

With a few exceptions, which form the connecting links with the Saurians, and are but a step removed in structure from the species last noticed, the Serpents are characterised by a remarkable looseness of the bones of the skull, and in particular by the mode in which the jaws are articulated. These reptiles are ordained to prey upon animals whose size much exceeds that of any part of their own bodies, or heads, and yet they are not furnished with any apparatus either of teeth or claws, by which their food may be divided; it must be swallowed whole. The elasticity of membranous viscera, such as the gullet or the stomach, we readily conceive, might be sufficiently great to allow of the passage of large masses of food; but the fixed and unyielding nature of the bones of the mouth in most animals would prevent the possibility of this. In the reptiles before us, however, a singular and beautiful deviation from this ordinary condition of fixity in the bones of the mouth meets the necessity of the case, and allows of an immense expansion of the parts. The structure may be thus familiarly explained. The lower jaw, which is much longer, and extends much farther back than the skull, is not hinged to the upper jaw, 
but is suspended at the end of a long slender bone, which is attached to the hinder-part of the skull by muscles and ligaments so as to be very moveable. It will be readily seen how this contrivance permits a very wide expansion of the posterior part of the lower jaw, which is attained

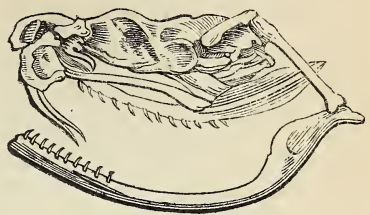

SKULL OF SNAKE.

in a less degree in front by the nature of the union of the two branches, they not being soldered together there as usual, but simply tied by ligaments. Other bones of the skull have a correspondent freedom.

Both pairs of jaws, for the most part, are set with numerous slender acute teeth, having a double curve, and pointing backwards: the bones of the palate also are furnished with similar teeth, so that there are four nearly equal rows of teeth in the upper part of the mouth, and two in the lower. The mode of swallowing prey is as follows:-Some of the front teeth being struck into the victim, one side of the lower jaw is thrust forward as far as the ligaments will allow, when the teeth of that side take a fresh hold, which is retained, while the other side of the jaw performs a corresponding movement; thus by the alternate advance of the two sides of the jaw, which their excessive mobility admits, and by the backward inclination of the teeth allowing the food to move much more readily in one direction than another, this is gradually drawn into the throat, forcing asunder, and dislocating, as it 
were, all the bones of the mouth, as it proceeds, until at length it is deposited in the elastic and expansible gullet.

In many of the species, the teeth of the upper jaw manifest a tendency to increase in size above those of the palate, and to decrease in number. The Water-serpents have but few, but the foremost one is larger than those which succeed it, and is hollowed in a peculiar manner, so as to form a curved and pointed tube, connected with a gland that secretes a poisonous fluid. At length in the most venomous of the whole Order, the upper jawbone is reduced to a small size, carrying a single curved and tubular tooth of great length, which is followed only by others of the same structure, undeveloped, and destined to replace it after its loss by decay or violence.

It is common to represent the poison-fang of a Serpent as simply tubular, or pierced through its centre; this, however, conveys a wrong impression. The substance of the tooth is not pierced at all. Let us suppose the simple tooth of a Boa, or of a common Snake, to be flattened transversely, and its edges then to be bent round until they meet, and to be soldered together, so as to form a tube open at each end. Such is the fang of the Viper, the line by which the edges unite running down the front of the tooth, where it is convex; while the posterior or concave side is that which contains the pulp-cavity or true centre, considered structurally. The union of the edges is incomplete towards the gum, forming an oblique aperture; and the extremity of the tooth is still more so, presenting the form of a very narrow longitudinal groove. 
The tube thus formed communicates with the poison-bag, into which the deadly fluid is poured from glands which lie on each side of the head beneath the eye. Each consists of a number of long narrow lobes, extending from the main duct which runs along the lower border of the gland upwards and slightly backwards. Each lobe gives off smaller lobes from its sides, and each of these is subdivided into smaller secreting sacs; and the whole gland is surrounded by a membrane connected with the muscles, by whose

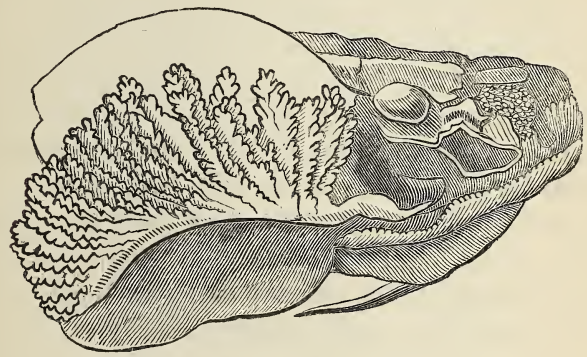

POISON-GLAND.

contraction the several lobes are pressed and emptied of the poison. This fluid is then conveyed through the duct to the poison-bag. "We may suppose," says Professor Müller, "that as the analogous lachrymal and salivary glands in other animals are most active during particular emotions, so the rage which stimulates the venomsnake to use its deadly weapon must be accompanied with an increased secretion and great distention of the poison-glands; and as the action of the compressing muscles is contemporaneous 
with the blow by which the Serpent inflicts its wound, the poison is at the same moment injected with force into the wound from the tip of the perforated fang."

A singular exception to the general structure of the teeth occurs in a South African Snake (Deirodon, Owen), described by Dr. Andrew Smith, which is so interesting that we quote Professor Owen's description of the dentition and its use. The teeth are so small as to be scarcely perceptible; and are besides so soon liable to be lost, that the reptile has been described as toothless. The office assigned to this Serpent is to keep down the inordinate increase of the smaller birds, by preying on their eggs; and, as has been observed, the apparent defect in its dentition is in reality one of those beautiful instances of adaptation of structure to the exigencies of the case, to which every naturalist has so often to advert. "If," says Professor Owen, "the teeth had existed of the ordinary form and proportion, in the maxillary and palatal regions, the egg would have been broken as soon as it was seized, and much of its nutritious contents would have escaped from the lipless mouth of the Snake in the act of deglutition; but, owing to the almost edentulous state of the jaws, the egg glides along the expanded opening unbroken, and it is not until it has reached the gullet, and the closed mouth prevents any escape of the nutritious matter, that the shell is exposed to instruments adapted for its perforation. These instruments consist of the inferior spinous processes of the seven or eight posterior cervical vertebræ, the extremities of which are capped by a layer 
of hard cement, and penetrate the dorsal (upper) parietes of the cesophagus: they may be readily seen even in very young subjects, and in the interior of that tube, in which their points are directed backwards. The shell being sawed open longitudinally by these vertebral teeth, the egg is crushed by the contractions of the gullet, and is carried to the stomach, where the shell is no doubt soon dissolved by the gastric juice."*

The tongue in this Order is slender, and divided into two long and pointed filaments, which are capable of being entirely retracted within a sheath, or of being protruded from the mouth, with great swiftness of motion. Serpents are said to be enabled to lap up fluids with this forked tongue, which, however, seems to be ill suited for such an operation. $\downarrow$ The vulgar notion which associates a hurtful power with the tongue, often spoken of as the "sting," is entirely erroneous.

The mode in which respiration is performed is described by MM. Duméril and Bibron to be as follows:- "The glottis, which has two lips, and represents a very simple larynx, opens in the mouth beneath the sheath of the tongue; by means of the muscles of the os hyoildes [or bone of the tongue], which push it, it is raised so as to be presented in a dilated state behind the back nostrils. The vacuum caused by the action of the ribs in the belly tends to dilate the lung, which through the medium of the trachea, immediately admits the air which is introduced during an inspiration: this is slow, continuing for some

* Odontography.

+ Our European Snakes drink by suction, not by lapping. 
seconds. This air, when it has performed its office, and has been deprived of its oxygen, is expelled in the same manner, but by an inverse mechanism, which is entirely due to the action of the muscles which tend to approximate the ribs to each other. When it is expelled rather briskly, a sort of vibration or hissing is heard."

The learned zoologists just cited have given some interesting illustrations of the absorbent powers of the intestines of serpents. Their fæcal evacuations afford a singular proof of this; for they present, as it were, the dry extract of the animal swallowed, in an entire state; the parts that could not be dissolved remaining unaltered, and absolutely in the same situation that they occupied in the carcase of the animal before it had passed through the whole length of the digestive tube. If, for instance, a rat has undergone this process, one may recognise in the dry and shapeless mass, the place occupied by the muzzle of the animal, the long whiskers of its cheeks, the down which covered the delicate cartilages of its ears, the hairs of various lengths and colours which correspond with those of the back, the belly, and above all, the tail; and finally, even the claws, which remain in their pristine state of integrity. All that was flesh or soft matter in the body has been completely absorbed; the earthy salt, nevertheless, which gave, by means of its union with the gelatine, consistence to the bones, still indicates by its presence, and especially by its colour, the place they occupied. Dissolution, compression, and absorption, have done their work upon this desiccated mass, which still, however, contains the elements of nourish- 
ment for the larvæ of the insects of the Family Dermestida.

When irritated or alarmed, some of the Serpents (the non-venomous ones, at least) have recourse to two very distinct actions, both of which seem to be means of defence. The first is the production of the shrill sound already alluded to, called hissing, by the forcible ejection of air from the narrow glottis. This sound, though so familiarly spoken of as to have become almost proverbial, we cannot help thinking, is uttered rather infrequently; as we have seen species of Colubridee and Boadee excited to rage, but do not remember ever to have heard the "hissing" in question. MM. Duméril and Bibron also state that they never could hear more than a sort of blowing (soufflement), such as would result from the rapid issue of a current of air through a simple pipe,-a quill, for instance. The other defence is much more certain, and less likely to be overlooked. It consists in the diffusion of a fetid, sickening odour, so nauseous as to be overpowering. It proceeds from certain glands situated near the orifice of the body. We have remarked in the Boa, that the urine, which is discharged in the form of a butyraceous pulp, like moist plaster of Paris, has the same fetor.

White of Selborne gives the weight of his testimony to both of these modes of defence. "6I wish I had not forgot to mention the faculty that snakes have of stinking se defendendo. I knew a gentleman who kept a tame snake, which was in its person as sweet as any animal while in good humour and unalarmed; but as soon as any stranger, or a dog, or a cat, came in, it fell to 
hissing, and filled the room with such nauseous effluvia, as rendered it hardly supportable."**

The eggs of serpents are enclosed in a calcareous covering, which is not hard and shelly, but tough, somewhat resembling kid-leather, or wet parchment. They are often numerous, and are deposited together, and connected by a sort of glutinous matter. Holes in the earth, in dunghills, or in heaps of decaying vegetable matter, are situations frequently chosen for their reception; and here they are left to be hatched by the heat of the weather, or by that which is developed in the putrefactive fermentation of the surrounding mass. The venomous species, as far as we are acquainted with their habits, are ovo-viviparous, the membrane of the egg being ruptured either before or during parturition.

We have said that the instruments of progressive motion in the Serpent tribes are the multitudinous ribs. The vertebræ of the spine admit of excessive flexibility, and the ribs are jointed upon them in a manner which allows the latter an extent of motion unusually great. The mode in which a Serpent proceeds will be understood from the following observations, the reader bearing in mind that the whole under surface of the body is shod, as it were, with broad plates, or scuta, the hinder margins of which are free. "When the Snake," says Sir Everard Home, "begins to put itself in motion, the ribs of the opposite sides are drawn apart from each other, and the small cartilages at the end of them are bent upon the upper surfaces of the abdominal scuta, on which the ends of the ribs rest; and

* Letter XXV. (1st series.) 
as the ribs move in pairs, the scutum under each pair is carried along with it. This scutum, by its posterior edge, lays hold of the ground and becomes a fixed point from whence to set out anew. This motion is beautifully seen when a snake is climbing over an angle to get upon a flat surface. When the animal is moving, it alters its shape, from a circular or oval form to something approaching a triangle, of which the surface on the

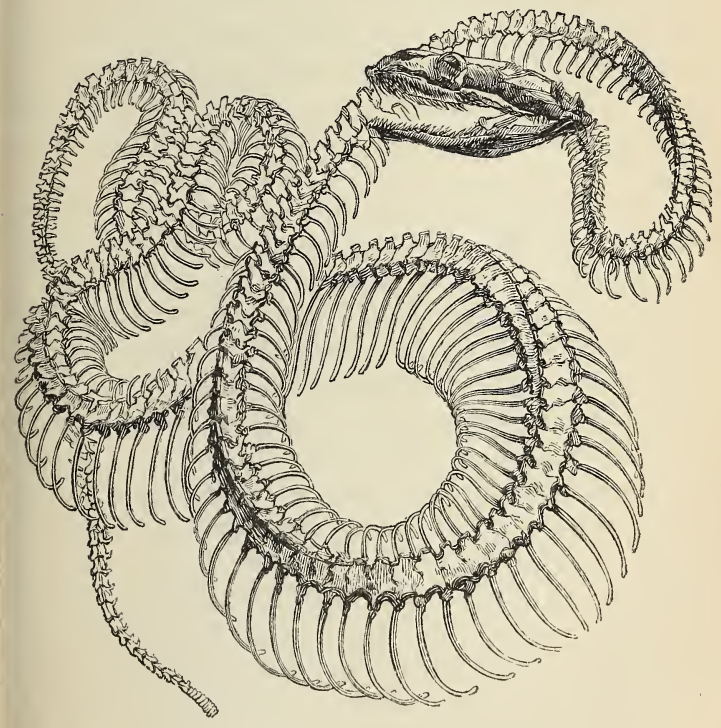

SKELETON OF BOA.

ground forms the base. The Coluber and Boa having large abdominal scuta, which may be considered as hoofs or shoes, are the best fitted for 
this kind of progressive motion.' observation of Sir Joseph Banks during the exhibition of a Coluber of unusual size first led to this discovery. While it was moving briskly along the carpet, he said he thought he saw the ribs come forward in succession, like the feet of a caterpillar. This remark led me to examine the animal's motion with more accuracy, and on putting the hand under its belly, while the Snake was in the act of passing over the palm, the ends of the ribs were distinctly felt pressing upon the surface in regular succession, so as to leave no doubt of the ribs forming so many pairs of levers, by which the animal moves its body from place to place."

It is doubtless by the expansion of these ribfeet, and by the application of them alternately to the surface on which they move, that Serpents are able to glide with facility up the trunks, and along the branches of trees, a feat which we have seen the Colubrida of America and the West Indies perform repeatedly, not (as absurdly represented in engravings) by encircling the tree in spiral coils, but gliding along with the body extended, exactly as a caterpillar crawls, but with far greater speed.

The earth is the sphere of activity of by far the greatest number of the Serpent races: they inhabit various situations, some frequenting woods, others heaths, and many preferring deserted buildings, old walls, and heaps of stones. A few species reside permanently among the foliage of trees; and others there are, which are truly aquatic, roving through the ocean even at considerable distance from the shores. These have the 
hinder parts of the body and the tail greatly compressed, so as to form a vertical oar. Many, if not all, of the terrestrial species, however, are capable of swimming, and will take to the water of their own accord.

The geographical distribution of the Ophidia is very extensive: they are spread over the whole torrid and temperate regions of the globe. With the exception of the Samoa group, the islands of Polynesia are, however, destitute of them. The Order is divided into five Families, $A m$ phisbanade, Boada, Colubride, Viperada, and Hydrophide.

\section{Family I. Amphisbenade.}

\section{(Double-walkers.)}

There are found in this Family of Serpents several traces of structure which belong rather to the preceding Order than to the present. Their food consists for the most part of ants and other small insects, the nature of which does not require that these Serpents should possess the power of dilating the mouth and throat, which we have described as common to the Order; hence the upper jaw is fixed to the skull and the intermaxillary bones, as in the preceding Orders of reptiles, and in the higher animals; while the lower jaw is jointed directly with the skull, and its two branches are soldered together in front. The bony frame of the orbit of the eye is incomplete behind, as we observed it in the Geckotida ; and the eye is so minute as in most cases to be with difficulty discernible in the adult animal; 
in the young, however, it is much more conspicuous.

The head is small, without any enlargement, and without any neck, and the tail is so short as to seem as if it had been abruptly cut off, and the wound simply rounded; so that the whole creature is uniform in thickness through its whole length from point to point. Hence it is difficult at first sight to determine which extremity is the head, and which the tail; and this circumstance, together with the habit which these reptiles have of proceeding with either end foremost, (their uniformly cylindrical shape and the smoothness of their scales permitting this with facility, has given rise to a popular notion very widely spread throughout the tropical parts of America, where these Serpents are found, that they are furnished with a head at each extremity. So wondrous an animal as a Serpent with two heads, is of course presumed to have equally wondrous endowments; it is declared impossible to destroy it by dividing the body in two, for the two heads mutually seek each other after such an accident, and on meeting, the severed parts reunite, and soon heal. Stedman, in his "History of Surinam," alludes to this and other extraordinary virtues ascribed to this "Two-headed Snake." "Another Snake, which I also observed here, is about three feet long, and annulated with different colours. It is called Amphisbæna, from the supposition of its having two heads; and the truth is, from its cylindrical form, the head and tail so much resemble each other, that the error is almost pardonable: besides which, the eyes are nearly imperceptible. This is the Snake which, 
supposed blind, and vulgarly said to be fed by the large ants (termites), is in this country honoured with the name of King of the Emmets. The flesh of the Amphisbæna, dried and reduced to a fine powder, is confidently administered as a sovereign and infallible remedy in all cases of dislocation and broken bones; it being very naturally inferred that an animal which has the power of healing an entire amputation in its own case, should at least be able to cure a simple fracture in the case of another."

The Amphisbenadae are covered with minute close-set scales, highly polished, either square and. set in circular rings around the body, or overlapping, as in the Slow-worms. A range of small pores runs in front of the vent, which is situated almost at the very extremity of the body; the jaws are furnished with a single row of small conical teeth, which are few and distant from each other; the palate is destitute of any. The mouth is very small. There are no poison-fangs, and these reptiles are consequently harmless and inoffensive; those specimens which have been brought alive to Europe are described as dull and inanimate, without grace or activity in their movements; "they crawled slowly about, and when handled, languidly twisted their bodies and ppened their mouths, but made no attempt to oite: their appearance was far from being atractive. One of these animals (Amphisbana fulijinosa), kept alive some time since in the Gardens of the Zoological Society, took milk very freely, and subsisted on it for six months." *

The food of these Serpents, as we have said, * Pict. Museum, ii. 98. 
consists of ants, termites, and other minute animals; and they are said to inhabit the earthy nests and hills of these industrious insects, through which their slender cylindrical bodies and polished scales enable them to burrow with great facility. They are oviparous, laying eggs in such situations, which are very large in proportion, and covered with a parchment-like skin.

The Family contains but a small number of species, which are, however, scattered over the tropical regions of both hemispheres.

\section{Genus Typhlops. (Schneid.)}

In the genus Typhlops are comprised a few Serpents, so small as to resemble earthworms in appearance, which are clothed with small overlapping scales, broader than long, very closely applied. They have the muzzle somewhat advancing beyond the lower jaw, and covered with broad plates; the tongue is rather long and forked like that of the true Serpents; the eye, minute and point-like, is scarcely or not at all visible externally. The body is slender, cylindrical, terminating very abruptly; the vent is close to the extremity. One lung is four times as large as the other.

Species of this genus are found in the warm regions of both continents, and in the large tropical islands. We shall describe that which has come under our own personal notice in Jamaica, where it is popularly known as the Two-headed Snake (Typhlops lumbricalis, LAcÉP.) In this species, which has been by some zoologists ranked as a genus, under the title of Argyrophis, the 
ore part of the muzzle is covered in front with single large plate, the anterior border of which orms a sharp edge: the tail, which is abruptly onical, terminates in a sharp horny point or ipple in the midst of a polished circular plate. this species is about thirteen inches in length,

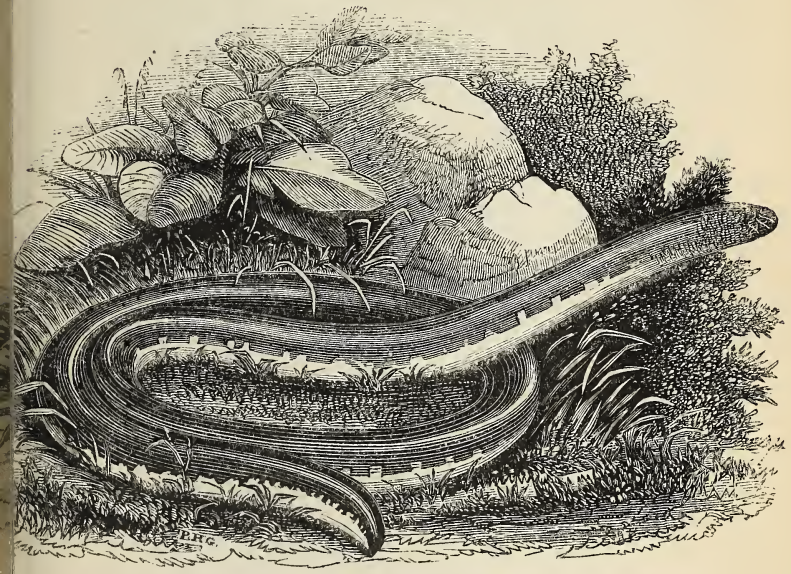

TYPHLOPS.

nd about one fourth of an inch in diameter; s colour above is an uniform pale bluish grey, lat of the under parts a pale yellowish white, metimes tinged with rose-pink. The whole urface of the body is beautifully smooth, and ighly polished during life; but when preserved spirits, the edges of the scales being raised, is appearance is quite destroyed, and the surface rough. 
It is frequently met with beneath large stones but is captured not without some difficulty, as its agility and its powers of burrowing are great As it crawls, it frequently protrudes and retract: swiftly the little white forked tongue, like othes Snakes: and on being held in the hand, the spinous nipple at the tip of the tail is strongly pressed against the flesh, as if its intention wert to wound in defence, but is not capable of more than a slight pricking, which does not pierce the skin. On being put into water, it swim: rapidly and elegantly, undulating the body like a leech. The egg is laid in the earthy nest of Termites, and is no less than an inch and al eighth in length, and five lines in diameter: $i$ is of an oblong form, of a clear buff hue, an of a stiffly membranous texture. The young on being hatched, is perfectly formed and coloured and very active.

\section{FAMILY II. BoAde.}

(Boas.)

All the gigantic Serpents which are the drea of man and beast in the sultry jungles an teeming forests of the tropics, and of which s many tales of terror are told, belong to thi Family. Some of the most interesting and bes authenticated of these narratives we shall pre sently repeat; meanwhile we may observe, tha though the power and the dimerisions of thes enormous reptiles have been popularly exagge rated, and somewhat of fable has mingled wit received statements of their habits, enough re 
mains indubitable to excite deserved astonishment, and to prove that both in size and strength these colossal Serpents are among the giants of the animal world.

The characters of the Family are few, but readily discriminated; the jaws, by a mechanism

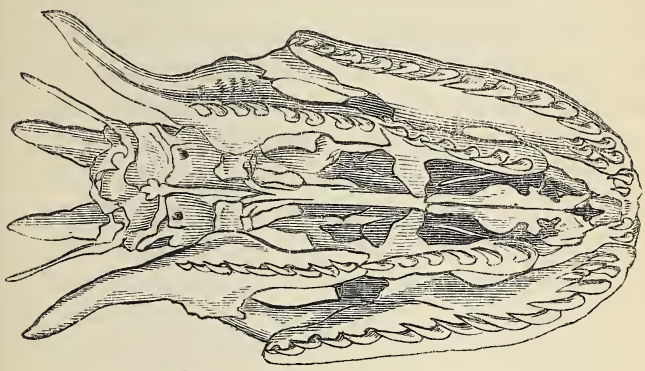

UPPER JAW AND PALATE OF PYTHON.

lready explained, are capable of enormous dilaation; the upper and the lower jaw are furnished

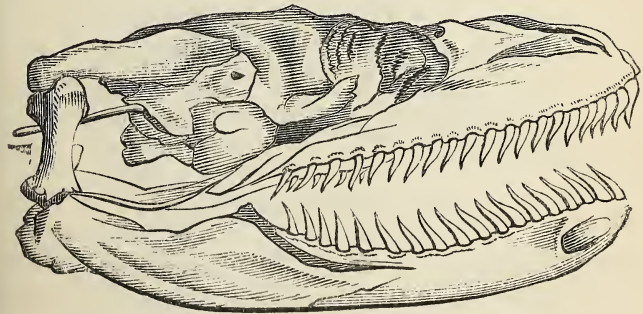

SKULI, OF PYTHON.

vith numerous curved and pointed teeth, nearly qual in length, all pointing backwards, and in 
the palate are two rows of similar teeth: there are no poison-fangs. The hind head is more or less bulging, the body, swelling towards the middle, somewhat compressed, not very lengthened, tapering to the tail, which is short and prehensile. One lung is but half shorter than the other. The body is clothed with imbricated scales, as is also the head,-at least, the hind head: the under surface of the body and tail, however, is covered with scaly transverse plates, arranged in a single series on the body; but on the tail, single in some genera, and in others double.

But that which is most characteristic of the Boadce is the presence of two hooks or spurs, situated one on each side of the vent. These are undoubtedly of great use to the reptile, as helping the prehensile tail to maintain a firm hold
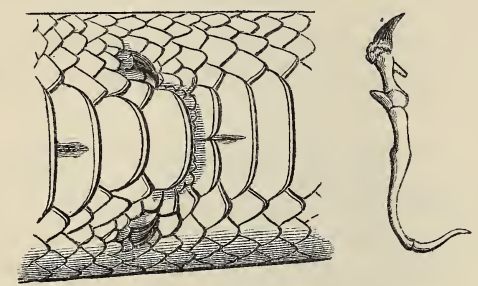

VENT AND HOOK OF BOA.

on the branch of a tree, from which the long body depends, with the head bent up a little above the ground, watching for the approach of prey. But these spurs are undoubtedly the rudiments of posterior limbs, the bones of which, very minute and imperfect, it is true, are detected 
beneath the skin. The accompanying engraving exhibits these appendages as they appear externally in the Boa of Jamaica (Chilabothrus inornatus, Dum.), and the bones of one dissected out of the flesh. Dr. Mayer considers that this spur or hook is a true nail, in the cavity of which is a semi-cartilaginous bone representing the last joint of a toe; this is jointed to a small bone cepresenting the metatarsus, the little projection from the swollen joint above is the tarsus, and the slender bone above is the tibia or leg-bone, mbedded in the muscles, and terminated by $\imath$ slender curved and pointed filament of cartiage jointed to it, which probably represents the vanescent rudiment of a femur or thigh-bone.

The muscles of these enormous reptiles are rery numerous, and their power immense, when xerted, as it is, for the purpose of depriving heir victims of life, in the constrictions of the rreat coils or knots of the lithe body around he prey. The strong bones of large quadrupeds wined in the fatal embrace of one of these Serpents are broken to pieces in a moment by he irresistible pressure, which is not relaxed ill the last motions of life have ceased in the niserable victim.

The mode in which the Boadae seize and ;wallow their prey, is graphically drawn by Sir Robert Ker Porter, in a letter which accompanied noble specimen of a South American species o the United Service Museum. The species s supposed to be Boa scytale (LinN.), and is ineteen feet and a half in length. After menioning that by the colonists it is known by the ames of Water-Serpent, and Deer-Swallower, the 
account proceeds thus:- It is not venomous, nor known to injure man (at least, not in this part of the New World); however, the natives of the plains stand in great fear of it, never bathing in waters where it is known to exist. Its common haunt, or rather domicile, is invariably near lakes, swamps, and rivers; likewise close to wet ravines, produced by inundations of the periodical rains; hence, from its aquatic habits, its first appellation. Fish, and those animals which repair there to drink, are the objects of its prey. The creature lurks watchfully under cover of the water, and whilst the unsuspecting animal is drinking, suddenly makes a dash at its nose, and with a grip of its back-reclining double range of teeth, never fails to secure the terrified beast beyond the power of escape. In an instant the sluggish waters are in turbulence and foam, the whole form of the Colubra is in motion, its huge and rapid coilings soon encircle the struggling victim, and but a short moment elapses, ere every bone is broken in the body of the expiring prey. On its ceasing to exist, the fleshy tongue of the reptile is protruded (taking a long and thinnish form), passing over the whole of the lifeless beast, leaving on it a sort of glutinous saliva that greatly facilitates the act of deglutition, which it performs gradually, by gulping it down through its extended jaws, - a power of extension of them it possesses to so frightful and extraordinary a degrce as not to be believed, when looking at the comparative smallness of the mouth and throat in their tranquil state. After having completely devoured, or rather hidden, its prey in the way described, it becomes powerless as to motion, and 
emains in an almost torpid state for some days, or until nature silently digests the swallowed inimal."

The author of the article BoA, in the Penny Jyclopædia, commenting on the above descripion, and noticing the asserted lubrication of he prey with saliva, makes the following obserations, in which we cannot help concurring, notvithstanding the almost invariable statement of uch a thing, - at least, by unscientific describers : - There is generally in these descriptions an ccount of the fleshy tongue of the reptile, and of ts application to the dead animal for the purose of covering it with saliva previous to the peration of swallowing it. A glance at the ongue of a Boa or a Python will convince he observer, that few worse instruments for such purpose could have been contrived. The deluion is kept up by the mode in which these serpents are sometimes preserved in museums, where they may be occasionally seen with fine rtificial, thick, fleshy, vermilion tongues in the lace of the small, dark-coloured extensile organs vith which nature has furnished them. We have requently watched constricting Serpents while aking their prey, and it is almost superfluous to idd that they never covered the victim with saliva rom the tongue before deglutition. When the rey is dead, and the Serpent is about to swallow $t$, the tongue of the destroyer is frequently hrust forth and vibrated, as if indicatory of the lesire for food; but the mucus is not poured out ill it is required to lubricate the dilated jaws and hroat for the disproportioned feast." *

$$
\text { * "Penny Cyclop." v. } 26 .
$$


The same spirit of fear which made the Crocodile an object of worship among the ancient Egyptians, made the great Boas to be regarded as deities by the inhabitants of Mexico. Peter Martyr tells of an enormous Serpent-idol which the Spaniards found at Campechy, " compacted of bitumen and small stones incorporated together, which was seven and fortie feete in length, and as thicke as a great oxe." And Bullock, in his "Six Months in Mexico," speaks of a noble specimen of a similar idol, almost perfect and of fine workmanship, which is represented in the act of swallowing a human victim, already crushed and struggling in its horrid jaws. That these figures were representations, perhaps somewhat exaggerated, of the form, dimensions, and habits of some of the native Boas, can hardly be doubted, from what we know of these reptiles. Hernandez, who speaks of the formidable powers of the Mexican Serpents, says, that he saw some as thick as a man's thigh, which had been tamed so completely as to climb amicably about the shoulders of their possessor, or else lay coiled up in a circle as large as a cartwheel, and peacefully received the food presented to them. Such an engine for working on the fears of the besotted multitude, Southey attributes to the Mexican priest in the following noble lines:-

"_- On came the mighty snake, And twined, in many a wreath, round Neolin, Darting aright, aleft, his sinuous neck, With searching eye, and lifted jaw and tongue Quivering, and hiss as of a heavy shower

Upon the summer woods. The Britons stood Astounded at the powerful reptile's bulk, And that strange sight. His girth was as of man, 
And easily could he have overtopped

Goliath's helmed head, or that huge king

Of Basan, hugest of the Anakim:

What then was human strength if once involved

Within those dreadful coils? . . . The multitude

Fell prone and worshipped."*

The Boadae are found in the continents and great islands of the torrid zone; the true Boas, distinguished by having the plates beneath the tail arranged in a single series, are confined to the western hemisphere, but the great Serpents

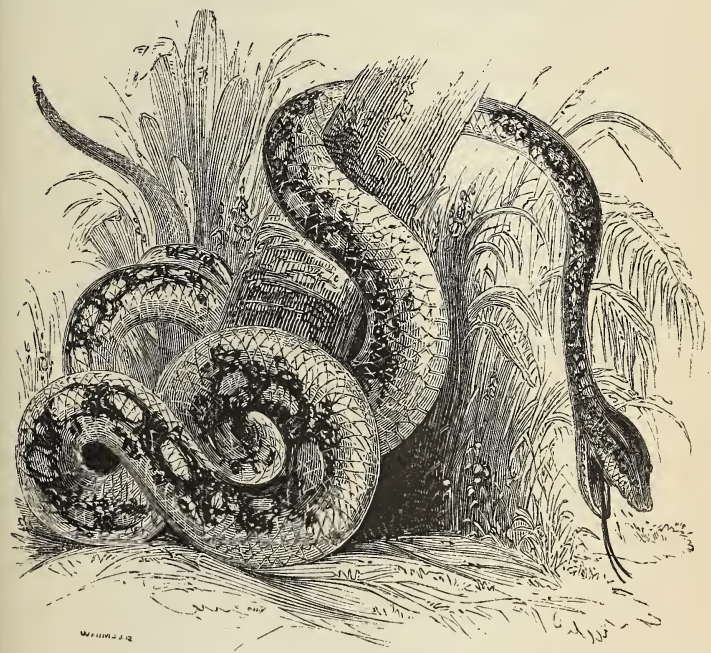

BOA CONSTRICTOR.

exhibited in our menageries, under the looselyapplied term Boa constrictor, are for the most part species of the genus Python, which is found only

$$
\text { * "Madoc," book vii. }
$$


in the Old World. The word constrictor, indeed, though expressive, cannot be considered as distinctive, for it is equally applicable to all the great species of the Family, signifying, as it does, one that binds tightly in its folds. It was, however, appropriated by Linnæus to the greatest of the American species, individuals of which have been known to attain an enormous length. Shaw mentions a skin of this Boa in the British Museum, which measured thirty-five feet.

Several narratives of personal encounters with the American Boas are on record, all of which are of great interest. Mr. Waterton's capture of the "Coulacanara," told in his own peculiarly graphic way, has been often quoted; but we select one less known, yet not less exciting, narrated by a military correspondent of the Edinburgh Literary Gazette.

This gentleman was at the time residing with a friend in British Guiana, and employing himself chiefly in shooting, and fishing in a neighbouring river. One sultry day, tired with unsuccessful sport, he threw his lines, and drew his canoe to the river's edge, for the purpose of refreshing himself in the water. Having done so, he stretched himself, half dressed, on the benches of his boat, with his gun at his head, loaded for a shot if a chance should occur. In this position he fell asleep. "I know not how long I may have slept," he continues, "but I was roused from my slumber by a curious sensation, as if some animal were licking my foot.* In that state of half-stupor felt after immediately waking from sleep, I cast my eyes downward, and never till * See remarks on page 167. 
my dying day shall I forget the thrill of horror that passed through my frame on perceiving the neck and head of a monstrous Serpent covering my foot with saliva, preparatory, as immediately flashed upon my mind, to commencing the process of swallowing it. I had faced death in many shapes-on the ocean-on the battle-field-but never till that moment had I conceived he could approach me in a guise so terrible. For a moment, and but a moment, I was fascinated. But recollection of my state soon came to my aid, and I quickly withdrew my foot from the monster, which was all the while glaring upon me with its basilisk eyes, and at the same instant I instinctively grasped my gun, which was lying loaded beside me. The reptile, apparently disturbed by my motion, (I conceive it had previously, from my inertness, taken me for a dead carcase,) drew its head below the level of the canoe. I had just sufficient time to raise myself half up, pointing the muzzle of my piece in the direction of the Serpent, when its neck and head again appeared moving backwards and forwards, as if in search of the object it had lost. The muzzle of my gun was within a yard or two of it: my finger was on the trigger; I fired, and it received the shot in its head. Rearing up part of its body into the air with a horrible hiss, which made my blood run cold-and, by its contortions, displaying to $\mathrm{my}$ sight great part of its enormous bulk, which had hitherto escaped my notice-it seemed ready to throw itself upon me, and to embrace me in its monstrous coils. Dropping my gun, by a single stroke of the paddles I made the canoe shoot up the stream out of his reach. Just as I was escap- 
ing, I could observe that the shot had taken effect, for blood was beginning to drop from its head. But the wound appeared rather to have enraged than subdued him. Unfortunately, all my shot was expended, otherwise I would most certainly, at a respectable distance, have given him a salutation of the same kind as I had just bestowed. All that I have described passed in a much shorter time than I have taken up in recounting it.

"As I went up the stream with all the velocity I could impart to the canoe, I heard the reeds, among which the animal was apparently taking refuge, crashing under its weight. I never once thought of the lines I had left; but hurrying as fast as the canoe would go through the water, I was not long in reaching the landing-place below my friend's house. Hastily mooring the canoe, I jumped ashore, and hurried up to the house, where you may be certain I lost no time in communicating the almost miraculous escape I had made, and the wound I had inflicted on the animal. 'In that case,' said Mr. H., 'it cannot escape ; we must immediately go in search of it;' and instantly summoning Cæsar (a black servant), he told him to get the guns ready, and to bring two of his fellows with him. "If you choose to assist us in finishing the adventure you have begun, and to have a second encounter with your novel antagonist, we shall shew you some of the best and most dangerous sport our country affords.' I protested that nothing was farther from my intention than staying behind, and added, that had not my shot been expended, we should not have parted on so easy terms. 'In general,' said he, 'it is very dangerous to attack 
them at close quarters after being wounded, as they become extremely infuriated; and there are not wanting instances in which life has been sacrificed by doing so. But we now take such precaution in approaching it, that it is next to impossible that any accident can happen. Just as he finished saying this, Cæsar reappeared, himself armed with a club, one of those who followed him carrying a weapon of the same kind, while the other was armed with a weapon similar to a billhook. This, Mr. H. told me, was to clear a road among the reeds, if the animal should have retreated amongst them,- the club being reckoned the best instrument for a close encounter. We were soon seated in the canoes, and gliding down the stream as fast as a couple of pairs of brawny arms could urge us. In a short time we reached the spot where my adventure had happened. The small part of the bank not covered with reeds, bore, from its sanguine hue, evident proof that the wound the animal had received could not have been slight. Exactly opposite this the reeds were crushed and broken, and a sort of passage was formed among them, so wide that a man could with little difficulty enter. My friend commanded a halt, to see that the arms were in proper order. All being right, we listened attentively, in order to hear if there was any noise which might direct us to our enemy. No sound, however, was heard. One of the negroes entered first, clearing with his billhook whatever obstructed our way. He was followed by Mr. H. and me with our guns; while Cæsar and his fellow-servant brought up the rear. The reeds were in general nearly double our height, and at the same time pretty close. However, we 
easily made our way through them, partly assisted by the track which the Serpent had evidently made.

"We had penetrated, I should suppose, about thirty yards, when the fellow who was in advance gave the alarm that we were close upon the animal. Mr. H. ordered him behind, and advancing along with me, we saw through the reeds part of the body of the monster coiled up, and part of it stretched out; but owing to their thickness, its head was invisible. Disturbed, and apparently irritated by our approach, it appeared, from its movements, about to turn and assail us. We had our guns ready, and just as we caught a glimpse of its head we fired, both of us almost at the same moment. From the obstruction of the reeds, all our shot could not have taken effect; but what did take effect seemed to be sufficient; for it fell hissing and rolling itself into a variety of contortions. Even yet it was dangerous to approach it. But Cæsar, who seemed to possess a great deal of coolness and audacity, motioning his master and me not to fire again in the direction of the animal, forced a way through the reeds at one side, and making a kind of circuit, came in before it, and succeeded in hitting it a violent blow, which completely stunned it; and a few repetitions of this gave us the victory. We could now examine the creature with safety. On measuring it, we found it to be nearly forty feet in length, and of proportional thickness. Mr. H. informed me that it was the largest he had seen killed, although he had often seen others under circumstances which convinced him that they must have been of a far greater size." 


\section{Genus Pithon. (Dum.)}

The great Serpents of the Old World are distinguished by the above name from those of the New, to which the generic term Boa is now restricted. The general organization, the appearance, and the habits of both are nearly identical; but the Pythons are distingushed by having the plates beneath the tail arranged in a doube series. The front of the head and muzzle are clothed with broad plates, and those on the lips are indented with pits or dimples. They attain a size fully equal, if not superior to the true Boas, there being authentic records of specimens approaching forty feet in length, and reports of their far exceeding even these colossal dimensions. Their appearance is very beautiful, the ground colour is commonly a yellowish grey, more or less intense, on which marks of brown of various shades are arranged in irregular patterns of bands, and spots, and chains. During life a rich iridescent gleam is reflected from the surface, in the sun, particularly

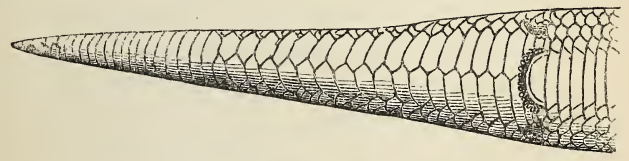

TAIL-PLATES OF PYTHON.

from the darker parts. The species are found in Africa (probably in most parts of that continent to the south of the Desert), in India, and in the great islands of the Oriental Archipelago.

The form and appearance of these great Ser- 
pents will be familiar to many of our readers, most of those which are exhibited in zoological collections belonging to this genus; their lethargic inanity, however, as they lie coiled up in the midst of blankets upon tins of hot water, gives us little idea of the fatal power and energy which they exhibit in their native climates. Many narratives of great interest might be quoted, illustrative of their strength, their ferocity, their voracity, and other particulars. We must content ourselves with a few of these, commencing with one of a painfully vivid character, recorded by Mr. M'Leod, in the "Voyage of H.M.S. Alceste." The specimen, which was a native of Borneo, was sixteen feet long, and about eighteen inches in circumference. "During his stay at Ryswick," observes the narrator, "he is said to have been usually entertained with a goat for dinner, once in every three or four weeks, with occasionally a duck or a fowl by way of a dessert. He was brought on board shut up in a wooden crib or cage, the bars of which were sufficiently close to prevent his escape; and it had a sliding door, for the purpose of admitting the articles on which he was to subsist; the dimensions of the crib were about four feet high, and five feet square,-a space sufficiently large for him to coil himself round with ease. The live stock for his use during the passage, consisting of six goats of the ordinary size, were sent with him on board, five being considered as a fair allowance for as many months. At an early period of the voyage we had an exhibition of his talent in the way of eating, which was publicly performed on the quarter-deck, upon which he was brought. The 
BOAS.

sliding door being opened, one of the goats was thrust in, and the door of the cage shut. The poor goat, as if instantly aware of all the horrors of its perilous situation, immediately began to utter the most piercing and distressing cries, butting instinctively, at the same time, with its head towards the serpent, in self-defence. The Snake, which at first appeared scarcely to notice the goat, soon began to stir a little, and turning his head in the direction of the goat, he at length fixed a deadly and malignant eye on the tremling victim, whose agony and terror seemed to ncrease; for, previous to the Snake seizing its prey, it shook in every limb, but still contiued its unavailing show of attack by butting it the Serpent, which now became sufficiently nimated to prepare for the banquet. The first peration was that of darting out his forked ongue, and at the same time rearing a little his lead; then suddenly seizing the goat by the fore eg with his mouth, and throwing it down, it was encircled in an instant in its horrid folds. So quick, indeed, and so instantaneous was the act, hat it was impossible for the eye to follow the apid convolution of his elongated body. It was lot a regular screw-like turn that was formed, but esembling rather a knot, one part of the body verlaying the other, as if to add weight to the nuscular pressure, the more effectually to crush is object. During this time, he continued to rasp with his fangs (though it appeared an unlecessary precaution) that part of the animal which he had first seized. The poor goat, in the neantime, continued his feeble and half stifled ries for some minutes, but they soon became 
more and more faint, and at last it expired. The Snake, however, retained it for a considerable time in his grasp, after it was apparently motionless. He then slowly and cautiously unfolded himself, till the goat fell dead from his monstrous embrace, when he began to prepare himself for swallowing it. Placing his mouth in front of the dead animal, he commenced by lubricating with his saliva that part of the goat, and then taking its muzzle into his mouth, which had, and indeed always has, the appearance of a raw lacerated wound, he sucked it in as far as the horns would allow. These protuberances opposed some little difficulty, not so much from their extent, as from their points; however, they also, in a very short time, disappeared, - that is to say, externally; but their progress was still to be traced very distinctly on the outside, threatening every moment to protrude through the skin. The victim had now descended as far as the shoulders; and it was an astonishing sight to observe the extraordinary action of the Snake's muscles when stretched to such an unnatural extent-an extent which must have destroyed all muscular power in any animal that was not, like himself, endowed with very peculiar faculties of expansion, and action at the same time. When his head and neck had no other appearance than that of a serpent's skin, stuffed almost to bursting, still the workings of the muscles were evident; and his power of suction, as it is erroneously called, unabated; it was, in fact, the effect of a contractile muscular power, assisted by two rows of strong hooked teeth. With all this, he must be sc formed as to be able to suspend, for a time, his 
respiration, for it is impossible to conceive that the process of breathing could be carried on while the mouth and throat were so completely stuffed and expanded by the body of the goat, and the lungs themselves (admitting the trachea to be ever so hard) compressed as they must have been by its passage downwards.

"The whole operation of completely gorging the goat occupied about two hours and twenty minutes : at the end of which time the tumefaction was confined to the middle part of the body, or stomach, the superior parts, which had been so much distended, having resumed their natural dimensions. He now coiled himself up again and lay quietly in his usual torpid state for about three weeks or a month, when his last meal appearing to be completely digested and dissolved, he was presented with another goat, which he killed and devoured with equal facility."

In an interesting memoir published in the Zoological Journal, vol. ii., Mr. Broderip has given a very similar account of the seizure of a rabbit by one of the large Pythons kept in the Tower. Our limits will not permit us to do more than refer to it; but we will cite the remarks of this zoologist on a point in Mr. M'Leod's account which seemed to him incorrect. "It is my opinion that the Boa [or Python] does respire when his head and neck have no other appearince than that of a serpent's skin stuffed almost to bursting ;' and I think that, upon a more close examination, the same phenomenon would have oeen observable in the Serpent shipped at Baavia. It is to be regretted that the dissection of he Serpent appears to have been confined to the 
stomach,-at least, nothing is said of any other part of the animal. I have never had an opportunity of dissecting the pulmonary system of a Boa, or of satisfying myself as to the structure of the extremely long trachea, which must be very firm to resist such an immense pressure; but I believe, from a near and accurate inspection, in company with others, that respiration goes on during the period of the greatest dilatation. While these Serpents are in the act of constringing or of swallowing their prey, they appear to be so entirely pervaded with the appetite which then governs them, that I am convinced they would suffer themselves to be cut in pieces before they would relinquish their victim. I have assisted in taking them up and removing them with their prey in their coils, without their appearing to be in the least disturbed by the motion, excepting that, if after the victim is no more, and the constriction is somewhat relaxed, an artificial motion be given to the dead body, they instantly renew the constriction. When thus employed they may be approached closely, and with perfect security, for the reason above stated; and I have uniformly found that the larynx is, during the operation of swallowing, protruded sometimes as much as a quarter of an inch beyond the edge of the dilated lower jaw.* I have seen, in company with others, the valves of the glottis open and shut, and the dead rabbit's fur immediately before the aperture stirred apparently by the Serpent's

* Since the publication of Mr. Broderip's Memoir, Mr. Joseph Henry Green, in his lectures at the Royal College of Surgeons, exhibited a drawing of two muscles which he had detected in the lower jaw of the Boa, the purpose of which is to bring the larynx forward during the operation of swallowing. 
breath, when his jaws and throat were stuffed and itretched to excess. In the case above mentioned, where the prey was taken very awkwardly, and the dilatation was consequently much greater han usual, I saw this wonderful adaptation of neans to the exigencies of the animal much more learly than I had ever seen it before."

It is reported that even large animals, such as itags, tigers, and buffaloes occasionally become the prey of these huge reptiles. In the German Ephemerides, we have an account of a combat beween an enormous Serpent and a Buffalo, by a person who assures us that he was himself a specator. The Serpent had for some time been waitng near the brink of a pool, in expectation of its rey, when a Buffalo was the first that offered. Having darted upon the affrighted animal, it nstantly began to wrap it round with its voluninous twistings; and at every twist the bones of he Buffalo were heard to crack. It was in vain hat the poor animal struggled and bellowed; its normous enemy entwined it too closely to get ree; till at length, all its bones being mashed to jieces, like those of a malefactor on the wheel, ind the whole body reduced to one uniform mass, he Serpent untwined its folds to swallow its prey $t$ leisure. To prepare for this, and in order to nake the body slip down the throat more glibly, $t$ was seen to lick the whole body over, and thus over it with its mucus. It then began to swalow it at that end that offered least resistance, vhile its length of body was dilated to receive its rey, and thus took in at once a morsel three imes its own thickness.

Nor are these gigantic serpents formidable only 
to the inferior animals; there are not wanting instances in which man himself has become their victim. In the "Bombay Courier" of August 31,1799 , the following dreadful incident is recorded. "A Malay prow was making for the port of Amboyna; but the pilot, finding she could not enter it before dark, brought her to anchor for the night, close under the island of Celebes. One of the crew went on shore in quest of betel-nuts in the woods, and on his return lay down, as it is supposed, to sleep on the beach. In the course of the night he was heard by his comrades to scream out for assistance. They immediately went on shore; but it was too late, for an immense Snake of this species had crushed him to death. The attention of the monster being entirely occupied by his prey, the people went boldly up to it, cut off its head, and took both it and the body of the man on board their boat. The Snake had seized the poor fellow by the right wrist, where the marks of the fangs were very distinct; and the mangled corpse bore evident signs of being crushed by the monster's twisting itself round the neck, head, breast, and thigh. The length of the Snake was about thirty feet; its thickness equal to that of a moderate-sized man; and on extending its jaws, they were found wide enough to admit at once a body of the size of a man's head."

The opportune rescue of a poor sailor from a similar fate has been made the subject of a wellknown painting by Mr. Daniell, which has been copied in the Oriental Annual, and which we here repeat. It is a spirited and graphic scene, though the details of the Serpent's body and head are not 
the sleeper, and was in the act of crushing him to death, when his companions fortunately returned; and attacking the monster, severed a portion of its tail, which so disabled it that it no longer retained the power of doing mischief. The Snake was then easily despatched, and was found to measure sixty-two feet and some inches in length.

Mr. M'Leod, whose interesting account of a Python seizing its prey we have quoted at length, adds, that at Whidah on the coast of Africa, he has had opportunities of observing Pythons more than double the size of the specimen he has described, which were capable of swallowing animals much larger than goats or sheep. "Governor Abson, who had for thirty-seven years resided at Fort William (one of the African Company's settlements there), described some desperate struggles which he had either seen or had come to his knowledge, between the Snakes and wild beasts, as well as the smaller cattle, in which the former were always victorious. A negro herdsman belonging to Mr. Abson (who afterwards limped for many years about the fort) had been seized by one of these monsters by the thigh; but from his situation in a wood, the Serpent, in attempting to throw himself around him, got entangled with a tree; and the man, being thus preserved from a state of compression which would instantly have rendered him quite powerless, had presence of mind enough to cut with a large knife, which he carried with him, deep gashes in the neck and throat of his antagonist, thereby killing him, and disengaging himself from his frightful situation. He never afterwards, however, recovered the use of that limb, which had sustained considerable 
injury from his fangs and the mere force of his jaws."

In one of the books of Livy, now lost, there was an account of a terrible serpent, which kept the whole Roman army at bay. Valerius Maximus gives us this abridgment of the story: "And since we are on the subject of uncommon phenomena, we may here mention the Serpent so eloquently and accurately recorded by Livy; who says, that near the river Bagrada, in Africa, a Snake was seen of so enormous a magnitude, as to prevent the army of Attilius Regulus from the use of the river; and after snatching up several soldiers with his enormous mouth, and devouring them, and killing several more by striking and squeezing them with the spires of its tail, was at length destroyed by assailing it with all the force of military engines and showers of stones, after it had withstood the attack of their spears and darts: that it was regarded by the whole army as a more formidable enemy than even Carthage itself; and that the whole adjacent region being tainted with the pestilential effluvia proceeding from its remains, and the waters with its blood, the Roman army was obliged to remove its station. He also adds, that the skin of the monster, measuring one hundred and twenty feet in length, was sent to Rome as a trophy."*. Silius Italicus and other writers mention this Serpent, which was doubtless a Python; and Pliny speaks of its existence as a matter of notoriety, adding, that its skin and jaws were preserved in a temple at Rome till the Numantine war.

Diodorus Siculus mentions a Serpent which was * Val. Max. i., 8. § 19. 
captured, not without loss of human life, in Egypt, and which was taken to Alexandria; it measured thirty cubits, or about forty-five feet in length. And Suetonius tells us that one was exhibited in front of the Comitium at Rome, which was fifty cubits, or seventy-five feet long.

Perhaps none of these examples were very accurately measured; or if we must suppose that the first was so, we may remark, that the skin of a Serpent, dragged off by rude and unscientific hands, is capable of stretching to an enormous extent; but with every allowance, it is evident that unless we reject the testimony of history, specimens of Serpents were seen in ancient times which very far exceeded any that have fallen under modern, or, at least, scientific observation. Some of the largest on modern record we will briefly recapitulate. The subject of Daniell's picture is said to have been sixty-two feet; but this is probably exaggerated: the specimen whose capture is narrated in the "Edinburgh Literary Grazette" was " nearly" forty feet; those which M'Leod saw at Whidah must have been thirty-two feet or more; Bontius speaks of some upwards of thirty-six feet; an American Boa is mentioned by Bingley, of the same length, the skin of which was in the cabinet of the Prince of Orange; Shaw speaks of a skin in the British Museum which measured thirtyfive feet; and finally, Dr. A. Smith saw a specimen of Python Natalensis, twenty-five feet long, though a portion of the tail was wanting.

We illustrate the genus by a figure of the Tiger Python (Python tigris, DAuD.), one of the most beautiful in its markings of the whole 


\section{BOAS.}

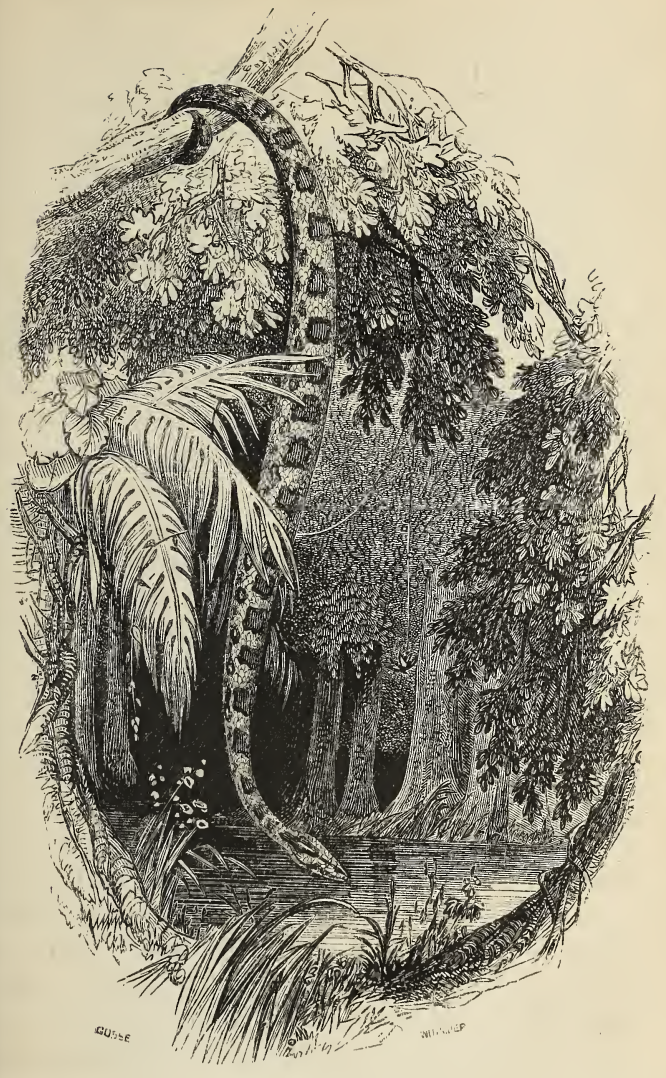

TIGER PYTHON.

Family, and the species most commonly met with in menageries, under the name of Boa constrictor. 
It is a native of the island of Java, and of the Indian peninsulas.

The ground-colour of the head of this Serpent is a greyish fawn, that of the body yellowish, of the sides greyish white; the under parts pale yellowish. A series of large spots of dark brown with a black margin runs down the back; they are of an irregular form, but somewhat square: there are smaller ones on the sides, which often have open disks. On the hind-head and nape is a large brown spot, somewhat like a spear-head, divided lengthwise by a pale line; a brown band runs off behind each eye. The shields of the belly are about two hundred and fifty, those of the tail from sixty to seventy pairs.

The Boas are oviparous; laying a number of eggs in holes in the soil, beneath decaying leaves, in crevices of the roots of trees, and in similar situations. At certain seasons of the year great numbers are said to congregate together and twist themselves into immense knots or contorted coils. This is at least true of the Yellow Snake of Jamaica (Chilabothrus inornatus), and the negroes and creoles declare that these réunions are connected with the reproduction of the species. But the individuals that thus collect, though numerous, are not to be compared with the convoluted host that the celebrated Humboldt once saw in South America. Their association he attributes, indeed, to a very different motive ; but we are inclined to believe that he has quite misinterpreted the phenomenon.

"In the savannahs of Izacubo, in Guiana, I saw the most wonderful, the most terrible spectacle that can be seen; and although it is not 
uncommon to the inhabitants, no traveller has ever mentioned it. We were ten men on horseback, two of whom took the lead, in order to sound the passages, whilst I preferred to skirt the green forests. One of the blacks who formed the vanguard returned at full gallop, and called to me, ' Here, sir, come and see Serpents in a pile!' He pointed out to me something elevated in the middle of the savannah which appeared like a bundle of arms. One of my companions then said, "This is certainly one of those assemblages of Serpents which heap themselves on each other after a violent tempest. I have heard of these, but have never seen any; let us proceed cautiously, and not go too near.' When we were within twenty paces of it the terror of our horses prevented our nearer approach, to which, however, none of us were inclined. Suddenly the pyramidal mass became agitated; horrible hissings issued from it; thousands of Serpents rolled spirally on each other, shot forth out of their circle their hideous heads, presenting their envenomed darts and fiery eyes to us. I own I was one of the first to draw back; but when I saw this formidable phalanx remain at its post, and appear to be more disposed to defend itself than to attack us, I rode round it, in order to view its order of battle, which faced the enemy on every side. I then sought what could be the design of this numerous assemblage ; and I concluded that this species of Serpents dreaded some colossean enemy, which might be the great Serpent or the Cayman, and that they reunite themselves after having seen this enemy, in order to attack or resist him in a mass." 
It is a curious fact but recently discovered, that some, at least, of the Pythons incubate their eggs like birds. This fact was lately witnessed in the case of a female of the Python bivittatus of Kuhl, in the menagerie of the Museum at Paris. Incubation was prolonged without interruption during nearly two months. The number of eggs laid was fifteen, all separate. After being deposited the snake collected them together, and coiled round them the posterior part of its body; a second coil was then formed upon the first, and a third upon the second, and so on, until the whole of its body was rolled into a spiral form, the several coils together forming a cone, at the top of which was its head, the eggs being all concealed within. Its temperature was sensibly augmented above that of the surrounding atmosphere while incubation was going on; it ate nothing during the whole period; but drank greedily several times. At length, at the end of fifty-six days, without the female having once quitted the eggs, one of the little Pythons was hatched; and in the course of a few days there were seven others; but no sooner were they evolved than the mother left them to themselves, shewing no further affection for the offspring which she had so sedulously incubated.*

* "Ann. des Sci. Nat." (2nd ser.), xvi. 65. 


\section{Family III. Colubride.}

\section{(Snakes.)}

More than half of the total number of species belonging to the Order Ophidia are of this Family, which is the most extensive of all the natural groups of Reptiles. They are widely scattered over the regions of both hemispheres, extending nearly to the limits of the Frigid Zones, though, like other Reptiles, most abundant in the tropics. Few of them attain a large size; but their form is for the most part slender and elegant, and many are adorned with the most brilliant hues and reflections.

The true Snakes are destitute of poison-fangs; they have two rows of teeth in the palate, and a similar row in each jaw; the head is covered with broad plates, the under parts with parallel shields or scuta, which beneath the tail are arranged in two series; the tail is lengthened, tapered,

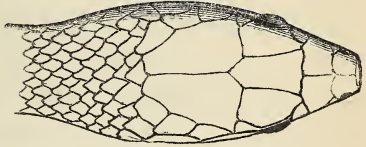

HEAD OF SNAKE. and destitute of any terminal appendage; there are no spurs or other vestiges of limbs, either externally or internally.

The prey of the Snakes consists of any small animals which they can procure ; lizards and frogs, small birds, mice, and shrews, are the food of the smaller kinds, and the larger devour rats, voles, and poultry; eggs and milk are delicacies with these reptiles. They are remarkably agile in their 
motions, and of some, as the Black Snake (Coluber constrictor) of North America, the fleetness on the ground is reported to be equal to that of a horse. Many of them climb about trees in search of prey, and are often seen lying along upon the branches, with the foreparts hanging down, or gliding from bough to bough; and there are some species (Leptophis) of great length and tenuity, distinguished by their bright colours and changeable metallic reflections, which spend their lives among the foliage of trees. Most of the Family will voluntarily take to the water on occasion, in which, though not displaying any especial natatory structure, they are able to swim with great elegance and rapidity both at and beneath the surface. The common Ringed Snake of our fields will often, as it is said, go into the water in the pursuit of frogs, its favourite prey.

The smaller harmless Snakes are exceedingly numerous in warm countries, and inhabit various localities and situations. Rocky places, old dry walls, heaps of stones and rubbish, are favourite haunts of many, others glide among the heaths of upland plains, and others rustle the fallen leaves beneath the trees of the damp forest; some live in the long grass of savannahs, some in the dense and impenetrable jungle; some resort to the naked and burning deserts of sand and stone, and not a few prefer the vicinity of swamps and morasses. They occur, in fact, everywhere ; "but the numerous enemies they have among the smaller quadrupeds and birds keep their increase in check. The wild hog, peccary, badger, hedgehog, weasel, civet, ichneumon, and other Carnivora, devour them with avidity; the stork, the 
;erpent-eater of the Cape, the kite, laughing alcon, and buzzard, are their implacable enemies ; while man wages incessant war against them wherever he and they come in contact."

Though the number of poisonous Serpents does ot amount to more than one-fifth of the whole, he malignity of those causes the whole to be ooked on with aversion; and as the means of liscrimination between the harmless and the 1oxious are scarcely known to any but naturalsts, it is considered safe to wage a war of externination against the whole Order; and a Snake s therefore commonly killed, as a sort of duty, wherever it can be met with. Yet it has been hown that not only are the majority of species iarmless, but some (probably most) are capable of being domesticated, and are susceptible of sersunal affection. Professor Bell observes of our British species, that "it is easily tamed, and may e made to distinguish those who caress and feed t. I had one many years since, which knew me rom all other persons ; and, when let out of his ox, would immediately come to me, and crawl under the sleeve of my coat, where he was fond f lying perfectly still, and enjoying the warmth. He was accustomed to come to my hand for a lraught of milk every morning at breakfast, vhich he always did of his own accord; but he vould fly from strangers, and hiss if they meddled vith him." In the Dictionnaire d'Histoire $\mathrm{Na}$ urelle, there is related an instance of a Snake wich had been so completely tamed by a lady, s to come to her whenever she called it, to follow er in her walks, writhe itself round her arms, nd sleep in her bosom. One day, when she 
went in a boat to some distance up a large river, she threw the Snake into the water, imagining that its fidelity would lead it to follow her, and that, by swimming, it would readily overtake the boat. The poor animal exerted all its efforts; but the current proving at that juncture unusually strong, owing to the advance of the tide, in spite of all its struggling it was borne down the stream, and was unfortunately drowned.

Like all other Serpents, the Snakes shed the outer layer of the skin at irregular periods, dependent on the state of the animal's health, on its abundance of food, on the temperature of the weather, and other circumstances. Sometimes the sloughing takes place four or five times a year. It appears that the skin is always reversed in the process, and is first split behind the head, when it is detached by the animal's drawing itself through narrow apertures. White of Selborne thus describes the cast skin. "About the middle of this month (September), we found in a field, near a hedge, the slough of a large Snake, which seemed to have been newly cast. It appeared as if turned wrong side outward, and as if it had been drawn off backward, like a stocking or a woman's glove. Not only the whole skin, but even the scales from the eyes, were pulled off, and appeared in the head of the slough like a pair of spectacles. The reptile at the time of changing his coat, had entangled himself intricately in the grass and weeds, in order that the friction of the stalks and blades might promote this curious shifting of his exuviæ.

"It would be a most entertaining sight, could a person be an eye-witness to such a feat, and see 
the Snake in the act of changing its garment As the convexity of the eyes in the slough is now inward, that circumstance alone is a proof that the skin has been turned; not to mention that now the inside is much darker than the outer. Thus it appears that Snakes crawl out of the mouth of their own sloughs, and quit the tailpart last, just as eels are skinned by a cook-maid. ..... While the scales of the eyes are becoming loose, and a new skin is forming, the creature in appearance must be blind, and must feel itself in a very awkward and uneasy situation."

\section{Genus $N_{A T R I X}$ (LAUR.).}

The distinctive characters of this genus are the following. The head is well marked, of a longoval form, flattened and covered with plates; the gape is wide; the body is very long, nearly cylindrical, but slightly flattened; the tail cylindrical andslender; the scales overlapping, placed in ongitudinal series, ance-shaped, geneally keeled; the olates or shields on

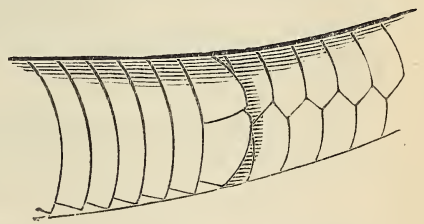

BELLY AND TAIL OF SNAKE. the belly are simple and arched at the margin; hose beneath the tail arranged in a double series.

Our own common Ringed Snake (Natrix torquata, $\mathrm{R}_{\mathrm{AY}}$ ) is a familiar example of this genus. It reaches the length of three, and even occaionally four, feet; and is of a pale olive or 
greenish hue above, with numerous black spots, placed in alternate rows; the under parts are pale yellow, chequered with black, or sometimes bluish lead-colour; a broad yellow collar passes behind the head, followed by two patches of black.

During the summer season, the Ringed Snake is rather common in rural districts, concealing itself among the brushwood of coppices, the herbage of ditches and hedges, gliding beneath the shelter of the dense heath, or basking in the

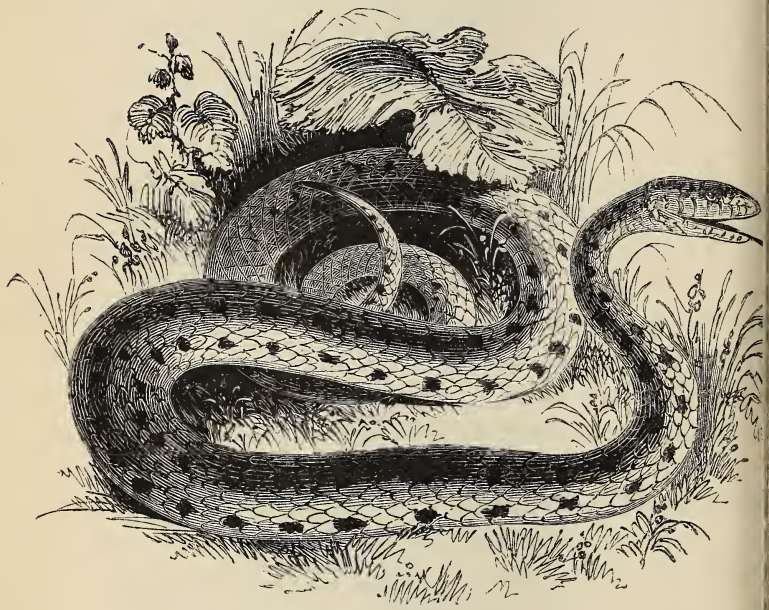

RINGED SNAKE.

sun on some exposed bank, or on the short turt by the road-side. Late in the autumn, it retires into winter quarters, in some situation usually selected for warmth; such as beneath the roots of 
a tree, or under a quickset hedge, where sometimes a considerable number spend the cold season, coiled up together in torpidity, until the balmy air of spring warms them into renewed life and activity. Dr. Carpenter mentions an instance which occurred within his own knowledge, in which thirteen hundred Ringed Snakes were found in an old limekiln.* This species does not usually climb, but Mr. Jesse states that it does occasionally ascend into the branches of a tree, probably for the purpose of rifling the nests of birds, on the eggs and young of which it often regales. It is fond of the water, in which it swims with elegance and facility, with the head and neck raised above the surface; and this is not surprising, when we consider that its favourite food is that expert swimmer and diver, the frog. Mr. Bell, in a very interesting manner, describes the mode in which the hapless victim is seized and swallowed, taking occasion to explain the peculiar mechanism of the jaws in this Order, a structure to which we have already alluded. "I have seen," observes this gentleman, "one of these voracious creatures in pursuit of a frog, which appeared perfectly conscious of its approaching fate, leaping with less and less power as it found its situation more hopeless, and the crisis of its fate approaching, and uttering its peculiar weak cry with more than usual shrillness, until at length it was seized by its pursuer by the hinder leg, and gradually devoured. The manner in which the Snake takes its prey is very curious. If it be a frog, it generally seizes it by the hinder leg, because it is usually taken in

$$
\text { * "Zoology," i. } 569 .
$$


pursuit. As soon as this takes place, the frog in most instances, ceases to make any struggle or attempt to escape. The whole body and the legs are stretched out, as it were, convulsively, and the Snake gradually draws in, first the leg he has seized, and afterwards the rest of the animal, portion after portion, by means of the peculiar mechanism of the jaws, so admirably adapted for this purpose. . . . When a frog is in the progress of being swallowed in this manner, as soon as the Snake's jaws have reached the body, the other hinder leg becomes turned forwards; and as the body gradually disappears, the three legs and the head are seen standing forwards out of the Snake's mouth in a very singular manner. Should the Snake, however, have taken the frog by the middle of the body, it invariably turns it by several movements of the jaws, until the head is directed towards the throat of the Snake, and it is then swallowed head foremost. This process will remind all who have witnessed the curious sight of the great Boa taking its food, of the manner in which that enormous reptile effects its deglutition, after it has, by the pressure of its mighty sides, killed and crushed the bones of its victim.

"The scene above described is one which I have often witnessed; and I once saw two Snakes seize upon the same hapless frog..... On placing a frog in a large box in which were several Snakes, one of the latter instantly seized it by one of the hinder legs, and immediately afterwards another of the Snakes took forcible possession of the fore-leg of the opposite side. Each continued its inroads upon the poor frog's limb and body, until at length the upper jaws of the 
two Snakes met, and one of them, in the course of its progress, slightly bit the jaw of the other; this was retaliated, though evidently without any hostile feeling; but after one or two such accidents, the most powerful of the Snakes commenced shaking the other, which still had hold of the frog, with great violence, from side to side, against the sides of the box. After a few moments' rest, the other returned the attack, and at length, the one which had last seized the frog, having a less firm hold, was shaken off, and the victor swallowed the prey in quiet. No sooner was this curious contest over, than I put another frog into the box, which was at once seized and swallowed by the unsuccessful combatant.

" The frog is generally alive, not only during the process of deglutition, but even after it has passed into the stomach. I once saw a very small one, which had been swallowed by a large 'Snake in my possession, leap again out of the mouth of the latter, which happened to gape, as they frequently do immediately after taking food; and, on another occasion, I heard a frog distinctly utter its peculiar cry, several minutes after it had been swallowed by the Snake. In taking lizards or birds, it always, as far as my observation goes, swallows the head foremost. After it has taken its food, it usually remains inactive for many days, not usually seeking a fresh meal until the former one is digested." *

Notwithstanding the high authority of Schlegel, who asserts that Snakes never drink, repeated observations have proved that they do. Dr. Cantor observes that the majority of Indian Serpents are partial to water, and that with the exception of * "British Reptiles," 49. 
the arboreal species, they both drink and moisten the forked tongue, which are distinct operations. The same observation has been made of African Serpents, and equally applies to our own Ringed Snake. It is particularly fond of milk, so that it often creeps into dairies to drink out of the vessels. It has been even accused of twining up the legs of cows, in order to suck their teats, but this is manifestly absurd. The fondness of Mr. Bell's tame Snake for milk, we have already cited.

The same appetite is observed in the Black Snake (Coluber constrictor, Linn.) of North America. So partial is it to this diet, that it is difficult to keep it out of a cellar where milk is kept, after it has once found its way thither. A pleasing story will be familiar to the memory of some of our readers, of a Black Snake in New England, that was accustomed to come and partake with a little child of its basin of bread and milk, the boy now and then correcting the greediness of his self-invited guest, by raps on the head with the spoon, when he thought it took more than its share.

In the museum of the Zoological Society is a tame Snake that had been eleven years in the possession of a gentleman, to whom it had shown strong attachment. Mr. Jesse mentions that Eton boys have always been great tamers of Snakes, and many school anecdotes are current of the attachment of these reptiles to their owners.* The Rev. R. Sheppard had one in his rooms at Caius College, Cambridge, nearly three months. He kept it in a box of bran; and during all that time, he never could discover that it ate any-

$$
\text { * "Gleanings," } 71 \text {. }
$$


thing, although he frequently put both eggs and frogs, the favourite food of this species, into the box. When he was in the room, he used to let the animal out of its prison. It would first crawl several times round the floor, apparently with a desire to escape; and when it found its attempts fruitless, would climb up the tables and chairs, and not unfrequently even up the chair of its owner, as he sat at table. At length it became so familiar as to lie in a serpentine form on the upper bar of his chair; it would crawl through his fingers, if held at a little distance before its head, or lie at full length upon his table, while he was writing or reading, and this for an hour or more at a time. When first brought into the room, it used to hiss and dart out its forked tongue; but in no instance did it emit any unpleasant vapour. In all its actions it was remarkably cleanly. Sometimes it was indulged with a run upon the grass in the court of the college; and sometimes with a swim in a large basin of water, which it seemed to enjoy very much." *

The following curious facts recorded by $\mathrm{Mr}$. Jesse, remind us of the stories told of the Indian Snake-charmers :- "A respectable land-surveyor informed me, that while he was making a survey of some property, he was attended by a man who had the character among his neighbours of being a shrewd fellow; but what more particularly entitled him to distinction was his extraordinary intimacy with Snakes. On being questioned on the subject, the man said he would soon show the party more than they had ever seen before. It was a sunny spring morning, and they were run-

* "Bingley's Animal Biogarpby," iii. 217. 
ning a line through a copse. The Snake-fancier suddenly dropped the chain-handle, and jumped upon a bank. 'The next moment he came forward with two full-sized Snakes writhing about his hands and wrists. After viewing them some time with much affection and admiration, he said: 'Why, bless you, sir, I know their ways as well as they do themselves.' He then stepped to a road which was near at hand, and placed one of the Snakes on the hard ground; taking a thin twig, he tapped the reptile very gently on the head. It immediately darted towards him, when he presented his hand to its open mouth, and continued to play with it, now and then gently tapping it on the head with the twig. He then said that it should counterfeit death, and soon afterwards, the Snake to all appearance lay dead. Those who were standing by thought that this was actually the case; but the Snake-fancier said that it would soon become sprack again, if they left off looking at it; and accordingly, on their removing to a distance of between twenty and thirty yards, the Snake was observed to glide speedily into the nearest hedge. On one occasion, and upon one only, the same person saw a Snake in the act of casting its skin. He said, to use his own words, that it reminded him of a labouring man drawing his round or smock-frock over his head. He further added, that the head of the reptile was about midway in the old skin, and it extricated itself from the worn-out garment by passing the body through what he called the venthole of the old skin. The new skin was perfect in colour and appearance; but the Snake appeared in a very languid and exhausted state." *

* "Gleanings," p. 359. 
The female lays from sixteen to twenty eggs, which are about as large as those of the Blackbird, connected by a glutinous matter in long strings or chains. They are laid in holes in banks that face the south, in dungheaps, in cucumber and melon beds; and, according to Mr. W. C. L. Martin, in the crevices of limekilns. They are not, in general, hatched until the following spring. The eggs are covered with a whitish, parchment-like membrane; filled with a glairy fluid, in the midst of which the embryo Snake is coiled up in a little spiral.

\section{Family IV. Viperade.}

(Poison-snakes.)

The curse pronounced upon that primal adversary of man, "the Serpent which beguiled Eve through his subtilty," announced a perpetual enmity between his seed and her seed; and while this without doubt referred to " that old Serpent, the Devil," it has had a subordinate fulfilment in that animal type under which he was represented; and the universal horror and aversion with which the venomous Serpents are regarded, is a perpetual memento of that solemn and humbling transaction with which the history of the human race commences. In the whole range of animal existence, there is none that can compare with the venomous Snakes, for the deadly fatality of their enmity ; the lightning stroke of their poisonfangs is the unerring signal of a swift dissolution, preceded by torture the most horrible; the bite of the American Rattlesnake has been known to 
produce death in two minutes. Even where the consummation is not so fearfully rapid, its delay is but a brief prolongation of the intense suffering. The terrible symptoms are thus described: -a sharp pain in the part, which becomes swollen, shining, hot, red, then livid, cold, and insensible. The pain and inflammation spread, and become more intense; fierce shooting pains are felt in other parts, and a burning fire pervades the body. The eyes begin to water abundantly; then come swoonings, sickness, and bilious vomitings, difficult breathing, cold sweat, and sharp pains in the loins. The skin becomes deadly pale or deep yellow, while a black watery blood runs from the wound, which changes to a yellowish matter. Violent headache succeeds, and giddiness, faintness, and overwhelming terrors, burning thirst, gushing discharges of blood from the orifices of the body, intolerable fetor of breath, convulsive hiccoughs, and death.

The subtil agent of such terrible effects is a transparent tasteless fluid, slightly tinged with yellowish green, and of the consistence of a thin solution of gum-arabic in water; when dried, it is more glutinous and adhesive. It is commonly said to be neither acid nor alkaline, but it invariably changes vegetable blues to reds, though in a slight degree, which proves it to have the properties of an acid. It has no peculiar smell, and when applied to the tongue, produces a greasy feeling. It produces no baneful effects except it be mingled with the blood; it may be received into the mouth and swallowed with perfect impunity, though any scratch or ulceration of the surface would render such an experiment highly 
dangerous. Several circumstances affect the result of a poisoned wound; the injection of the venom into an artery, the heat of the weather, the more direct and forcible character of the stroke, the vigour of the reptile, the time that has elapsed since it last exerted its powers, and the debility of the sufferer, are all important circumstances.

We have already described the peculiar structure of the gland by which this deleterious fluid is secreted from the blood, and accumulated; and we now quote from the distinguished zoologist to whom these pages are so much indebted, an account of the interesting mechanism by which it is injected into the wound.

"It will not perhaps be wholly uninteresting," observes Professor Bell, "to describe the very beautiful apparatus by which the poison wounds are inflicted, which render these, and so many other Serpents, so formidable. On each side of the upper jaw, instead of the outer row of teeth which are found in non-venomous Serpents, there exist two or three, or more, long, curved, and tubular teeth, the first of which is larger than the others, and is attached to a small movable bone, articulated to the maxillary bone, and moved by a muscular apparatus, by which the animal has the power of erecting it. In a state of rest, the fang reclines backwards along the margin of the jaw, and is covered by a fold of skin; but when about to be called into use, it is erected by means of a small muscle, and brought to stand perpendicular to the bone. The tooth itself is, as it were, perforated by a tube, the mode of formation of which, was not understood until it was demon- 
strated by Mr. Smith in the "Philosophical Transactions" for 1818. This tube, although completely enclosed, excepting at its basal and apical orifices, must be considered as formed merely by the closing round of a groove in the external part of the tooth itself, and hence not in any way connected with the inner cavity of the tooth, in which exists the pulp upon which the substance of the tooth is formed. The base of the tooth, and consequently the basal orifice of the tube just described, is embedded in a sac, into which the poison is poured from the ducts of the glandular structure by which it is secreted, and which is believed to represent the parotid gland of the higher Vertebrata. The poisonous fluid itself is inodorous, tasteless, and of a yellow colour. It is secreted in greater quantity, and its qualities are more virulent in a high temperature than in cold. Its secretion may be greatly increased by local irritation; as is evidenced by the following fact. Some years since I was dissecting very carefully and minutely the poison apparatus of a large Rattlesnake, which had been dead for some hours; the head had been taken off immediately after death, yet as I continued my dissection the yellow poison continued to be secreted so fast as to require to be occasionally dried off with a bit of rag or sponge; I believe that there could not have been less altogether than six or eight drops at the least.

"When the animal inflicts the wound, the pressure on the tooth forces a small drop of the poison through the tube; it passes through the external orifice, which is situated on the concave side of the curved tooth, and is in the form of a 
slit. The manner in which the blow is inflicted is as follows. The animal throws itself in the first place into a coil more or less close, and the anterior part of the body is raised. The neck is bent somewhat abruptly backwards, and the head fixed almost horizontally. In an instant, the head is, as it were, launched by a sudden effort towards the object of its anger, and the erected tooth struck into it, and withdrawn with the velocity of thought. It is found by experiment, that the effect of subsequent wounds is greatly diminished either by the diminution of the quantity of venom, or by some deterioration of its strength: so that if a venomous Serpent be made repeatedly to inflict wounds, without allowing sufficiently long intervals for it to recover its powers, each successive bite becomes less and less effective. A gentleman of my acquaintance had some years since received a living Rattlesnake from America. Intending to try the effects of its bite upon some rats, he introduced one of these animals into the cage with the Serpent; it immediately struck the rat, which died in two minutes. Another rat was then placed in the cage ; it ran to the part of the cage farthest from the Serpent, uttering cries of distress. The Snake did not immediately attack it; but after about half an hour, and on being irritated, it struck the rat, which did not exhibit any symptoms of being poisoned for several minutes, and died twenty minutes after the bite. A third and remarkably large rat was then introduced into the cage: it exhibited no signs of terror at its dangerous companion, which, on its part, appeared to take no notice of the rat. After watching for 
the rest of the evening, my friend retired, leaving the Serpent and the rat together; and on rising early the next morning, to ascertain the fate of his two heterogeneous prisoners, he found the Snake dead, and the muscular part of its back eaten by the rat. I do not remember at what time of the year this circumstance took place, but I believe it was not during very hot weather."*

Though there are no external characters by which the venomous Serpents may invariably be distinguished from those which are harmless, yet
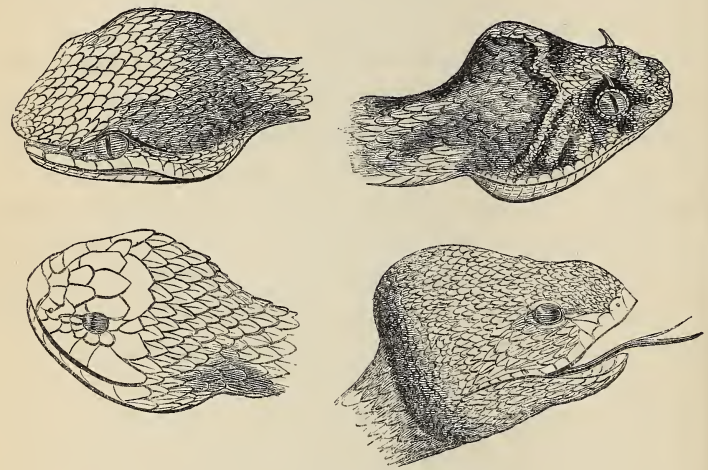

HEADS OF VIPERADE.

there is in most an aspect of malignity, which well indicates their deadly character. Their flattened head, more or less widened behind, so as to approach a triangular figure, their wide gape, and extensile tongue, and the sinister expression of their glaring eye, cause an observer to retreat with shuddering precipitancy. They are

* "British Reptlies," 60. 
in general bold and fierce, rearing up themselves, and with sparkling eyes advancing resolutely to the combat, instead of retreating from the foe, sometimes springing with great agility on an intruder to inflict the fatal stroke. The Najas or Hooded Snakes of Africa and India, Dr. Smith describes as always ready for fight, advancing, when their haunts are invaded, upon the intruder with the head and forepart of the body almost perpendicular, the neck expanded, and an expression sufficiently indicative of the malignant purpose they have in view: nor does the retreat of their enemy always put a stop to their advance. An officer of the Cape Corps, worthy of implicit credence, assured Dr. Smith that he had been chased twice round a waggon by an enraged Naja, and was delivered only by a Hottentot, who disabled the savage reptile by a blow with a long stick. ${ }^{*}$ Some species, as the Horned Vipers (Cerastes), will neither remove to avoid danger, however imminent, nor give any indication of their presence, until actually trodden on by the unwary foot, when the sudden injection of the deadly poison tells the intruder of his fate. Others, as the Rattlesnakes (Crotalus), on the approach of danger, give warning by agitating a series of horny cells, loosely articulated within each other, with which the extremity of the tail s furnished, and thus often permit the avoidance of their deadly stroke.

Besides the important distinction of this Family of Serpents, which is derived from the form and tructure of their poison-fangs, they are for the nost part marked by the large size and great

* "Zoolology of South Africa." 
width of the head, which is covered with small scales; by the scales of the body being in general rough and keeled; and by the tail being usually short in comparison with the body, and often thin or slender. The belly is clothed with broad bandlike shields or plates, as in the Snakes : there are no vestiges of limbs. Some have a deep pit, like a second nostril on the cheek, just in front of the eye, as the Rattlesnakes, whose singular caudal appendage we have just noticed. Others have the tail terminating in a small recurved spine, and others have two minute spines resembling recurved horns, on the tip of the nose. The Najas have the power of dilating the skin of the neck to an enormous extent when irritated. All the species with which we are acquainted, bring forth their young alive, the eggs being hatched in the moment of birth: the term Viper is an abbreviation of vivipara, which expresses this quality.

One of the most remarkable phenomena in Natural History is the power which, from time immemorial, has been exercised in the East by certain persons over the most venomous Serpents. It is more than once alluded to in the Sacred Scriptures, $*$ and multitudes of modern writers have described the practices of these Snakecharmers with more or less of accuracy. The Snakes chiefly subjected to their skill are the various species of Cerastes, or Horned Vipers, anc of Naja, or Hooded Snakes, which are commor. both in Africa and India. Many persons affirm that there is nothing extraordinary in the process that the Snakes are tamed for the purpose, anc deprived of their fangs, before the exhibition; bu

* Ps. lviii. 4, 5.-Jer. viii. 17. 
there are facts well attested that cannot be so summarily disposed of. Bruce, who often witnessed these performances, affirms that there can be no doubt of their reality. "Some," he says, " have doubted that it was a trick, and that the animals so handled had been first trained, and then disarmed of their power of hurting; and, fond of the discovery, they have rested themselves upon it, without experiment, in the face of all antiquity. But I will not hesitate to aver, that I have seen at Cairo (and this may be seen daily, without trouble or expense) a man who came from above the catacombs, where the pits of the mummybirds are kept, who has taken a Cerastes with his naked hand from a number of others lying at the bottom of the tub, has put it upon his bare head, covered it with the common red cap he wears, then taken it out, put it in his breast, and tied it about his neck like a necklace; after which it has been applied to a hen, and bit it, which has died n a few minutes; and, to complete the experinent, the man has taken it by the neck, and, beyinning at the tail, has ate it, as one would do a carrot or a stock of celery, without any seeming epugnance.

"I can also avouch, that all the black people in he kingdom of Sennaar, whether Funge or Nuba, re perfectly armed against the bite of either corpion or viper. They take the Cerastes in their lands at all times, put them in their bosoms, and hrow them at one another as children do apples r balls, without having irritated them by this isage so much as to bite. The Arabs have not his secret naturally; but from their infancy they cquire an exemption from the mortal con- 
sequences attending the bite of these animals, by chewing a certain root, and washing themselves (it is not anointing) with an infusion of certain plants in water. One day, when I was sitting with the brother of Sheikh Adelan, prime minister of Sennaar, a slave of his brought a Cerastes, which he had just taken out of a hole and was using with every sort of familiarity. I told him my suspicion that the teeth had been drawn; but he assured me they were not, as did his master Kitton, who took it from him, wound it round his arm, and at my desire ordered the servant to carry it home with me. I took a chicken by the neck, and made it flutter before him; his seeming indifference left him, and he bit it with great signs of anger; the chicken died almost immediately. I say his seeming indifference, for I constantly observed that, however lively the Viper was before, yet, upon being seized by any of these barbarians, he seemed as if taken with sickness and feebleness, frequently shut his eyes, and never turned his mouth towards the arm of the person who held him."

Sir W. Jones was assured by a learned native of India, that he had frequently seen the most venomous and malignant Snakes leave their holes upon hearing notes from a flute, which, as $h \epsilon$ supposed, gave them peculiar delight. Mr. Go. gerly, a missionary in India, confirms this state. ment. He observes, that some persons who were incredulous on the subject, after taking the mosi careful precautions against any trick or artifice being played, sent a charmer into the garden tc prove his powers:- "The man began to play upon his pipe, and proceeding from one part 0 : 
the garden to another, for some minutes stopped at a part of the wall much injured by age, and intimated that a Serpent was within. He then played quicker and his notes were louder, when almost immediately a large Cobra di Capello put forth its hooded head, and the man ran fearlessly to the spot, seized it by the throat, and drew it forth. He then showed the poison-fangs, and beat them out; afterwards it was taken to the room where his baskets were left, and deposited among the rest." "The snake-charmer," observes the same writer, "applies his pipe to his mouth, and sends forth a few of his peculiar notes, and all the Serpents stop as though enchanted; they then turn towards the musician, and approaching him within two feet, raise their heads from the ground, and bending backwards and forwards, keep time with the tune. When he ceases playing, they drop their heads and remain quiet on the ground."

The "Penny Magazine" for April 1833, contains the following very precise and circumstantial narrative, communicated by a gentleman of high station at Madras. "One morning as I sat at breakfast, I heard a loud noise and shouting among my palankeen-bearers. On inquiry, I learned that they had seen a large Hooded Snake, and were trying to kill it. I immediately went out, and saw the Snake creeping up a very high green mound, whence it escaped into a hole in an old wall of an ancient fortification; the men were armed with their sticks, which they always carry in their hands, and had attempted in vain to kill the reptile, which had eluded their pursuit, and in his hole had coiled himself up secure, 
whilst we could see his bright eyes shining. I had often desired to ascertain the truth of the report, as to the effect of music upon Snakes. I therefore inquired for a snake-catcher. I was told there was no person of the kind in the

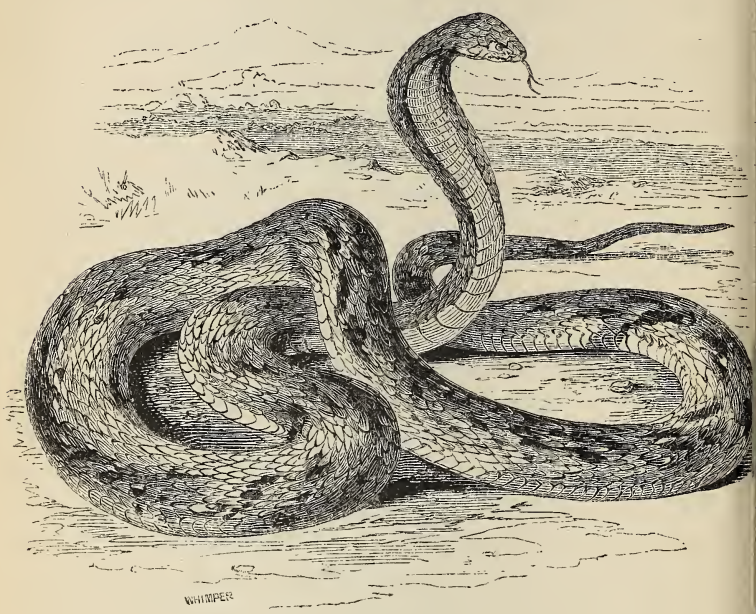

HOODED SNAKE.

village; but after a little inquiry, I heard there was one in a village distant about three miles. I accordingly sent for him, keeping a strict watch over the Snake, which never attempted to escape, whilst we, his enemies, were in sight. About an hour elapsed when my messenger returned, bringing a snake-catcher. This man wore no covering on his head, nor any on his person, excepting a small piece of cloth round his loins: he had in 
his hands two baskets, one containing tame Snakes, the other empty: these, and his musical pipe were the only things he had with him. I made the snake-catcher leave his two baskets on the ground, at some distance, while he ascended the mound with his pipe alone. He began to play: at the sound of music the Snake came gradually and slowly out of his hole. When he was entirely within reach, the snake-catcher seized him dexterously by the tail and held him thus at arm's length; whilst the Snake, enraged, darted his head in all directions, but in vain: thus suspended, he has not the power to round himself, so as to seize hold of his tormentor. He exhausted himself in vain exertions; when the snake-catcher descended the bank, dropped him into the empty basket, and closed the lid: he then began to play, and after a short time, raising the lid of the basket, the Snake darted about wildly, and attempted to escape ; the lid was shut down again quickly, the music always playing. This was repeated two or three times; and in a very short interval, the lid being raised, the Snake sat on his tail, opened his hood, and danced quite as quietly as the tame Snakes in the other basket, nor did he again attempt an escape. This, having witnessed with my own eyes, I can assert as a fact."

Fatal accidents, however, sometimes occur to the professors of the psyllic art, for there are still to be found "deaf adders," "which will not listen to the voice of the charmer." "In Madras," says a writer in "Chambers's Miscellany," "this belief [in the powers of the charmers] received a sad shock by a circumstance that occurred. One of the most noted serpent-charmers about the 
district chanced one morning to get hold of a Cobra of considerable size, which be got conveyed to his home. He was occupied abroad all day, and had not time to get the dangerous fang extracted from the Serpent's mouth. This at least is the probable solution of the matter. In the evening he returned to his dwelling, considerably excited with liquor, and began to exhibit tricks with his Snakes to various persons who were around him at the time. The newly-caught Cobra was brought out with the others, and the man, spirit-valiant, commenced to handle the stranger like the rest. But the Cobra darted at his chin, and bit it, making two marks like pin points. The poor juggler was sobered in an instant. 'I am a dead man,' he exclaimed. The prospect of immediate death made the maintenance of his professional mysticism a thing of no moment. 'Let the creature alone,' said he to those about him, who would have killed the Cobra; 'it may be of service to others of my trade. To me it can be of no more use. Nothing can save me.' His professional knowledge was but too accurate. In two hours he was a corpse! I saw him a short time after he died. His friends and brother jugglers had gathered around him, and had him placed on a chair in a sitting position. Seeing the detriment likely to result to their trade and interests from such a notion, they vehemently asserted that it was not the envenomed bite which had killed him. ' No, no; he only forgot one little word-one small portion of the charm.' In fact, they declared that he was not dead at all, but only in a sort of swoon, from which, according to the rules of the 
cabalistic art, he would recover in seven days. But the officers of the barracks, close to which the deceased had lived, interfered in the matter. They put a guard of one or two men on the house, declaring that they would allow the body to remain unburied for seven days, but would not permit any trickery. Of course the poor serpentcharmer never came to life again. His death, and the manner of it, gave a severe blow, as has been already hinted, to the art and practice of snakecharming in Madras."

Roberts also mentions the instance of a man who came to a gentleman's house to exhibit tame Snakes; and on being told that a Cobra, or Hooded Snake was in a cage in the house, was asked if he could charm it; on his replying in the affirmative, the Serpent was released from the cage, and, no doubt, in a state of high irritation. The man began his incantations, and repeated his charms, but the Snake darted at him, fastened upon his arm, and before night he was a corpse.

These and similar occurrences, however, so far from proving the falsehood of the snake-charmers' pretensions, seem to our judgment to be additional evidences of their truth; inasmuch as they make it manifest that these men believe their own powers, though they may sometimes fail. There is, in the present day, a far greater tendency to explain away, or to disbelieve, or boldly to deny, whatever cannot be readily accounted for, than to confess ignorance, or to weigh the evidence by which any assertion is supported; and we have often wondered at the disingenuous manner in which writers will pretend to explain away some straightforward, but 
unaccountable narration, by carping at some unimportant particulars, while the real gist of the matter is left untouched.

\section{Genus Pelias. (Merrem.)}

In this genus the head is depressed, almost oval, somewhat compressed before, and wider behind the eyes: the upper part is covered with small scaly plates, three of which (the vertical, and the two occipitals,) are larger than the rest; the scales of the body are lance-shaped, and keeled; the belly is clothed with broad shields, and those beneath the tail are arranged in a double series; the tail is short, and tapers abruptly; there are no pits or grooves in the scales before the eyes.

The Common Viper,

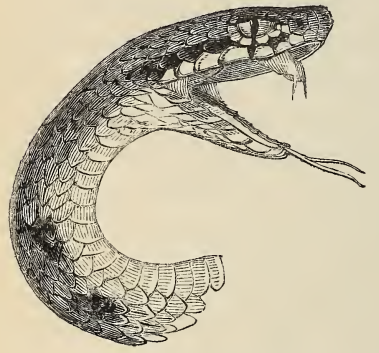

HEAD OF VIPER. or Adder (Pelias verus, Linn.), the only venomous reptile found in the British Isles, is even more common than the Ringed Snake, particularly in the northern part of Great Britain; in Ireland, however, it is unknown. It is less fond of water than the

Ringed Snake, preferring dry woods, sandy heaths, and chalky districts. It grows from two to three feet in length, and is commonly of a yellowish olive hue, marked with a black zigzag band down the body, formed by a series of lozenge-shaped spots, which run into each other 
at their points; a row of triangular spots runs down each side; a mark somewhat like a V is on the hind head, and between the eyes is a large central dark patch. The species is subject to much variety in colour, from white with black marks, to deep black, in which the marks are visible only in the play of light. It may be readily distinguished from the Common Snake by its zig-zag band, by its darker belly, by its wider head, and in particular by its short and abruptly tápered tail.

The Viper, as its name imports, is viviparous;

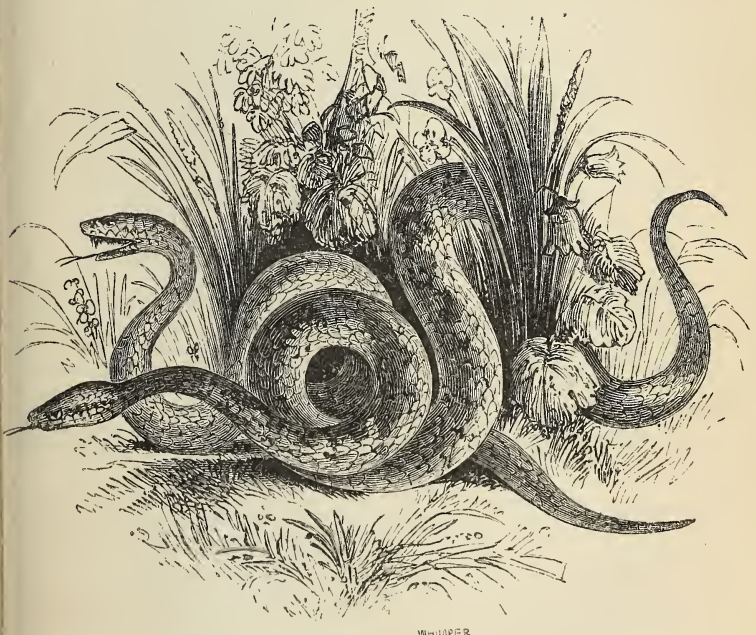

VIPER.

or rather the membrane which invests the egg is so tender, that it is ruptured in the moment 
of parturition. Mr. Bell has examined several in which the young appeared ready to be excluded, but has always found the investing membrane entire, though so thin and soft as to be torn by the slightest force. He gives a figure of the young Viper in this state, the membrane having been removed. It is coiled up so closely as almost to appear like a solid mass; but no sooner is it emancipated, than it assumes all the activity and virulence which belong to the species. The membrane seems to have been unobserved by White in the dissection which he thus records. "On August 4th, 17\%5, we surprised a large Viper, which seemed very heavy and bloated, as it lay in the grass, basking in the sun. When we came to cut it up, we found the abdomen was crowded with young, fifteen in number; the shortest of which measured full seven inches and were about the size of

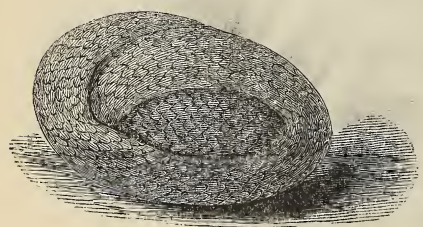

YOUNG IN FGG. full-grown earthworms. This little fry issued into the world with the true viper spirit about them, shewing great alertness as soon as disengaged from the belly of the dam: they twisted and wriggled about, and set themselves up, and gaped very wide when touched with a stick, shewing manifest tokens of menace and defiance, though as yet they had no manner of fangs that we could find, even with the help of our glasses." *

* "Natural History Selby," Lett. xxxi. (2nd Series.) 
Potent medicinal qualities were by our forefathers attributed to the Adder-egg, or Adderstone; the ovum anguinum of Pliny, the glein neidr of the ancient British. The Druids connected its production with the convoluted assemblages of Snakes which have already been noticed, and Mason, in his "Caractacus," has embodied the tradition in the following spirited lines :-

${ }^{66}$ From the grot of charms and spells,

Where our matron sister dwells,

Brennus, has thy holy hand

Safely brought the Druid wand,

And the potent Adder-stone,

'Gendered 'fore the autumnal moon?

When, in undulating twine,

The foaming snakes prolific join,

When they hiss, and when they bear

Their wond'rous egg aloof in air ;

Thence, before to earth it fall,

The Druid, in his hallow'd pall

Receives the prize;

And instant flies,

Followed by the envenom'd brood,

Till he cross the crystal flood."

Divested of poetry and superstition, these "Adder-stones," however, are nothing more than perforated beads of blue glass of great antiquity.

It has been often asserted, and the same thing is reported of the Rattle-snake, and other Serpents of this Family, that the young when alarmed, retreat into the mouth and gullet of the parent, and there remain until the danger is past. Some viper-catchers deny that this ever takes place, while others as strenuously affirm it. "There is no physiological reason against it. The young might live in 
such a situation for some time: it is well known that frogs will live and cry in the stomach of a Serpent." *

The food of the Viper consists of mice, shrews, moles; of lizards and frogs; and occasionally, of birds. It does not appear to strike the prey with its fangs, so as to poison it, but to take it exactly in the manner of the harmless Snakes. It is capable of long abstinence; individuals having been kept in a box for six months without food, yet retaining their health and vivacity unabated.

Although the poison of the Viper is rarely followed by fatal results to man in this country, it frequently produces severe symptoms of a highly threatening character. The remedies considered most efficacious are ammonia, administered internally, and olive oil applied externally; especially the latter. For the successful application of salad or olive oil to the part bitten by a Viper, we are indebted to William Oliver, a viper-catcher at Bath, who discovered the remedy more than a century ago. The public experiments on this subject are thus recorded:- ${ }^{\text {"On }}$ the 1 st of June, 1735, in the presence of a number of persons, Oliver suffered himself to be bit by an old black Viper (brought by one of the company) upon the wrist and joint of the thumb of the right hand, so that drops of blood came out of the wounds: he immediately felt a violent pain both at the top of his thumb and up his arm, even before the Viper was loosened from his hand: soon after he felt a pain, resembling that of burning, trickle up his arm; in a few * "Penny Cyclopedia," xxvi. 348. 
minutes his eyes began to look red and fiery, and to water much: in less than an hour he perceived the venom seize his heart with a pricking pain, which was attended with faintness, shortness of breath, and cold sweats; in a few minutes after this his belly began to swell, with great gripings and pains in his back, which were attended with vomitings and purgings: during the violence of these symptoms his sight was gone for several minutes, but he could hear all the while. He said that, in his former experiments, he had never deferred making use of his remedy longer than till he perceived the effects of the venom reaching his heart; but this time, being willing to satisfy the company thoroughly, and trusting to the speedy effects of his remedy, which was nothing more than olive oil, he forbore to apply anything till he found himself exceeding ill, and quite giddy. About an hour and a quarter after being bit, a chafing-dish of glowing charcoal was brought in, and his naked arm was held over it, as near as he could bear, while his wife rubbed in the oil with her hand, turning his arm continually round, as if she would have roasted it over the coals: he said the poison soon abated; but the swelling did not diminish much. Most violent purgings and vomitings soon ensued; and his pulse became so low, and so often interrupted, that it was thought proper to order him a repetition of cordial potions: he said he was not sensible of any great relief from these; but that a glass or two of olive oil drunk down seemed to give him ease. Continuing in this dangerous condition, he was put to bed, where 
his arm was again bathed, over a pan of charcoal, and rubbed with salad oil, heated in a ladle over the charcoal, by Dr. Mortimer's direction, who was the physician that drew up the account. From this last operation he declared that he found immediate ease, as though by some charm: he soon after fell into a profound sleep, and, after about nine hours' sound rest, awaked about six the next morning, and found himself very well; but in the afternoon, on drinking some rum and strong beer, so as to be almost intoxicated, the swelling returned, with much pain and cold sweats, which abated soon, on bathing the arm as before, and wrapping it up in brown paper soaked in the oil."

The medicinal virtues supposed to reside in the flesh of the Viper are now known to be apocryphal: as late as the last century, however, they were sufficiently credited to cause a demand for these reptiles in the shops of apothecaries. Many persons were thus encouraged to practise the art of viper-catching as a means of living, who sometimes caught the reptile with a pair of wooden tongs, and at others with a forked stick, which being driven down upon the neck secured the head, while the operator seizing the end of the tail, suddenly threw the animal into a bag. A curious story is told of the alarm produced in the house of an apothecary of the old school, by the escape of a whole collection of Vipers from the ill-closed box in which they arrived. Among other terrors resultant, a great black one was discovered coiled up between the sheets of one of the beds, just as its occupant was about to step into it. 


\section{Family V. Hydrophide.}

\section{(Sea-snakes.)}

The number of species contained in this group is not great, and they have all been made known to science within a comparatively recent period. They are not of large size; their forms are slender; but they are most readily distinguished by the oar-like form of their tail, which organ, as well as the posterior part of the body, is flattened vertically, so as greatly to resemble that of an eel, and in some cases, is dilated in the same direction. The nostrils are closed by a scale, and, as well as the eyes, are so situated as to have a vertical aspect; the pupils are circular, indicating diurnal activity; the ventral plates, formed of two united scales, are narrow, and occupy only the central line of the

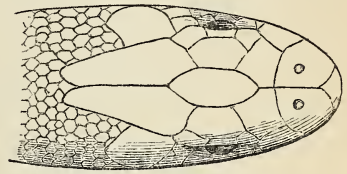
belly instead of its whole HEAD AND TAIL OF SEA SNAKES. breadth; there are no spurs, nor any vestiges of limbs.

These Marine Snakes are highly venomous, though their teeth display a structure somewhat differing from that of the fangs of the Viperade "The character," remarks Professor Owen, " most commonly adduced from the dental system as distinguishing the venomous from the nonvenomous Serpents, is, that the former have two, 
the latter have four rows of teeth in the upper jaw; the two outer, or maxillary rows being wanting in the venomous species, and their place being supplied by the single poison-fang. The exceptions to this rule, however, are too numerous for its value as a distinguishing character, in a question of such practical moment as the venomous or non-venomous properties of a Serpent. In all the family of the Marine Serpents, the poison-fang is only the foremost of a row of fixed maxillary teeth. In the Hydrophis striatus there are four teeth, and in Hydrophis schistosa five teeth behind the venom-fang, of rather smaller size than it: the two coloured Sea-Snake (Pelamys bicolor) has also five maxillary teeth, in addition to the perforated one. The poison-fang in this genus is relatively smaller than in the venomous Serpents of the land, but presents the same peculiar structure.... It is a curious fact that the smaller non-venomous teeth of the poisonous Serpents all present a trace of the structure of the functional venom-fang, being more or less deeply grooved along the convex interior side; and in the Hydrus, this groove commences by a depression analogous to the oblique basal aperture of the poison-canal in the true fang." *

The prevailing colour in this Family is yellowish, often varying towards green, blue, or white, and often relieved by blackish rings, or by broad lozenge-shaped spots placed transversely across the upper parts.

The Hydrophidae are natives of the Indian Seas, and the coasts of Australia, but some occasionally stray as far as the shores of New Zea* "Odontography." 
land, and the coral islands of the Pacific. Mr. J. E. Gray affirms that they sleep on the shore coiled up, and that they have been surprised asleep on the calm surface of the tropical seas; but they are oftener seen associated in shoals, keenly pursuing the fishes which constitute their prey. Other authorities affirm that they rarely, if ever, leave the water, that no instance is on record of any having been caught on shore, and that they are incapable of living out of the sea. It is remarked by the Rev. M. John, that he never found a land, a river, or a tank-Snake with a flat tail; such as are sometimes found in rivers, have been brought in by the tide, and can live only a short time out of the salt-water. $\mathrm{He}$ further remarks that it is difficult to procure Sea-Snakes, for though often caught in nets, they are held in such dread by the native fishermen, that the offer of almost any inducement will scarely procure them. The latter remark, however, scarcely agrees with Dr. Cantor's observations.

Dr. Russell describes the Marine Serpents in the water as active and elegant in their movements, but as possessing scarcely any power of locomotion on the land; they speedily die when brought ashore, or put into fresh water. $\mathrm{He}$ found in the belly of a female Hydrophis, nine perfectly formed young, inclosed each in its own enveloping membrane, from which circumstance we may infer that in common with other venomous Serpents, these are viviparous.

They are said not to be very ferocious, allowing themselves to be handled when taken out of the water, without manifesting a readiness 
to bite, but other observations tend to prove that this mildness must not be relied on.

M. Peron saw the Marine Serpents gliding gracefully along in great numbers on the surface of the Indian Seas, waging destructive warfare on shoals of small herrings, which fled precipitately into deeper water. In the stomachs of some which he captured, he found small fishes and various species of marine crustacea. The Serpents, in their turn, become the prey of sharks, - a fact which at first seems remarkable, when we consider the swift agility of the former contrasted with the unwieldiness of the latter; but the naturalist accounts for the fact by supposing that the prey is seized when asleep on the surface. So sound are their slumbers as they float on the waves, that a large ship may pass close among them, without awaking them by the surging of its prow, or by the voices of its crew. They swim and dive with equal facility; often at the very instant when the voyagers are throwing their nets over the slippery reptiles, they will disappear beneath the waves, diving to a great depth, and remaining more than half an hour without ascending to the surface, reappearing at length, at a very great distance from the spot where they had been seen to descend.

The salt water creeks and ditches on the shores of India and the great islands are greatly infested by the Sea-Snakes, and this is probably what Cuvier means when he affirms that the Chersydrus inhabits the bottoms of rivers in Java; for no species inhabits fresh water.

Mr. Gray observes of the geographical distribution of the Family, that of the forty-eight species 
known [in 1837] twenty are found in the Indian Ocean, sixteen in the salt water ditches of India and the neighbouring Islands, and six in similar situations in tropical America.*

\section{Genus HYDRophis. (DAUD.)}

The belly in this genus is furnished with a range of scales a little larger than those which cover the body; the head is small, not bulging behind, rounded in front, and surmounted by large plates. The species are found in the salt-water canals of Bengal, and in the Indian Ocean.

We illustrate this genus, of which little is known, by the Banded Sea-Snake, or Chittul (Hydrophis fasciatus, SHAw), a slender species about five feet in length, the ground-colour of which is blue, with alternate circular bands of yellowish white.

Our acquaintance with this interesting group is mainly due to the observations of Dr. Cantor, embodied in a paper on the Marine Serpents, published in the Proceedings of the Zoological Society. The author alludes to the Marine Ophidians as a group of Vertebrata, to which but little attention had hitherto been given, from the circumstance of the danger attending their examination in the living state, and also from their geographical distribution being entirely confined to the tropical seas. The author being stationed in the East India Company's service, on the Delta of the Ganges, had during a considerable period, most favourable opportunities for study* "Proceedings of the Zoological Society," 1837, p. 135. 
ing these Serpents, many of which were captured in the nets employed for fishing. His observations are principally directed to the anatomical characters which distinguish the marine from the

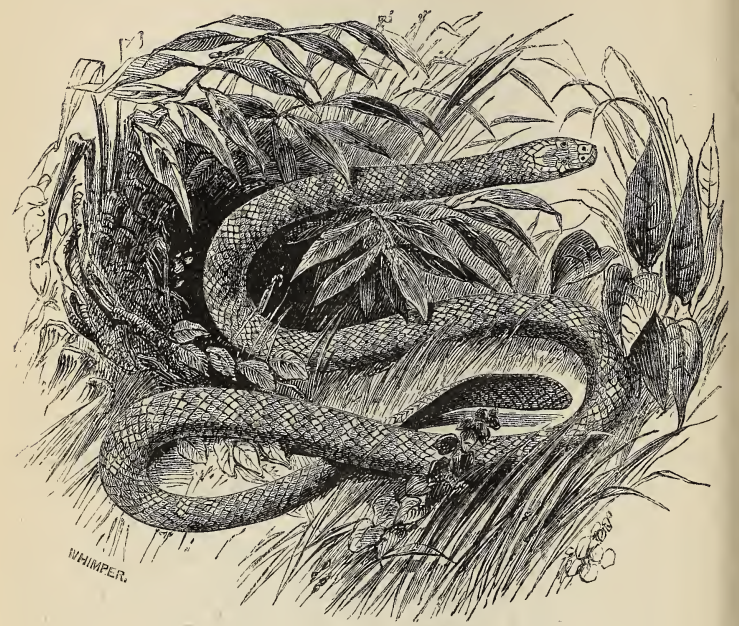

CHITTUL.

terrestrial Serpents, and to the modifications of structure by which the former are adapted to the elements in which they exist. With respect to their physiology, the principal point of interest he establishes is, the circumstance of all the species, without exception, being highly venomous, - a fact which has been denied by Schlegel, who states that the Marine Snakes are harmless; and the same erroneous idea is very current with the natives. Dr. Cantor in proof of the contrary refers to the recent death of an officer in $\mathrm{Her}$ 
Majesty's service, within an hour or two after the bite of a Serpent which had been caught at sea, and also to numerous experiments of his own, in which fowls, fish, and other animals invariably died within a few minutes after the bite had been inflicted."*

Soon after the opening of the bar in October, 1815, reports prevailed at Madras, that a large shoal of Sea-Snakes had entered the river, and that many natives had been bitten while crossing, and had died in consequence. A reward was then offered for each specimen captured, that should be brought to the Superintendent of Police. Pandauls (or temporary hospitals?) were erected, opposite the two principal fords, and skilful natives under the direction of Dr. M'Kenzie, to whom we are indebted for the account, were provided with eau-de-luce and other remedies, and ordered to afford immediate aid to those that were bitten. Many were wounded, and all exhibited symptoms common to those suffering from animal poisons; but none died. A native woman crossing near the customhouse, was seen, on emerging from the stream, to shake off some object from her foot, which to the bystanders appeared to be a Water-Snake. After proceeding a few paces, she fell down, and was carried in a state of insensibility to the pandaul. On examining her feet, two small but distinct wounds were observed on the ankle of the right leg; her skin was cold, her face livid, her breathing laborious, her pulse scarcely perceptible. A ligature was immediately placed above the wound, which had been previously enlarged with a lancet,

" "Proceedings of the Zoological Society," 1838, p. 80. 
and a piece of carbonate of ammonia, well moistened with pure nitric acid, applied; while thirty drops of eau-de-luce were administered nearly at the same time in a glass of water. In five minutes a similar dose was poured down her throat, which seemed to increase the spasmodic action of the chest, but the pulse at the wrist became distinct, though feeble. A third dose was given in three minutes more, on which she uttered a scream, and began to breathe more freely. Ten minutes had now elapsed since she had been brought to the pandaul, and in about three minutes more a teaspoonful of eau-de-luce was given, which almost immediately produced violent nausea, and profuse perspiration. When a little salt was put into her mouth, she declared that it was not salt, but sugar: and this the natives deemed an infallible sign of still continued danger. She soon, however, entirely recovered, and merely complained for three or four days of a numbness in the limb, above the wound.

Another case is recorded by a Lascar, who was bitten while in the midst of the river; the symptoms and the treatment were similar to the above; he also recovered, but complained for several days, that he had no left leg.

THE consideration of the Hydrophidae naturally suggests an allusion to an animal of great size, and serpent-like form, believed to inhabit the ocean, and commonly spoken of as the Great SeaSerpent. For ages the conviction of its existence has prevailed among the inhabitants of Norway; 
and the fjords, or deep inlets, which mark the rocky coast of that country are the scenes where it is reported to have been most frequently seen. The shores of New England in North America are also said to have been favoured with frequent visits by the mysterious animal during the present century; and very recently reports have been published of its appearance in the midst of the ocean, at a considerable distance from land. A multitude of witnesses of unimpeachable character for veracity, both in Europe and America, have testified to personal observation of the monster, and a great body of evidence exists on the subject; yet it cannot be denied that when these testimonies are carefully collated and examined in detail, they present discrepancies, anomalies, and improbabilities, which greatly diminish their value. Perhaps the most that can with safety be predicated, at present, is that there probably exists some marine animal of colossal size, and lengthened form, which has not yet been received into systematic zoology.

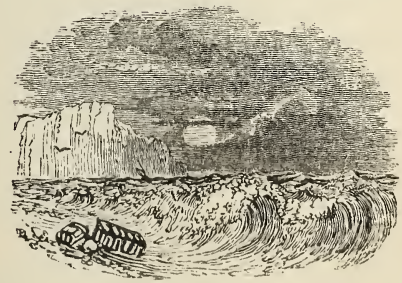




\section{SUB-CLASS II. AMPHIBIA.}

\section{(Naked Reptiles.)}

So important are the differences between the animals we have been considering, and those at which we are now arrived, that some zoologists of the greatest eminence consider them as forming two distinct Classes, or groups equal in rank to the Mammalia, Birds, and Fishes; though others of high reputation prefer to give to the latter no higher rank than that of an Order of the Class RePtrima, thus making this group only equal in value to the Testudinata, or Sauria respectively. It is principally for the convenience of describing both in a single volume, that we assign to the Amphibia an intermediate place; making them a group of equal rank to the rest of the $R_{\mathrm{EP}}$ TILIA put together, but not one of the primary divisions of the VERTEBRATA.

The Amphibia, though widely distributed, are not very numerous, nor do any of them attain a large size. Destitute for the most part of the attractions of form and colouring, they are not generally considered interesting, except to the philosophical observer of the works of God; but he, however, perceives in them abundant evidences of creative wisdom.

The most obvious character of these animals is that of their integuments. The skin is naked, not being defended by plates or scales, or any 
similar apparatus; it is in general moist or clammy, and in many cases is provided with numerous glands which pour out a viscid secretion. The outer skin, or epidermis, is sloughed at irregular intervals like that of the Lizards and Serpents. The form is generally more or less lizard-like, but in one Order, that of the Frogs, this form is lost at an early period of life. They possess, in general, four limbs; but, like the Lizards, they shew a tendency to merge into a serpentiform condition, by the lengthening of the body, and loss of the hinder extremities in the Sirens, and by the total absence of feet, and snake-like contour of the Cacilia.

Most of the Amphibia undergo a metamorphosis, or change of form, which is connected with a change in the character of their respiration and in the medium in which they live. Thus the Frog is, in its first stage of active existence, a fish-like Tadpole, breathing the water by means of gills, but afterwards undergoes a great change of form, gradually acquires four well-developed limbs, throws off its tail, and at the same time loses its external gills, and becomes an air-breathing animal, possessed of internal lungs, and capable of crawling on the land as well as swimming in water. Some of the genera, indeed, possess both series of respiratory organs during their whole life, and are consequently Amphibia in a more strict and literal sense, possessing a capacity of living and breathing in two elements.

The reproduction is effected by means of eggs, which are numerous, more or less globular in figure, pellucid, and destitute of a calcareous 
covering. In general, they are enveloped in a transparent glaire or jelly.

The organization of the skeleton, as well as other peculiarities in the anatomy, manifest that the Amphibia are formed on a grade of structural development, inferior to that of the Enoplia. The skull is united to the spine by two processes,

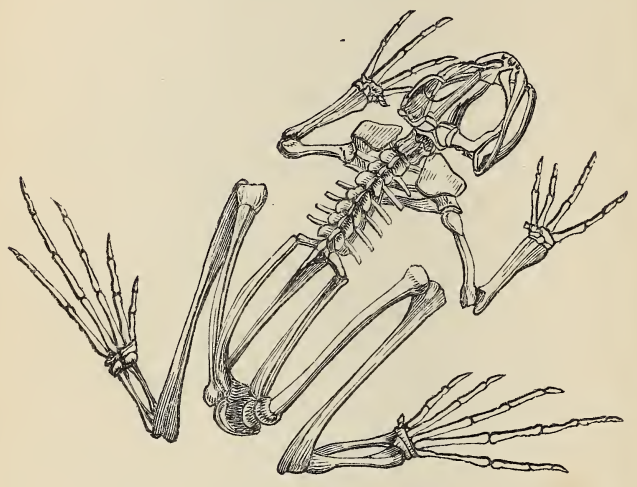

SKELETON OF FROG.

or condyles, instead of one, the ribs are either rudimentary or altogether wanting, and the sternum or breast-bone is imperfectly developed, or absent.

"To any person," observes Professor Bell, "capable of appreciating the interest attached to the study of physiological phenomena, the contemplation of an animal, which, at one period of its life, is endowed exclusively with the organs of aquatic respiration, resembling the gills of fishes, with means of locomotion adapted only to a con- 
stant residence in the water, and with a digestive apparatus, fitted exclusively for the assimilation of vegetable food, assuming by degrees the function of atmospheric respiration, acquiring limbs which are formed for leaping on land with great strength and agility, and manifesting the most voracious carnivorous appetite, will not only excite feelings of the deepest admiration, but necessarily lead to the investigation of the laws by which such extraordinary changes are governed, and of the relations which they bear to the theory of continuous affinity before alluded to, and to that of progressive development through the whole of the animal kingdom. That such phenomena are exhibited by the typical forms of this Class, will be sufficiently established by the slight sketch of their structure, habits, and development, which will presently be offered." *

The Amphibia are arranged by the eminent zoologist just quoted in five Orders, distinguished by the general form, the presence and number of the limbs, and the character of the respiration. They are named Anoura, Urodela, Amphipneusta, Abranchia, and Apoda.

$$
\text { * " British Reptiles," } 72 .
$$

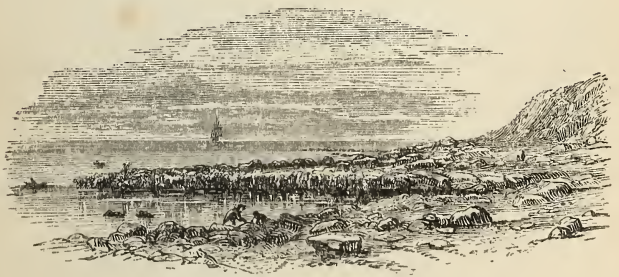




\section{ORDER I. ANOURA.}

\section{(Frogs and Toads.)}

In the adult or perfect condition, the form of these animals differs much from that common to the Amphibia, the body being short, broad, and flattened horizontally, and destitute of every vestige of a tail. There are four limbs, well developed, and furnished with toes, five on each foot, but the thumb of the fore foot is a mere tubercle; the posterior limbs are longer than the others, and are formed for leaping. The ribs are totally wanting; the vertebrce or joints of the spine are few and soldered together. The tympanum or drum of the ear is exposed.

In the tadpole condition, the form is fish-like, the body being lengthened, compressed, and terminating in a long thin tail; there are no limbs, these being developed in the process of metamorphosis; the water is the medium which the animal in this its infancy inhabits, in which it swims with ease, by the lateral undulation of its oarlike tail. Respiration is performed by gills or branchice alone, which project on each side of the neck in the form of little tufts. As the period of the change approaches, these are gradually withdrawn into the chest, and the animal becomes an air-breathing Frog or Toad, more or less terrestrial in its habits.

The eggs are enveloped in a clear and tenacious jelly, and are laid either in long strings, or in 
large masses; they are fertilized externally, in the process of deposition, which always takes place in the water.

The head of these animals is very large, but the cavity of the skull is very small; and yet the brain is scarcely sufficient to fill it. The gape is enormous.

The Anoura are distributed over the whole habitable globe; but they abound most in America, while Africa presents us with very few. These facts are sufficiently explained by the abundance of water in the one continent, and by the scarcity of it in the other. The Order contains four Families, Ranada, Hylada, Bufonida, and Pipada.

\section{Family I. Ranade.}

\section{(Frogs.)}

The Frogs proper are distinguished from the Toads by having small teeth in the upper jaw; most of the species have also teeth in the palate, or rather pointed processes forming a part of the bones to which they are attached, as in the case of certain fishes. From the Tree-frogs they are distinguished by having the toes ending in blunt points, scarcely or not at all dilated, and by terrestrial and aquatic habits. They have always four toes on each anterior foot, and five on the posterior, which are commonly united by a broad swimming membrane, like those of web-footed birds. At the base of the first finger of the hand, there is generally a prominence, more or less obvious, which proves, on dissection, to be the 
rudiment of a thumb, and at the outer edge of the ankle of the hind foot there is for the most part a tubercle, which in some genera is expanded into a large oval disk with free edges; this tubercle is analogous to one of the little bones of the human ankle, and is not, as has been supposed, the rudiment of a sixth toe.

The motions of the Frogs are lively, and the muscular power displayed by them very great, particularly in swimming and leaping. "The muscles of the abdomen," as Mr. Broderip observes, "are more developed than in the other reptiles, offering, in this particular, some analogy to the abdominal structure of the Mammifers. But it is in the disposition of the muscles of the thigh and legs, in the Frogs and other Anourous Batrachians, that the greatest singularity is manifested. These, whether taken conjointly or singly, present the greatest analogy with the muscular arrangement of the same parts in man. We find the rounded, elongated, conical thigh, the knee extending itself in the same direction with the thigh-bone, and a well-fashioned calf to the leg. It is impossible to watch the horizontal motions of a frog in the water, as it is impelled by these muscles and its webbed feet, without being struck by the complete resemblance in this portion of its frame to human conformation, and the almost perfect identity of the movements of its lower extremities with those of a man making the same efforts in the same situation. By the aid of these well-developed lower limbs, and the prodigious power of their muscular and bony levers, a Frog can raise itself in the air to twenty times its own height, and traverse, at a 
single bound, a space more than fifty times the length of its own body."

The food of the Frogs in the tadpole condition consists of decaying vegetable matter, though they do not refuse to prey upon animal substances also. In the adult state they feed on insects, slugs, \&c., in the taking of which the tongue is principally employed. This organ, which is soft and fleshy, and covered with a glutinous secretion, is fixed to the inner part of the front of the jaw, so that when at rest its tip points backwards towards the throat. When the Frog takes its prey, the tongue, observes Mr. Martin, "becomes considerably elongated, and turns on the pivot of its anterior fixture, being reversed in such a manner that the surface which was undermost when the tongue was lying in a state of repose in the mouth, is now the uppermost, the original position being regained, when it turns on its pivot back again into the mouth. The rapidity with which the Frog or Toad launches this organ at insects or slugs is extraordinary, insomuch that the eye can scarcely follow the movement; never is the aim missed; the prey touched by the tongue adheres firmly, the viscid saliva being very tenacious, and is instantaneously carried to the back of the mouth and swallowed.

"We have often presented slugs on bits of straw or stick to Toads, and watched with surprise the sudden disappearing of the prey, which seemed to vanish from the stick as if by magic." *

The Frogs are endued with considerable powers of voice; their efforts, it is true, are not very musical; a hoarse guttural croaking is the sound

$$
\text { * "Pict. Mus. ii." } 126 .
$$


with which we are most familiar, but some foreign species utter various other discordant noises, such as shrieks long-protracted, and intolerably shrill and piercing, whistlings, snorings as of a person in oppressed slumber, or the deep bellowings of a bull.

In temperate countries they become torpid during winter, retiring on the approach of cold weather into the mud at the bottom of ponds, where multitudes huddle together in numerous assemblages. The mild air of spring awakens them from their death-like sleep, when they separate, emerge from their retreats and soon make the shores of our waters vocal, if not musical, with the pertinacity of their sexual call.

\section{Genus $R_{A N A}$ (Linn.)}

The skin in this, the typical genus, is smooth; the hinder legs are very long, muscular, and formed for leaping; the toes of the hind feet are connected by a web; there are teeth on the upper jaw, and on the palate; the gape is very wide; the tongue, broad, soft, notched at the extremity, is folded back, the anterior portion lying ordinarily on the posterior; the eyes are brilliant and prominent, and elevated above the forehead.

The Common Frog (Rana temporaria, Lins.) is familiar to every child. Every rivulet and river, every lake, pond, and pool, every stagnant or running ditch by the road-side, and even the little collections of rain-water that lie in the gravel-pits of the common, are pretty sure to be tenanted by this vigorous and graceful swimmer, or by its black and wriggling tadpoles. When full grown the Frog is rather more than 
two inches and a half in length; it varies much in colour and markings, but is commonly of a yellowish brown, sometimes greenish or reddish, irregularly spotted with dark brown patches,

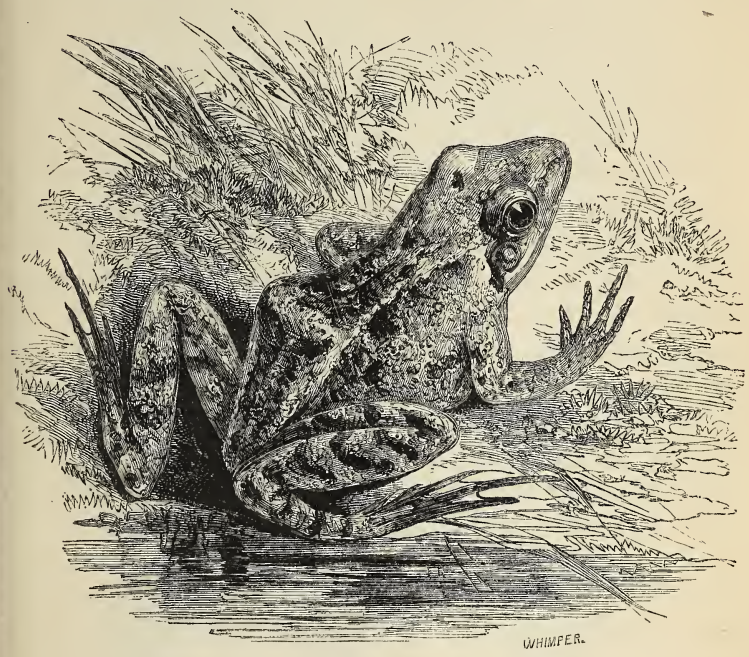

FROG.

which on the limbs take the form of transverse bands: there is generally an oblong patch of brown behind each eye, and a pale line down each side: the under parts are yellowish white.

Early in spring the Frog deposits its eggs at the bottom of water; these resemble black dots distributed at equal distances throughout a large mass of transparent jelly. After a while the mass rises to the surface. In about a month after the deposition, in this country, but much 
sooner in warmer climates, the little Tadpoles are hatched. They appear to consist of an enormous head and a long, thin, vertically flattened tail ; from the hinder part of the head, on each side, are seen to project two minute tufts, divided into branched leaflets. These are the branchice or gills, by means of which oxygen is separated from the water for the renewal of the vital power of the blood. These tufts rapidly enlarge, and soon attain their greatest development, in which state they form, as Mr. Bell assures us, one of the most charming objects for microscopic observation which can be conceived, and to view which a very high power is not necessary nor even desirable. The current of the blood poured in regular pulsations at each contraction of the heart, passes up each stem or main branch of the branchir, and a distinct stream is given off to each leaf; it is propelled to the extremity, and
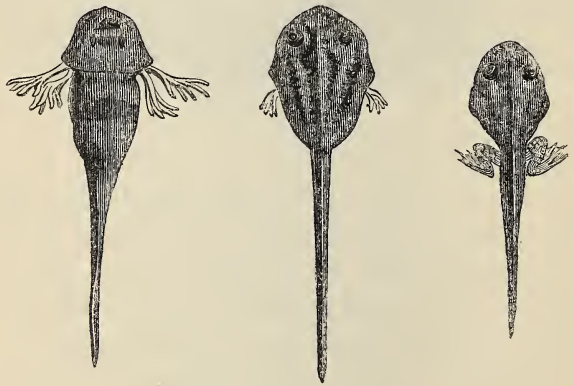

TADPOLES.

then returns down the opposite sides in the most regular manner, and the parts are so transparent 
that every globule of blood is distinctly and beautifully visible.*

The branchial tufts now begin to diminish, while the Tadpole increases in bulk, until at length the limbs bud forth and assume their form and toes, the hinder pair being developed first. The tail is now gradually absorbed, the absorption commencing at the tip and proceeding towards the base until the last trace has disappeared. The gills are by this time so much reduced as to be withdrawn beneath the skin, and are no more visible; the eyes and mouth are fully formed; the colour has changed to an olive-green, spotted with yellow on the under parts ; and, in short, the animal is no longer a Tadpole, but a little Frog.

The respiration is now carried on by means of large cellular lungs; but the action of breathing is not performed as in most other Vertebrata, by alternate contraction and dilatation of the chest, for the Frog has no ribs, by the depression of which to enlarge the thoracic cavity,- - but by the actual swallowing of the air, the element being forced down the windpipe into the lungs, by an action perfectly similar to that by which food is forced down the gullet into the stomach.

But there is another agent employed in the respiration of these animals beside the lungs, namely, the whole surface of the skin. Numerous and careful experiments have proved that the blood is purified, and the vital functions go on for a considerable time, after all access of air to the lungs has been cut off, and even (by an experiment, the wicked cruelty of which we cannot

* "British Reptiles" 96. 
mention without reprobation) after the lungs had been totally cut out. It is necessary, however, that the skin should be maintained continually moist; for if it become dry, its action ceases, and death is the speedy result. "But," remarks Professor Bell," as the frog is frequently exposed to a dry atmosphere, it is essential that there should be some provision made for a constant supply of moisture to the skin. This is effected by a secretion of fluid from the surface itself. The extent of the skin is, however, so great that the whole internal moisture of the animal would speedily be exhausted, unless a reservoir were provided for an extraordinary demand; and I now proceed to shew what this reservoir is, and by what means it is replenished. Every one knows that when a Frog is hastily seized, or even quickly pursued, it voids a considerable quantity of water, which is generally but erroneously, supposed to be the urine. This water is limpid and pure, containing no traces of the usual component elements of the urinary secretion. It is contained in a sac, which has also been mistakenly believed to be the urinary bladder. This is the reservoir to which I have alluded. When, therefore, the frog is happily placed in a damp atmosphere, or in the water, the skin absorbs a quantity of water, which there is every reason to believe is secreted into the bladder just mentioned, where it is kept in store until the dryness of the skin requires a supply for the purpose of respiration, when it is again taken up, and restored to the surface, by which it had been first absorbed." * The Frog is capable of being tamed, and of * "British Reptiles," 79 . 
discerning those who treat it kindly. If kept in a garden, it proves a very useful inhabitant, by its services in devouring noxious insects, and particularly the small species of slug which is so destructive to vegetation. The number of these which a single Frog will devour is truly surprising.

\section{Family II. HyLade.}

\section{(Tree-frogs.)}

This is the most numerous in species of all the Families of the Amphibia, and the one which deviates most in its manners from the rest. The Tree-frogs reside habitually among the foliage of trees, among which they hop and leap almost with the agility of the birds that tenant the groves conjointly with them. They are able to cling to the leaves on which they alight, with exact precision, and to walk on them in all positions, and even on their under surfaces, without falling off, just as a fly alights on the ceiling of a room, and rests or crawls there. The smoothness of the leaves, or other surfaces on which they rest, offers no impediment to the security of their position, for they do not derive their power from the inequalities of the surface. "The monkey grasps with its paws the perch on which it rests; the bird with its claws; the snake twines itself around the branch; the iguana uses its long toes and hooked nails; the chameleon holds the bough tight between its vice-like toes; but the foot of the Tree-frog acts differently from the foot of these animals: it is not a grasping organ, nor is it furnished with claws for clinging; but it 
is provided with suckers, analogous to those we have noticed in the foot of the Gecko." * Each toe, both of the fore and hind feet, is dilated at the tip into a circular pallette or pad, varying in size in different genera: these little cushions are, it is true, moistened with a glutinous fluid, as is the whole surface of the body; but we believe that this viscidity is not, as has been supposed, the agent by which the animal so powerfully adheres against gravity; but that the pallettes act as suckers, being sustained in their position by the pressure of the atmosphere, a vacuum being produced beneath them, or removed at the creature's will.

The colours of the Tree-frogs are various, and are often brilliant and beautiful; like many other Reptiles they have the faculty of changing their hues to an extent that often affords them protection, by rendering them difficult to be discerned. They are very numerous in the damp woods of tropical America, residing habitually by day in the concealment afforded by the huge Bromeliacea or Wildpines, and other parasitical plants that grow in tufts on the trunks and branches of great trees, the sheathing bases of whose leaves not only afford them umbrageous bowers in which to dwell, but also form reservoirs in which the rain-water collects, and thus provide the moisture without which they would soon expire. The under-surface of the bodies of these arboreal Frogs is very different from that of the terrestrial species; the skin, instead of being smooth, is covered with granular glands pierced by numerous pores, through which the * "Popular History of Reptiles," 303. 
dew or rain spread on the surface of the leaves is rapidly absorbed into the system, and reserved to supply the moisture needful for cutaneous respiration, as already explained. In the night, they are active and vociferous, and the woods in the tropics then resound with the various sounds emitted by these creatures. Some utter a pleasing chirp, or clear whistle, like the voice of a bird; others produce a ringing shriek, so loud and piercing as to be almost unbearable, while yet others supply the bass of this nocturnal concert, groaning and snoring in great variety of deep, hollow, guttural sounds. These noises reiterated with incessant pertinacity, through the livelong night, mingled with the shrill crinking of locusts and Cicade, quite banish sleep from a stranger's eyes; but habit, as in other things, soon familiarises the ear to these discordant noises, and they cease to be perceived. These cries are uttered only by the males; which are furnished beneath the throat with a dilatable skin, capable of being inflated into a tense globose bladder, during the emission of the sound.

The prey of the Hyladae consists of insects and similar small creatures, which are taken by the instantaneous projection of the tongue. Their upper jaw is furnished with teeth like that of the Frogs, but the manner in which they are arranged differs in different genera. The form of the tongue also varies; in some it is forked, in others it is heart-shaped, and in others it is long and ribbon-like. The toes are for the most part webbed, but in several genera they are free, and in one they are fringed with a free membrane 
on each side; in one genus the first toe is opposible to the others, thus forming a sort of hand.

The early history of the Tree-frogs does not differ materially from that of their humbler terrestrial brethren. The eggs are laid in the water, in which the Tadpoles spend their existence; and in temperate climates the perfect animals resort to the same element to spend the winter in a torpid insensibility.

The sixty-four species which MM. Duméril and Bibron enumerate as belonging to this $\mathrm{Fa}$ mily are thus distributed:- one is found in southern Europe; five are peculiar to Africa; eight to Asia; ten to Australasia and the Indian Archipelago; and thirty-seven to America. Of three species, the native locality is unrecorded.

\section{Genus $H_{\text {Yla }}$ ( (Laur.)}

The extreme elegance and beauty of the European Tree-frog (Hyla viridis, LAUR.) have made it a general favourite wherever known. It is small and of slender proportions; the upper parts are of a delicate green, the inferior parts white; on each side of the body runs down a stripe of yellow bordered with violet or purple, extending along the limbs. It is spread over the whole of southern Europe, extending also into North Africa, but is not a native of Great Britain. During winter it remains torpid at the bottom of ponds, but through the balmy months of summer this beautiful little creature resides in trees, principally resorting to the higher branches, where it leaps to and fro, or 
lurks among the foliage in search of insects. These it captures with much dexterity, stealing softly towards a vagrant fly or beetle, as a cat does upon a mouse, its green hue rendering its approach among the quivering leaves undistinguishable, till, being arrived at a proper nearness, it suddenly launches and retracts its tongue with a lightning stroke, and the unsuspecting insect vanishes within its mouth.

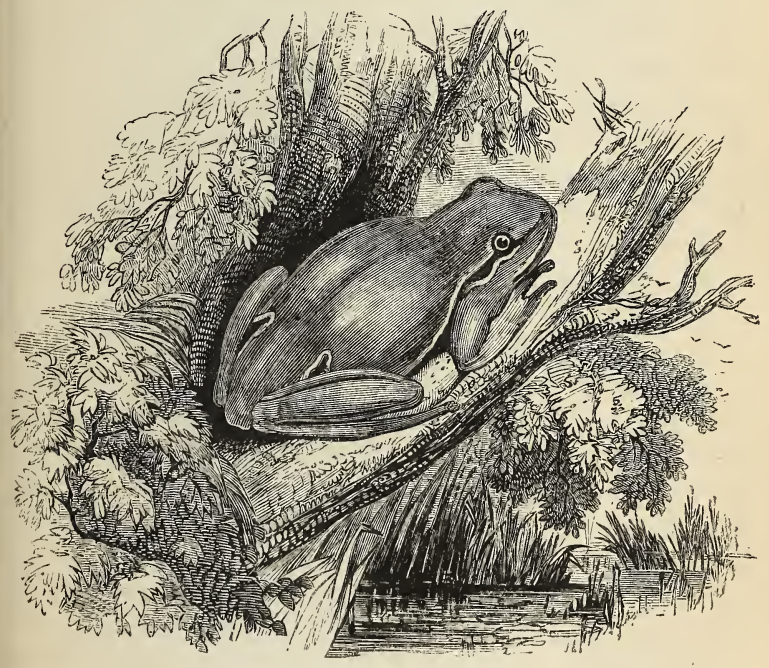

TREE-FROG.

The croak of the Tree-frog is very loud and hoarse, so as to be heard at a great distance. The commencement of this note is the signal for all to join that are within hearing, and a chorus is formed that is said to resemble the 
baying of a pack of hounds. During the emission of the sound the skin of the throat is inflated so as to form a sphere nearly as large as the head. Some interesting observations on the respiration of these animals are recorded by Dr. Townson. He kept his Tree-frogs in a window, and appropriated to their use a bowl of water, in which they lived. They soon grew quite tame; and to two that he kept a considerable length of time, and were particular favourites, he gave the names of Damon and Musidora. In the hot weather, whenever they descended to the floor, they soon became lank and emaciated. In the evening they seldom failed to go into the water, unless the weather was cold and damp; in which case they would sometimes remain out for a couple of days. When they were out of the water, if a few drops were thrown upon the board, they always applied their bodies as close to it as they could; and from this absorption through the skin, though they were flaccid before, they soon again appeared plump. A Tree-frog that had not been in water during the night was weighed, and then immersed: after it had remained about half an hour in the bowl it came out, and was found to have absorbed nearly half its own weight of water. From other experiments on Tree-frogs, it was discovered that they frequently absorbed, by the under-surface only of their bodies, nearly their whole weight of water. These animals will even absorb moisture from wetted blotting-paper. Sometimes, with considerable force, they eject water from their bodies, to the quantity of a fourth part or more of their own weight.

Both Frogs and Toads will frequently suffer 
their natural food to remain before them untouched, yet if it make the smallest motion, they instantly seize it. A knowledge of this circumstance enabled Dr. Townson to feed his favourite Tree-frog, Musidora, through the winter. Before the flies, which were her usual food, had disappeared in autumn, he collected for her a great quantity, as winter provision. When he laid any of them before her, she took no notice of them; but the moment he moved them with his breath, she sprung upon and ate them. Once when flies were scarce, the Doctor cut some flesh of a tortoise into small pieces, and moved these by the same means. She seized them, but the instant afterwards rejected them from her tongue. After he had obtained her confidence, she ate from his fingers dead as well as living flies. Frogs will leap at a moving shadow of any small object; and both Frogs and Toads will soon become sufficiently familiar to sit on the hand, and be carried from one side of the room to the other in order to catch flies as they settle on the wall. At Gottingen, Dr. Townson made them his guards for keeping these troublesome creatures from his dessert of fruit, and they acquitted themselves to his satisfaction. He has even seen the small Tree-frogs eat humble bees, but this was never done without some contest. The Frogs were in general obliged to reject them, being incommoded by their stings and hairy roughness; but in each attempt the bee was farther covered with viscid matter from the Frog's tongue, and, when sufficiently covered with this, it was easily swallowed.*

* “Bingley's Animal Biography," iii. 162. 
Family III. Bufonide.

(Toads.)

The Toads are totally without teeth, both in the jaws and in the palate; the body is thick and swollen, and the skin is set with warts or tubercles; behind each eye is a glandular protuberance, studded with pores, from which a milky secretion exudes; the head is large and flat on the top; the hinder limbs are not much longer than the fore, and consequently their powers of leaping are but small. They habitually crawl, and when they jump, it is with little agility, and only to a short distance. In the tadpole state they inhabit the water, and resemble the members of the preceding Families; but after their metamorphosis, they are much less dependent on the presence of that element, rather affecting dry situations. They are for the most part nocturnal in their habits, crawling about in the twilight and darkness in search of insects and slugs, but retiring during the day into holes in the earth, beneath stones, roots of trees, and other obscure retreats.

Some of the foreign Toads are marked by curious peculiarities of structure. One genus has the back armed with a long dorsal shield; another has the muzzle set with beards: some have only four toes on the hind foot; others have on the same foot two large oblong tubercles in addition to the five normal toes.

Geographically the Toads are said to be thus distributed:- Europe possesses four species, 
which are not, however, peculiar to it; Asia nine; Africa two; Australia one; and America seventeen; and there are four or five whose locality is unrecorded. This enumeration, however, must be greatly under the mark; as many species have been lately added to those previously known.

\section{Genus Bufo. (Laur.)}

The characters by which the true Toads are distinguished are thus enumerated by Professor Bell. Body inflated, skin warty, parotids (or glands behind the eyes) porous, hind feet of moderate length, toes not webbed, jaws without teeth, nose rounded.

Eighteen species of this genus are recorded, of which the best known is the Common Toad (Bufo vulgaris, Laur.), which is spread over Europe, Asia, and North Africa, being found from Great Britain to Japan. It is nearly three inches and a half in length, of an unpleasing form and aspect; the body puffed and swollen, covered with warts, which are larger on the upper parts, smaller, but more numerous beneath. The colours are commonly a dull lurid blackish hue above, with the warts brown; and a dirty yellowish white beneath.

The Toad is not poisonous in the sense in which the Viper is; but the popular prejudice is not wholly without foundation, which attributes "sweltered venom" to this animal. On the back and sides are situated many glands in the skin, which secrete a fetid and acrid matter. This substance exudes from the glands on pressure, 
"6 in the form of a thick yellowish fluid, which, on evaporation, yields a transparent residue, very acrid, and acting on the tongue like extract of aconite. It is neither acid nor alkaline; and since a chicken inoculated with it, received no injury, it does not appear to be noxious when absorbed, and carried into the circulation!*"

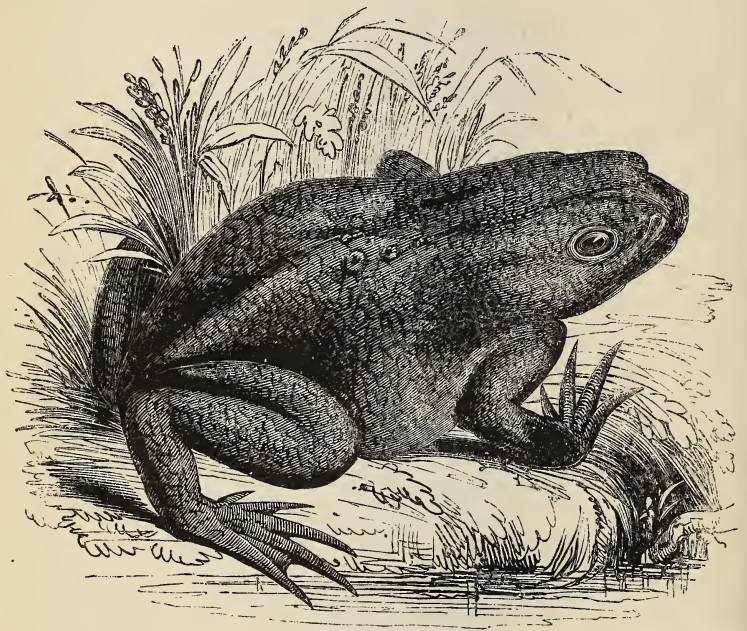

TOAD.

The prey of the Toad is the same as that of the Frog,-insects of all kinds, slugs and earthworms; and hence it is a useful inhabitant of a garden, in which it may be often kept with more facility than the Frog, from its indifference to water, which is needful to the comfort * Dr. Davy, quoted in " British Reptiles," 113. 
of the Frog. It takes its food in the same manner, but refuses that which is not alive, and even in actual motion. It is sluggish in its motions, neither leaping nor running, its pace being a kind of crawl. On being alarmed, it stops, swells its body, and on its being handled, a portion of the acrid secretion exudes from the glands, and a quantity of pure water, alluded to in our account of the Frog, is suddenly discharged from the internal reservoir.

Like the other Amphibia, the Toad casts its skin at uncertain periods, after which its colours are much brighter than before. The outer skin divides in a line, extending down the middle of the back and of the belly, and is gradually pushed down in folds towards each side, until it is detached, when it is pushed by the two hands into the mouth in a ball, and swallowed at a single gulp. The hands are used in the same manner, to push into the mouth earthworms, which in their writhing, twist about the animal's muzzle and head.

The Toad is more easily tamed than the Frog: Professor Bell mentions a very large one which would sit on one of his hands, and eat from the other; and Pennant in his "British Zoology" has immortalized a pet Toad of one of his correspondents in a narrative, which is interesting in another respect also, as shewing the great longevity of this Reptile.

"Concerning the Toad," writes Mr. Arscott, " that lived so many years with us, and was so great a favourite, the greatest curiosity was its becoming so remarkably tame. It had frequented some steps before our hall door, some 
years before my acquaintance commenced with it, and had been admired by my father for its size (being the largest I ever met with), who constantly paid it a visit every evening. I knew it myself upwards of thirty years; and, by constantly feeding it, brought it to be so tame, that it always came to the candle and looked up, as if expecting to be taken up and brought upon the table, where I always fed it upon insects of all sorts. It was fondest of fleshmaggots, which I kept in bran: it would follow them, and when within a proper distance, would fix its eyes, and remain motionless for near a quarter of a minute, as if preparing for the stroke, which was an instantaneous throwing of its tongue at a great distance upon the insect, which stuck to the tip by a glutinous matter. The motion is quicker than the eye can follow. I cannot say how long my father had been acquainted with the Toad before I knew it; but when I was first acquainted with it, he used to mention it as 'the old Toad I have known for so many years.' I can answer for thirty-six years." The end of this Toad was somewhat tragical. A tame Raven seeing it at the mouth of its hole, pulled it out, and before help could come, destroyed one of its eyes, and so injured it, that, though it survived a year, it never enjoyed itself again, nor could take its prey with the same precision as before. $\mathrm{Up}$ to that accident it had seemed to be in perfect health. 


\section{Family IV. Pipade.}

In this Family, which consists of a single genus confined to South America, the tongue is entirely wanting. The body is flattened and very broad; the head also is large, flat, and somewhat triangular; the tympanum is concealed, the toes are divided into star-like points.

\section{Genus Pipa. (Laur.)}

The large triangular head in this singularly uncouth reptile, bears a distant resemblance to that of a hog, having the muzzle prolonged into a sort of tube in which the nostrils terminate; the eyes are minute and situated on the upper surface of the head, near the margin; the eyelids are merely rudimentary, incapable of covering the eyes. There is no tongue, nor any teeth either in the jaws or palate, nor any external trace of the great parotid glands, so conspicuous behind the eyes of our common Toad. The gape of the mouth is very wide, the upper jaw is furnished with a little barbule, which depends on each side, and a cutaneous appendage, somewhat like a little ear, is affixed to the angle of the mouth. The fore feet are furnished with four toes each, which are long and slender, and divided at their tips into four distinct points, each of which, when examined with a microscope, is found to be obscurely divided almost in a similar manner. The hind limbs are short and stout, the feet large with five toes, united by broad membranes. The 
skin differs from that of the Amphibia generally, being covered with minute hard granules, among which are scattered small conical tubercles of a horny substance. The male has an enormous larynx, which takes the form of a triangular bony box, within which are two moveable bones, which can close the divisions of the

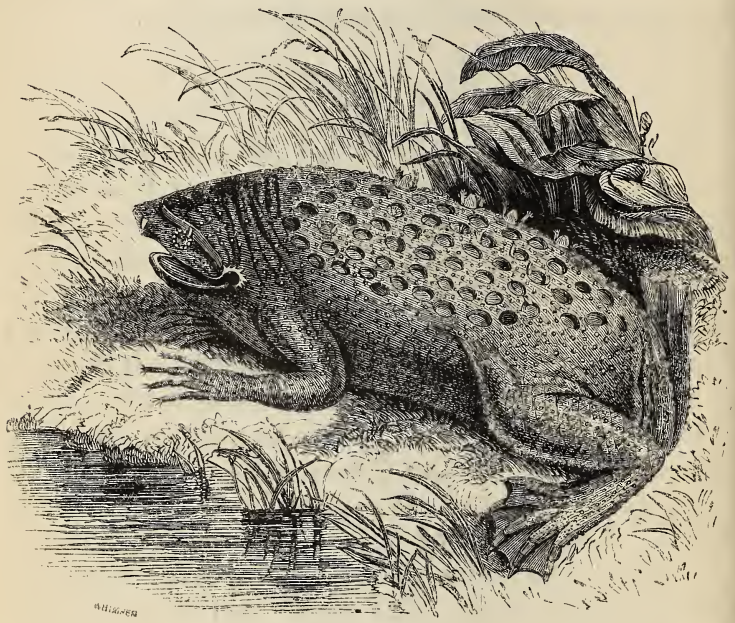

PIP A.

windpipe, and thus influence the intonation of the voice.

Two species of this singular reptile are known, of which we shall adduce only the Surinam Toad (Pipa Surinamensis, Daud.). This is much larger than our Toad, growing to six or eight inches in length; it is of a dark brown colour, 
covered with reddish tubercles. It has a granulated back, with three longitudinal ranges of larger granules. It inhabits cellars and obscure corners of houses in Guiana, and other parts of South America, where, notwithstanding its repulsive aspect, its flesh is eaten with relish by the negroes.

The continuation of the species in this Reptile is attended with phenomena no less extraordinary than its figure. The female presents at certain times the strange spectacle of a great number of young ones in various stages of development, lodged in or proceeding from cells dispersed over the upper surface of her body. It was at one period supposed that the eggs were produced in these cells, and not deposited in the usual manner; but it is now known that the female deposits her spawn at the edge of some stagnant pool, where the male, collecting it with great care, places it on the broad and flat back of his mate. The presence of the ova is believed to produce a sort of suppuration, whereby a number of pits or circular cells are formed in the substance of the skin; these are about half an inch in depth and a quarter of an inch in diameter. Each of these having received an egg, closes over it, and thus the skin resembles the closed cells of a honey-comb. The cells are formed only in the substance of the skin, which is thickened for the purpose, and do not penetrate to the muscles beneath. The true skin is indeed separated from the muscles by large reservoirs of fluid.

The female Pipa, having received her burden, retires into the water; and in due time the 
enclosed eggs are hatched, and the young tadpoles pass their stage of existence within the cells, from which they do not emerge until they have passed their metamorphosis, and assumed the form of the adult animal, though very small. This takes place in about eightytwo days from the time when the eggs were first placed on the back of the mother. Those cells which occupy the middle part of the back are first evacuated, doubtless because they were first occupied. The mother, relieved of her charge, now resorts to the land, where, it is reported, she frees herself from her honeycombed skin by rubbing her body against a stone.

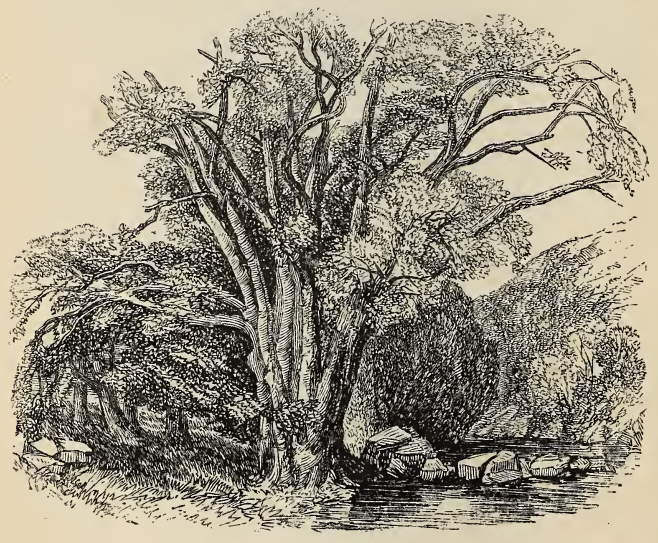




\section{ORDER II. URODELA.}

\section{(Salamanders.)}

In this Order the body is lengthened, slender, and lizard-like, with four well-formed limbs, furnished with toes, and a long tail, which remains through life. The ribs are very short, the vertebre or joints of the spine numerous and moveable. The tympanum, or membrane of the ear, is concealed beneath the skin. Respiration in the earlier stages of existence is aquatic, the necessary oxygen being separated from the water by external gills, as in the tadpoles of the Anoura; in the adult or perfect condition it is aërial, and performed by means of cellular lungs. Both jaws are furnished with minute teeth, and there are two longitudinal rows of equal teeth on the palate, attached to the bone. The head is much flattened.

The Urodela undergo a metamorphosis similar to that of the Anoura; the young animal is a tadpole of similar form, inhabiting the water; and this is the case no less with those species that are terrestrial in their perfect state, than with those that are permanently aquatic. In the metamorphosis, the fore limbs are first developed, an order contrary to that which prevails in the Frogs.

The power of reproducing certain parts of the body which have been injured or removed 
by accident or disease, is very remarkably displayed by these animals. Numerous experiments, the cruelty of which

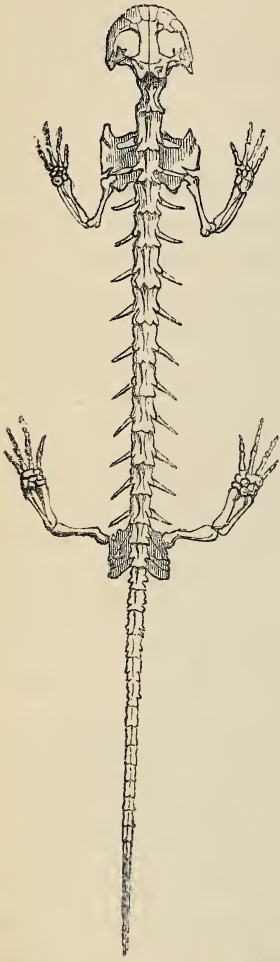
we must again condemn, have been made on them by physiologists of eminence, especially by Bonnet, the results of which are very curious. "The arms and thighs of Tritons amputated "sometimes on one side, sometimes on the other, or both on the same side, were constantly reproduced, and the toes were gradually again formed and endowed with motion. The tail too, cut off at various points, was renewed, pushing out by little and little from the amputated base. In one case the same limb was reproduced four times consecutively in the same animal. Bonnet found that this reproduction was favoured by heat and retarded by cold. He observed that the parts of excised limbs were often reproduced with remarkable alterations, SKELETON OF SALAMANDER. either of defect or excess; the deficiency or exuberance of certain parts taking upon themselves very singular forms. In many species of Tritons the long 
bones of the limbs detached from their principal articulation, and remaining suspended by some points which still caused them to adhere to the flesh, were found completely consolidated in a few days. The most extraordinary observation was that consequent on the total extirpation of the eye, which was entirely reproduced and perfectly organized at the end of a year. Dufay has recorded their faculty of remaining frozen up in ice for a long period without perishing." An experiment by M. Duméril, remarkably shewed the tenacity of life in these Reptiles. A Triton, deprived of its head, lived for three months, in evident consciousness of existence, walking cautiously, and occasionally coming to the surface of the water; though deprived of the organs of every sense, except that of touch.

The Urodela are found in all the temperate and warm regions of the globe. They are all comprised in a single Family.

\section{Family I. SalamandradÆ.}

\section{(Salamanders.)}

We need not repeat the distinctive characters of this Family, as these have already been enumerated in our account of the Order Urodela, with which it is.co-extensive. They are for the most part animals of small size, rarely exceeding a few inches in length: the Gigantic Salamander (Sieboldtia maxima, Bonap.), however, recently found in the mountain lakes of Japan, is three feet long. This species, a specimen of which was brought alive to Europe, feeds on fishes; but the ordinary prey of the Salamanders, both 
terrestrial and aquatic, consists of worms, slugs, insects and their larvæ, \&c.

We have several examples of this Family in Great Britain, all of which are aquatic in their habits. They are commonly known under the appellations of Eft or Evet, and Newt.

\section{Genus Lissotriton (Bell).}

The Smooth-newts, which are separated by Professor Bell from the Warty-newts, present the following characters. The tongue is semiglobular, slightly free at each side, free and pointed behind; the palate has two longitudinal rows of minute teeth; there are four toes on the fore feet, and five on the hind, all destitute of nails; the skin is smooth, not set with warts; there are two patches of glandular pores on the head, but none on the back or sides. The back of the male is furnished during the summer with a sort of fin or crest, which, commencing at the hind head, runs without interruption to the extremity of the tail. In winter this crest is no longer found, being absorbed on the approach of cold weather, to be renewed in spring; but the tail retains at all periods a finny expansion running along its upper and lower edges, diminished in winter.

The Common Smooth-newt (Lissotriton punctatus, DAuD.), which is found in almost every clear ditch and pond in summer, is a beautiful little animal. The male is about three inches and a half in length, of a brownish hue above, merging into yellow beneath, which in spring becomes a rich bright orange; the whole studded 
with large round blackish spots : on the head are two stripes. The crest, which is notched along the edge, is often tipped in spring with bright red or violet. The female is light yellowish brown, with scattered brown dots, which are frequently wanting on the belly.

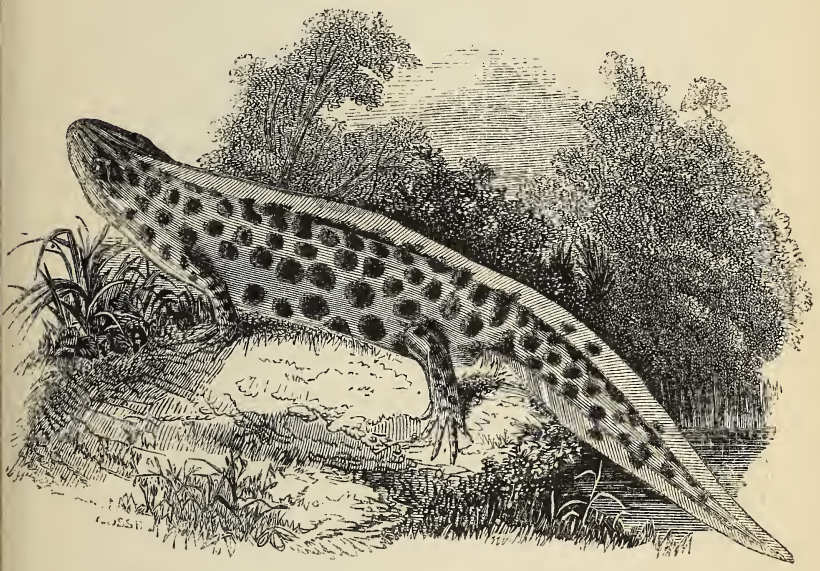

SMOOTH-NEWT.

Early in the spring the crest of the male assumes a size and hue which make him a conspicuous object; and he may be seen pursuing the other sex through the water, frequently doubling his fin-like tail forwards in a sort of bight or loop, and vibrating it with a rapid tremulous motion. Soon after this the female begins to deposit her eggs, which she does on the leaves of water-plants, sometimes selecting 
the angle at the base of the footstalk, and at others, placing them within a folded leaf. In the latter case, the manner in which she proceeds is interesting and curious. We quote Professor Bell's words of another species, which are, however, sufficiently descriptive of this:- "The female, selecting some leaf of an aquatic plant, sits, as it were, upon its edge ; and folding it by means of her two hinder feet, deposits a single egg in the duplicature of the folded part of the leaf, which is thereby glued most securely together, and the egg is thus effectually protected from injury." * The process goes on through the spring and early part of the summer, continuing much longer than that of the Anourous Amphibia.

In its growth and development, the Tadpole of the Newt does not materially differ from that of the Frog. Like that, it presents a beautiful object for microscopic examination, the leaf-like gills exhibiting the branchial circulation of the blood, the red globules of which are seen " accelerated by momentary jerks through the vessels ;"while the beautiful transparency of the oar-like tail offers no impediment to the view of the vital fluid in the general or systemic circulation.

About the beginning of July many of the young Newts, having completed their metamorphosis, leave the water, and remain on land. And not long afterwards, the adults follow their example, and creep about the herbage of the banks, or resort to damp hollows, cellars in the neighbourhood of rivers, and similar humid retreats. The fine crest of the male begins to " "British Reptiles," 122. 
be absorbed, and his brilliant hues disappear; but these begin to be both renewed about the close of the year.

The Newts cast their skins at short but irregular intervals. From seven individuals, kept by Mr. Baker for several months in a jar of water, for the purposes of observation, it appears that they generally perform this operation at the end of every fortnight or three weeks. He informs us, that for a day or two before the change, the animal always appeared more inactive than usual, taking no notice of the worms that were given to it, which, at other times, it greedily devoured. The skin in some parts of the body appeared loose, and in colour not so lively as before. The animal began the operation of casting its skin, by loosening that part about the jaws. It then pushed it backward gently and gradually, both above and below the head, till it was able to slip out first one leg and then the other. With these legs it proceeded to thrust the skin as far backward as they could reach. This done, it was under the necessity of rubbing its body against the gravel at the bottom of the water, till it was more than half freed from the skin, which appeared doubled back, covering the hinder part of the body and the tail. The animal now bent back its head, taking the skin in his mouth; and then set its feet upon it, and, by degrees, drew it entirely off; the hind legs being dragged out in the same manner that the others had been before. On examining the skin, it was, in every instance, found to be turned inside out, but without any breach except at the jaws. 
These creatures do not, however, like some of the snakes, put off the coverings of the eyes along with the skin; for two round holes always appear where the eyes have been. This operation occupies nearly half an hour; and after it is finished, the Newt appears in full vigour. If the skin be not taken away very shortly after it is cast, the animal usually swallows it. Sometimes it begins with the head part first; and the tail, being filled with air and water, becomes like a blown bladder, and proves so unmanageable, that it is very diverting to see the pains it costs to discharge these, and to reduce it to a condition to pass down the throat.

M. Dufay informs us, that it frequently happens to a Newt, not to be able to get the old skins removed from one of the feet; and that the portion of the skin which remains, becoming corrupted, often occasions a species of gangrene in the foot. This foot soon afterwards falls off; but instead of killing the animal, it is, in a little while, replaced by another. Newts are still more liable to lose their toes in this manner. The cast skins of Newts are frequently to be seen floating on the surface of stagnant waters.

The Smooth-newt feeds on the larvæ of waterinsects, the grubs of gnats, blood-worms, \&c., on flies and gnats that alight on the water, on the spawn of frogs and toads, as well as on slugs. In its turn it becomes the prey of a kindred species, the Great Warty-newt (Triton cristatus). 


\section{ORDER III. AMPHIPNEUSTA.}

\section{(Doubly-breathing Reptiles.)}

In these animals the body is much lengthened, and adapted for swimming; the limbs are small, feeble, and far removed from each other, and in some species the hind pair are wanting. The tail is compressed, and remains through life. The respiration is performed in a two-fold manner, in water by means of gills, which are external, and continue throughout the whole term of existence, and in air, by means of lungs, likewise permanent. The eyes are furnished with eyelids.

The term Amphibia, having reference to the two-fold medium and manner in which is carried on the most important function of life, the renewing of the vitality of the blood, is with literal strictness applicable to these singular forms: for it is descriptive, not of a preparatory and rudimentary condition of existence, but of that which, subsisting through life, is truly proper to the animal. "The simultaneous existence and action of branchial tufts and lungs in these animals," observes Cuvier, "can no more be contested than the most certain facts of natural history; I have before me the lungs of a Siren of three feet in length, where the vascular apparatus is as much developed and as complicated as in any reptile: nevertheless this Siren had its branchia 
as complete as the others." Cuvier further observes that whilst the branchice subsist, the aorta, in coming from the heart, is divided into as many branches on each side as there are branchice. The blood of the branchice returns by the veins, which unite towards the back in a single arterial trunk, as in the fishes; it is from this trunk, or immediately from the veins which form it, that the greatest part of the arteries which nourish the body, and even those which conduct the blood for respiration in the lung, spring. But

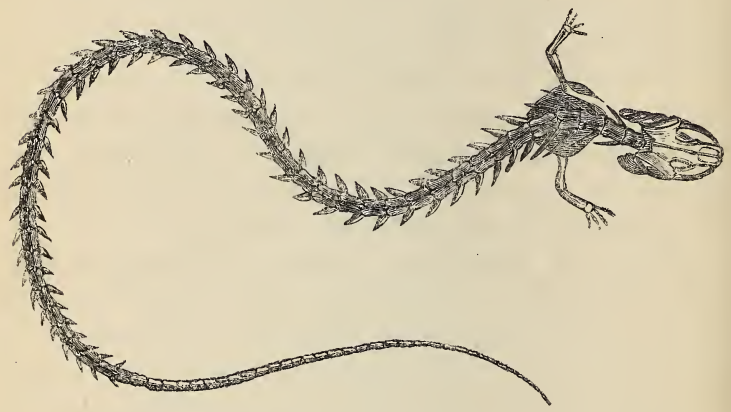

SKELETON OF SIREN.

in the species which lose their branchia naturally, the branches which go there become obliterated, except two which unite in a dorsal artery, and of which each gives off a small branch to the lung. "It is," adds this eminent comparative anatomist, "the circulation of a fish metamorphosed into the circulation of a reptile."

The same author observes that it had been objected that it would be impossible for these 
animals to respire air without ribs or diaphragm, and without the power possessed by the tortoises and frogs to cause it to enter by the nostrils, in order that, so to speak, it might be swallowed, because the nostrils of the Sirens do not lead into the mouth, and the branchial apertures must let it escape. But his own observations, made upon well-preserved individuals, showed Cuvier that the nostrils in the Siren do communicate with the mouth by a hole pierced as in the Proteus, between the lip and the palatal bone which carries the teeth. The membranous opercula of their branchiæ are muscular internally, and capable of hermetically sealing the apertures; then it is very easy for the Siren, by dilating its throat, to introduce the air into the mouth, and to force it afterwards, by contracting the throat, into its larynx. Even without this structure of the nostrils, the animal could produce the same effect by opening its lips a little: a theory which Cuvier applies to the Proteus as well as the Siren.

Professor Owen has contributed some interesting observations to the Penny Cyclopædia, * on the size of the blood-disks (commonly called globules) in the Amphibia as compared with other animals. Their size in these Reptiles is very great, and their magnitude seems to bear a proportion to the permanency of the external gills, or branchia. In the double-breathing animals before us, the Sirens and Protei, these disks are so large as to be distinguishable even with the unassisted eye, while their appearance under a microscope is exhibited in the accompanying

* Vol. xxii. p. 61 . 
figures. The large oval figures exhibit their form as seen directly and sideways; the smaller ones represent the human blood-disk for the purpose of comparison; both are magnified seven hundred times in linear dimensions. The blood from which the former figures were taken was
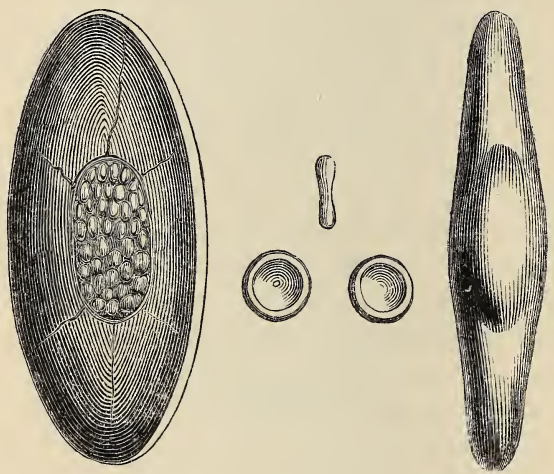

BLOOD-DISKS OF SIREN AND OF MAN.

obtained from one of the external gills of a Siren lacertina twenty inches in length, which was then (1841) living at the Zoological Gardens, Regent's Park. Though subjected to examination immediately, the large figure shows, in the crossing lines, traces of folds produced by the partial drying of the external capsule.

The species contained in this Order are very few, and compose but a single Family, Proteida; they are rather large animals, of dull sluggish manners, much resembling eels in form, with minute rudimentary feet, inhabiting the mud of 
lakes, in America and Europe. They subsist on worms, and probably other soft-bodied animals, which they find in the mud or water.

\section{Genus Proteus (Laur.).}

In this genus, which, from the singularity of its structure and appearance, and still more from the anomalous character of the situation in which it is found, has excited great interest among zoologists, there are four short limbs, each pair greatly separated from the other, of which the fore feet have three toes, and the hind only two: the tail is vertically compressed, so as to form a swimming organ ; the muzzle is lengthened and depressed; both jaws are furnished with minute teeth; the tongue is but slightly moveable, free at the anterior part: the eyes are excessively small and concealed beneath the skin of the head: the ear-drum is also concealed. The skel-

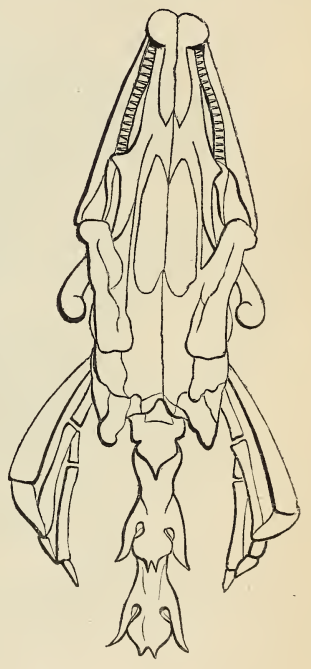

SIULL OF PROTEUS. eton has considerable resemblance to that of the Salamanders, but the conformation of the skull is different; and the vertebræ are much more numerous, while the rudimentary ribs are fewer. The skin is smooth, viscid, and colourless. The branchice project from each side of the neck in the form of tufts, of a crimson hue. 
The European Proteus (Proteus anguinus, LAUr.) is much like an eel with minute feet, and is one of the most interesting links in the chain of animated nature, connecting the Reptiles with the Fishes. The deep and dark subterranean lakes of Austria are the only locality in which this singular creature has yet been discovered. One of the most romantic and

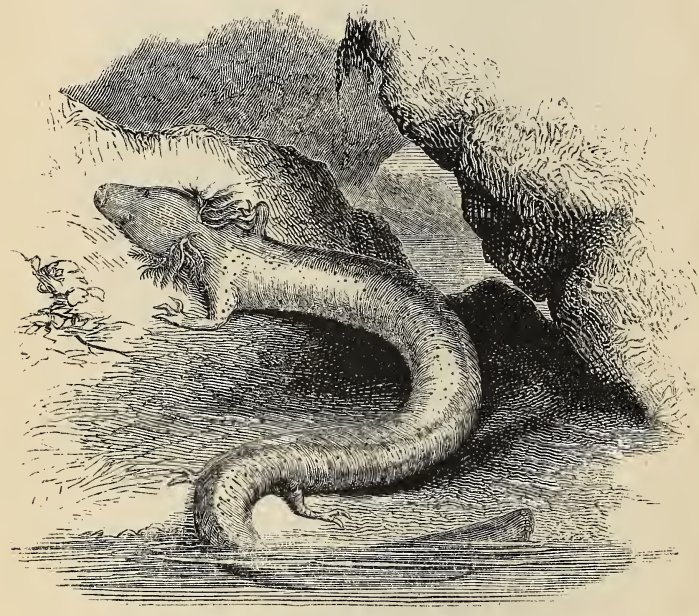

PROTEUS.

splendid caverns in Europe is the Grotto of the Magdalene, near Adelsburg, in the duchy of Carniola. The whole of that region consists of bold craggy rocks and mountains of limestone formation, perforated with spacious branching caverns, in whose awful recesses sleep the 
sluggish waters of vast subterranean lakes, whence many rivers take their origin. In these dreary reservoirs, over which a gleam of light has never played, save when the torch of the inquisitive traveller is flashed back from the unruffled surface, are found many Protei, swimming through the waters, or burrowing in the mud which is precipitated by them.

Nearly all that is known of these strange tenants of the bowels of the earth is comprised in the following extract from Sir Humphrey Davy's "Consolations in Travel," where the appearance of the Protei is graphically described. In a conversation supposed to take place in the magnificent cavern above-named, Eubathes, one of the speakers, says, "I see three or four creatures, like slender fish, moving on the mud below the water."

"The Unknown.-. I see them; they are the Protei; now I have them in my fishing-net, and now they are safe in the pitcher of water. At first view, you might suppose this animal to be a lizard, but it has the motions of a fish. Its head and the lower part of its body and its tail bear a strong resemblance to those of the eel; but it has no fins, and its curious branchial organs are not like the gills of fishes; they form a singular vascular structure, as you see, almost like a crest, round the throat, which may be removed without occasioning the death of the animal, which is likewise furnished with lungs. With this double apparatus for supplying air to the blood, it can live either below or above the surface of the water. Its fore feet resemble hands, but they have only three claws or fingers, 
and are too feeble to be of use in grasping or supporting the weight of the animal; the hinder feet have only two claws or fingers, and in thelarger specimens are found so imperfect as to be almost obliterated. It has small points in the place of eyes, as if to preserve the analogy of nature. It is of a fleshy whiteness and transparency in its natural state, but when exposed to light its skin gradually becomes darker, and at last gains an olive tint. Its nasal organs appear large; and it is abundantly furnished with teeth, from which it may be concluded that it is an animal of prey; yet in its confined state it has never been known to eat, and it has been kept alive for many years by occasionally changing the water in which it was placed.'

"Eubathes.-'Is this the only place in Carniola where these animals are found?'

"The Unknown.- 'They were first discovered here by the late Baron Zois ; but they have since been found, though rarely, at Sittich, about thirty miles distant, thrown up by water from a subterraneous cavity; and I have lately heard it reported that some individuals of the same species have been recognised in the calcareous strata in Sicily.'

"Eubathes._" This lake in which we have seen these animals is a very small one; do you suppose they are bred there?'

"The Unknown.-' Certainly not; in dry seasons they are seldom found here, but after great rains they are often abundant. I think it cannot be doubted that their natural residence is in an extensive subterranean lake, from which in great floods they sometimes are forced through 
the crevices of the rocks into this place, where they are found; and it does not appear to me impossible, when the peculiar nature of the country in which we are is considered, that the same great cavity may furnish the individuals which have been found at Adelsburg and at Sittich."

Observations on the living animal, as well as the study of its anatomy, render it certain that it is in a perfected condition, and not, as has been supposed, the larva or tadpole of some large unknown Triton or Salamander inhabiting those Tartarean recesses. It has been found of various sizes, from the thickness of a quill to that of a man's thumb, but the form of the respiratory organs has always been the same. Its whole comparative anatomy forbids the conclusion that the form in which we see it is that of a creature in a state of transition. Professor Wagner, who had an opportunity of dissecting a male and a female, immediately after death, observes (in some notes communicated to the Zoological Society, November 1837) that he has no doubt that the pulmonary sacs or vesicles really perform the function of lungs. Each lung contains a large artery and a still larger vein, which are connected together by means of large and numerous vessels. $\mathrm{He}$ found the ova in the female very beautifully developed; their structure, as well as that of the ovary, corresponding perfectly with that of the other naked Amphibia, especially the Triton. It is an animal in fact well calculated to exalt our views of the greatness of Grod, who is able to produce and perpetuate animal life, and doubtless enjoyment, in situations, 
which we should at first suppose to be barren wastes, incapable of sustaining organized existence. But it suggests curious speculations of the wonders that may exist in the bowels of our globe, of which man has as yet no knowledge.

The Proteus has been frequently brought alive to England; the observations which have been made on them in confinement, prove their extreme susceptibility to the presence of light, the stimulus of which seems painful to them. "We have always noticed," says Mr. Martin, "that they shrouded themselves in the darkest part of the vessel in which they were placed, when the covering was taken off in order to inspect them; and that they betrayed a sense of uneasiness by their actions, when exposed to the light of open day, creeping round the sides of the vessel, or under the shelter of any substance, which threw a partial shadow on the water. . . Though these animals lived many months, and were healthy and vigorous, they were not supplied with any food, nor know we on what they subsist, though we have every reason to believe them carnivorous."* A kindred animal, the Siren of North America (Siren lacertina) kept in captivity in the Gardens of the Zoological Society, was fed on earth-worms, of which it ate a dozen and a half every other day.

In June 184\%, a living Proteus was exhibited to the Linnean Society, by a gentleman who had had it in his possession eighteen months. This individual had never been observed to eat.

* "Pictorial Museum," ii. 135. 
Those specimens which have been preserved were at first of a very pale flesh-colour, with pink branchial tufts; but after a while the general hue became a light olive, and the tuft deepened into crimson.

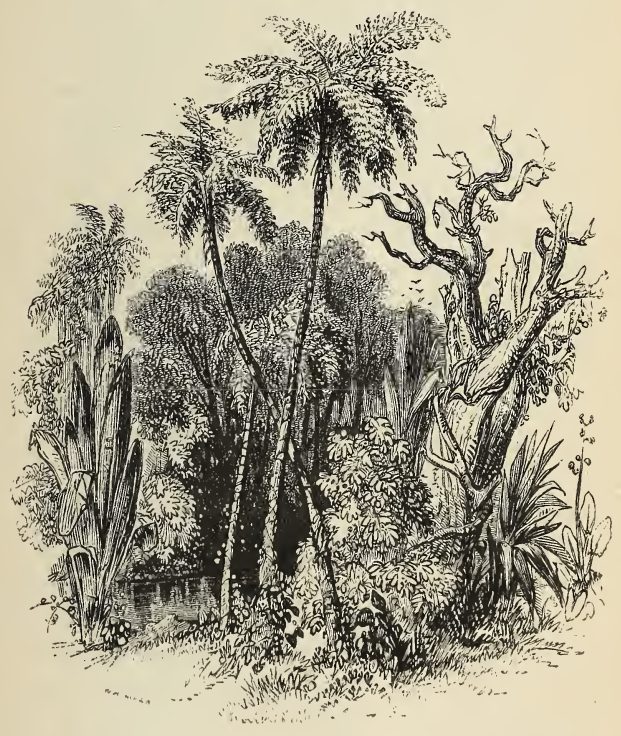




\section{ORDER IV. ABRANCHIA.}

\section{(Amphibia without gills.)}

North America, which presents us with all the anomalous forms that we have been considering, with the exception of the Proteus, produces two or three species which are still more eellike in their appearance than the Sirens. The body is greatly lengthened, flexible, and formed for swimming, terminating in a thin, and vertically compressed tail. The skull is solid. There are four limbs, but in one of the genera, these are so widely removed, so short and slender, and so rudimentary, the toes being almost evanescent, as to convey the idea of tentacula rather than feet. But what is most remarkable in these animals, is the peculiarity on which the name of the Order is founded, the absence of branchiae, or gills. These organs have not been observed at any period of life, but there is an orifice on each side of the neck. Respiration is performed exclusively by lungs, the structure of which is reticulated, and puckered into longitudinal folds: hence these animals are airbreathers, though habitual residents in water. It is believed that this is the permanent condition of their existence, and that they undergo no metamorphosis. 


\section{Genus Amphiuma (Gard.).}

The very lengthened form, and smooth lubricated skin of these Reptiles renders them exceedingly like eels; a resmblance which is but slightly lessened by the four limbs, as their projection is so small, as but little to modify the general contour of the body; while the toes, which are in one species three and in the other but two on each foot, are minute wartlike divisions without joints or nails. There is an aperture in the neck on each side, whence some have supposed that these animals are possessed of branchice at an early stage of their existence; but none have ever been discovered in any specimen. There are teeth in the jaws and in the palate: the former are arranged in a single close-set series along the border of both the upper and lower jaws; the latter are set in two rows running along the margin of the bone called the vomer, and meeting behind at an acute angle. All the teeth are conical, pointed with a slight curve backwards and inwards; their points glisten with a yellow metallic lustre. There are no ribs; the vertebra present at each extremity a concave surface, thus resembling in structure those of fishes. The eyes are very minute.

The Southern States of North America are the regions which have afforded these singular animals, the intermediate links that unite so imperceptibly the Reptiles with the Fishes. In the stagnant waters of Louisiana, Georgia, South Carolina and Florida, they abound, burying them- 
selves on the approach of winter in the mud at the bottom. In the process of clearing marshy ground, cleansing ponds, \&c., immense numbers are sometimes found thus concealed at a depth of three or four feet from the surface. Dr. Harlan was informed by Major Wace, that great numbers in a state of torpidity were thrown up in the winter season, by persons engaged in digging near a street in Pensacola. They were burrowing in the soft mud, two or three feet deep.

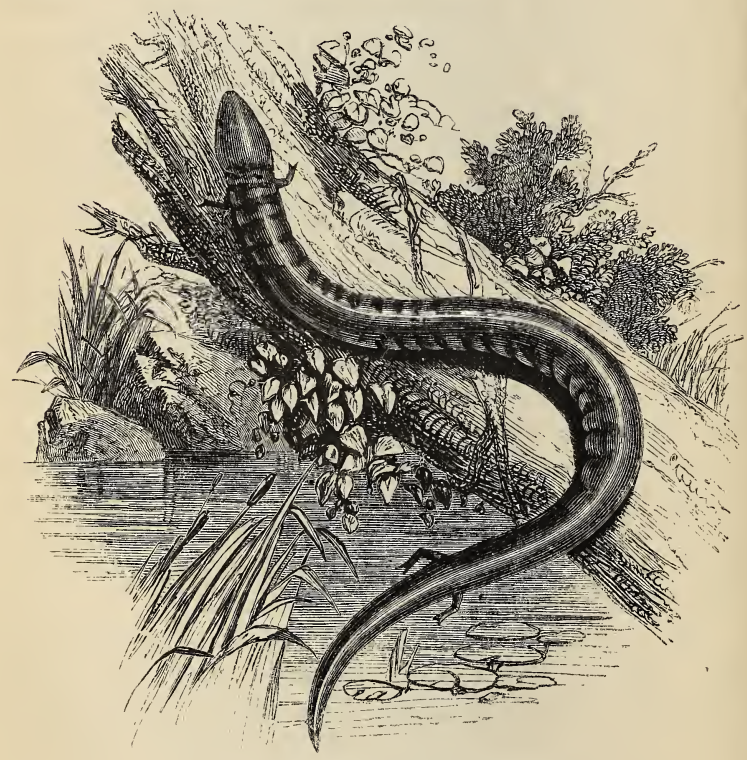

TWO-TOED AMPHIUMA. 
The Two-toed Amphiuma (Amphiuma means, GARD.), of which the above observations are recorded, is the smaller of the two known Species, being only about eighteen inches in length, while its fellow ( $A$. tridactylum) attains twice these dimensions. The former is called Congo-snake by the negroes of Florida, by whom it is reputed highly venomous, but without any foundation. It was first noticed by Dr. Garden of South Carolina, who described it in a letter to Linnæus in 1771. It is properly an inhabitant of the fetid ponds and ditches of those marshy regions, where it probably feeds on worms and waterinsects, but it is capable of living on the land, though for what period has not been ascertained. It is sometimes found lurking under the decaying trunk of a fallen tree, in humid woods; and Dr. Harlan speaks of one in the possession of Dr. Mease, which having escaped from the vessel of water in which it was kept, was found brisk and lively several days afterwards.

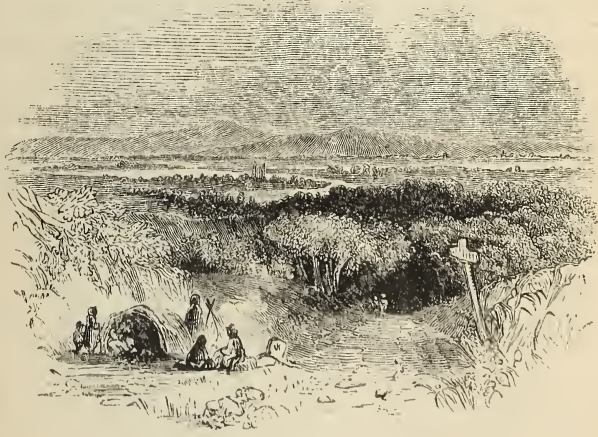




\section{ORDER V. APODA.}

(Footless Amphibia.)

We have seen by how gradual steps the $A m$ phibia approach the Fishes; we now come to a group which links them, in a manner equally interesting, to the Serpents. A zoologist no less able than the illustrious Cuvier, actually arranged them with the latter, by the title of "' naked Serpents."

The form is snake-like, lengthened, cylindrical through its whole length, without any trace of limbs; the skin apparently naked and covered with a viscid secretion, but marked with numerous annular wrinkles or folds, * within which are concealed numerous rings of flat, delicate, overlapping scales, very minute, resembling those of fishes, their rounded edges being free. The tail is very short, neither compressed nor tapering, but ending suddenly with a round or conical extremity. The skeleton is furnished with ribs, which are forked at the end that joins the spine: the sternum, or breastbone, is wanting. The opening of the mouth is rather small, the lower jaw is shorter than the upper, and both are furnished with teeth, which are long, sharp, and, for the most part,

* Dr. Mayer, however, considers these wrinkles to be no true character, but as produced mainly by the contraction of the skin, by means of the spirit in which the animals are preserved. 
curved backwards: one lung is larger than the other.

In these particulars there is a greater or less degree of affinity to the Ophidian forms, and perhaps more particularly to those which present the evanescent characters of the lowest Saurians, as Anguis, and Typhlops. It must be observed that the two branches of the lower jaw are firmly soldered together in front, and that they are jointed behind immediately on the skull, without the intervention of a bony foot-stalk, in both which particulars they vary from the true Serpents.

But there are characters of more importance which demand the arrangement of these animals among the Amphibia, notwithstanding all these affinities with a higher type. The first of these is the articulation of the skull to the first vertebra of the spine, by means of two separate and well marked projections (condyles), - a strongly distinctive mark of this Sub-class; secondly, the vertebræ are hollowed in front and in rear into conical excavations; and (what is decisive, if it may be depended on) the presence of branchice, involving a metamorphosis, is said to have been detected in the young. Müller announced the discovery of branchial apertures in a young Cacilia hypocyanea preserved in the Museum of Natural History at Leyden. He noticed an orifice a line in width on each side of the neck, some distance behind the gape, situated in the yellow stripe which runs down the side, and communicating freely with the mouth. The edge of the hole was rough, and in the interior he observed black fringes, which appeared to 
be fixed to the branchial arches, but they did not project beyond the external orifice. These observations were made on a specimen four inches and a half in length, (without dissection, however,) while an adult specimen more than a foot long, exhibited no trace of the apertures.

We may add that these Reptiles resemble the Eels among Fishes in the form and structure of the skeleton, the articulation of the jaws, the mode of implantation of the teeth, and some other particulars; but the junction of the head with the spine by two condyles, the presence of lungs, and the nostrils opening distinctly within the cavity of the mouth, remove them from the Class of Fishes.

The tongue is large, thick, co-

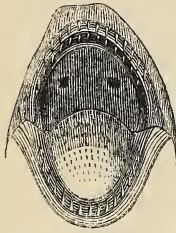
vered with papilla, fixed by its edges on the gums in the hollow of the lower jaw; not protractile, nor forked, nor sheathed at the base. The eyes are excessively minute, nearly hidden by the skin, sometimes not distinguishable: and MOUTH OF the orbits are pierced with only a RINGED CECILIA. small hole in the skull. The latter presents one continuous vaulted piece, forming a bony buckler.

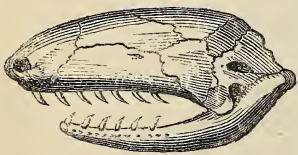

SKULL OF CAECILIA.

Of the habits of these curious animals, exceedingly little is known. Cuvier states that their intestines have been found charged with vegetable matter, together with soil, and sand; but the character of their teeth as well as ana- 
logy would rather induce the presumption that they are carnivorous, and devour living prey. They are said to bury themselves in the moist earth, or in the soft mud of marshy places, burrowing through it like earth-worms, which they much resemble, often several feet below the surface. Their motion on the ground is said to be slow, but in the water they swim with facility, with lateral undulations. In these particulars they agree with the Amphibia which we have recently noticed; but with the curious diversity of relation that marks these doubtful animals, their reproduction, on the other hand, carries back our thoughts to the Angues and Typhlopes, for like these, the Cacilia are ovoviviparous. M. Leperieur, during his stay at Cayenne, having procured a living specimen, which he placed in a vessel filled with water, saw it bring forth, in the space of some days, from five to seven young, perfectly similar to their mother. MM. Duméril and Bibron, who give us this information, remark on it, that the fecundation of the ova in this Order, must be effected within the interior of the body; and that the metamorphosis must take place in the body of the mother, as in the case of the Black Salamander of the Alps. M. Müller's observation of branchice in the Leyden specimen, however, is adverse to this last conclusion.

Nine species are described, arranged in three genera; the greater number of these are found in the warm regions of America; two are natives of India, and one of the American species is found also in the Seychelles Islands, in the Indian Ocean. 


\section{Genus Rhinatrema. (Dum.)}

In this genus the head is lengthened, and slightly depressed, resembling in form that of certain Serpents: the muzzle is obtuse; the teeth, both of the jaws and palate, loose in structure, sharp, and pointing backwards. The tongue is entire, of a velvety surface; the eyes distinct through the skin. There are no pits, neither under the muzzle, nor below the eyes. The body is somewhat thickened in the middle, and is covered with numerous circular wrinkles.

The only known species of this genus is the Two-lined Cæcilia, (Rhinatrema bivittatum, Duм.)

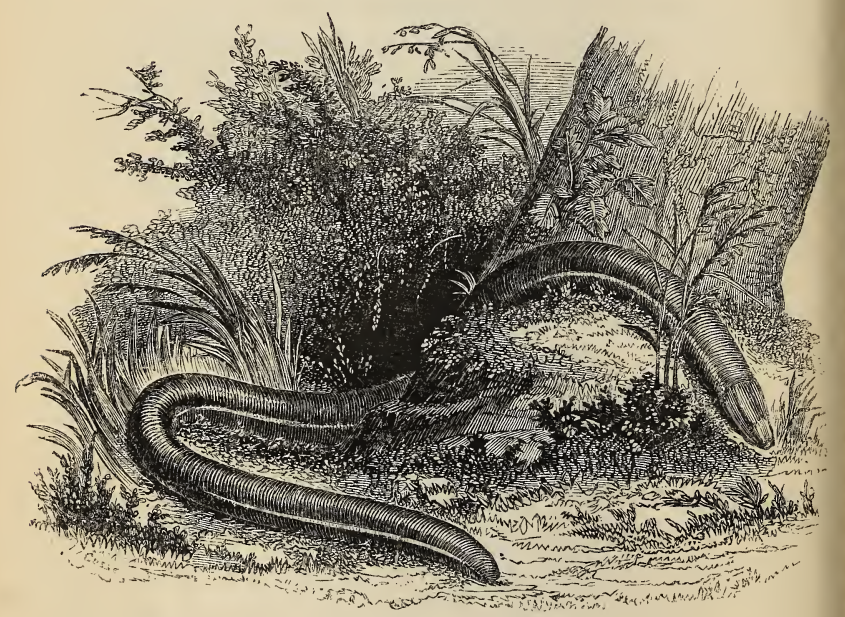


believed to be a native of South America. yellow band runs down each side of the body, the general hue of which is blackish; the under jaw, the margin of the vent, and a stripe upon the tail, are also yellow. The contour is more elegant in this species than in most of this Order, swelling a little in the middle, and gently tapering to each extremity. There is a small, but distinct, conical tail. The ringed wrinkles are perfectly continued round the body, and are very numerous, amounting to three hundred and forty. These folds may be easily raised by the point of a pin, revealing a great number of minute transparent scales, of a circular form, the surface of which is covered with a sort of network pattern, of projecting lines.

$W_{E}$ have thus gone through the diverse and extensive Class denominated Reptiles; and we trust that the particulars that we have detailed may induce some of our readers to régard with fresh interest many animals which may have hitherto excited no feelings but those of fear, disgust, and aversion. Some of them, we have seen, are deservedly looked upon with dread; and it is desirable to know how such may be discriminated, that our fear and hate may not be unreasonably extended to a whole Class of animals, most of which are innocent, many beautiful, and some useful; and all of which demonstrate the glory of Grod, who is infinitely great in all His works. "By His 
Spirit $\mathrm{He}$ hath garnished the heavens; His hand hath formed the crooked Serpent."**

. The study of the wondrous organisation of the living beings with which this globe is profusely stocked, of their various intelligence, their instincts, their powers, their habits, their relations to man and to each other, is chiefly valuable as it brings before the mind fresh discoveries of God. Like all other knowledge, if it lead not to Him, it will prove, for the most part, worse than useless, a curse rather than a blessing. But we would remind our young readers, that there may be much knowledge of Grod's works, and a measure of recognition of His glorious attributes as the wise and good Creator of all things, without any acquaintance with Him in that relation which affects our eternal happiness. "The heavens declare the glory of God, and the firmament sheweth His handy-work;" but neither these nor all the works of Creation beside, afford any light whereby a sinner can discover the way of being reconciled to the Holy God. It is His blessed Word that reveals this, and that points to the Lord Jesus Christ,-God manifest in the flesh, - as healing the sin-poisoned wounds inflicted by " that old Serpent the Devil." The Seed of the woman has bruised the Serpent's head; and through the shedding of His blood is preached unto man the forgiveness of sins. 
And as Moses lifted up the serpent in THE WILDERNESS, EVEN SO MUST THE SoN OF Man be Lifted UP; That whosoever BELieveth in Hrm should not PeRish, bUt have eternal life. For God so loved the world, that He gave his only-begotten Son, that WHOSOEVER BELIEVETH IN HIM SHOULD NOT PERISH, BUT HAVE EVERLASTING LIFE.

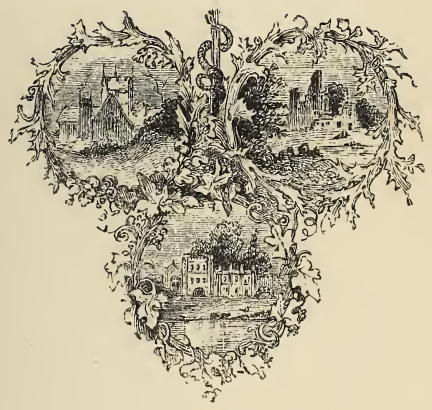




\section{IN DEX.}

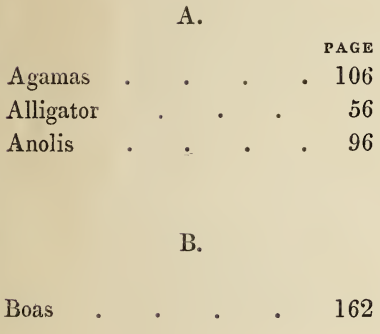

C.

Chameleons . . 70 Chittul . . . . 230 Crocodiles . . 50,53

D.

Double-breathers ～. 271 Double-walkers . . 157

F.

Footless Amphibia . 286 Frogs . . . . 239
G. Gally-wasp . . . 136

Geckos • . . $\quad 82$

Gill-less Amphibia . 282

Green Turtle . . . 34

H.

Hawksbill Turtle . . 44

I.

$\begin{array}{llll}\text { Iguanas . } & \text {. } & 93\end{array}$

Indian Tortoise . . . 13

L.

Land Tortoises . . 11

Leathery Turtles . $\quad$. 25

Lizards . . $\quad 66,121$

M.

Mailed Reptiles . . . 7

Marsh Tortoises . . 18 


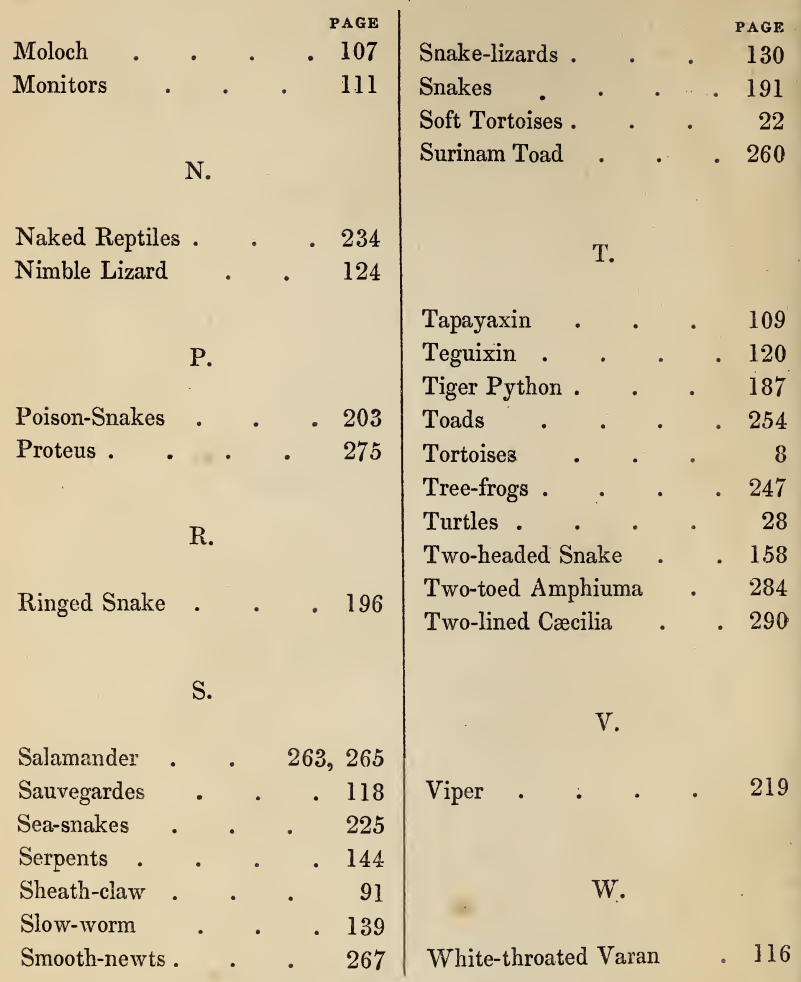

\section{FINIS.}






\section{(8)}

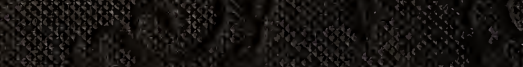

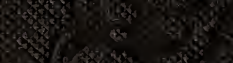

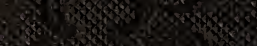

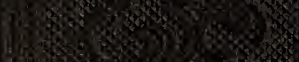

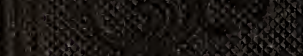

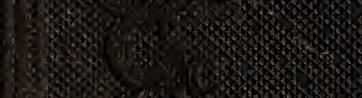

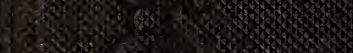

1.5. 3.

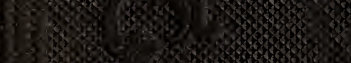

-

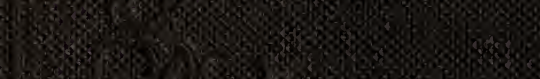

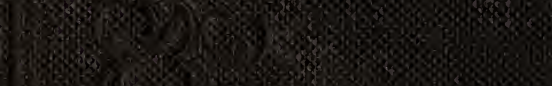

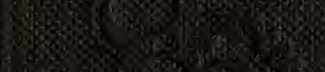

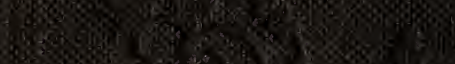

2.

Jo

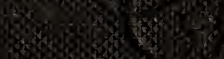

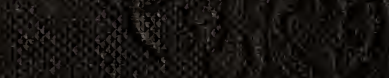

